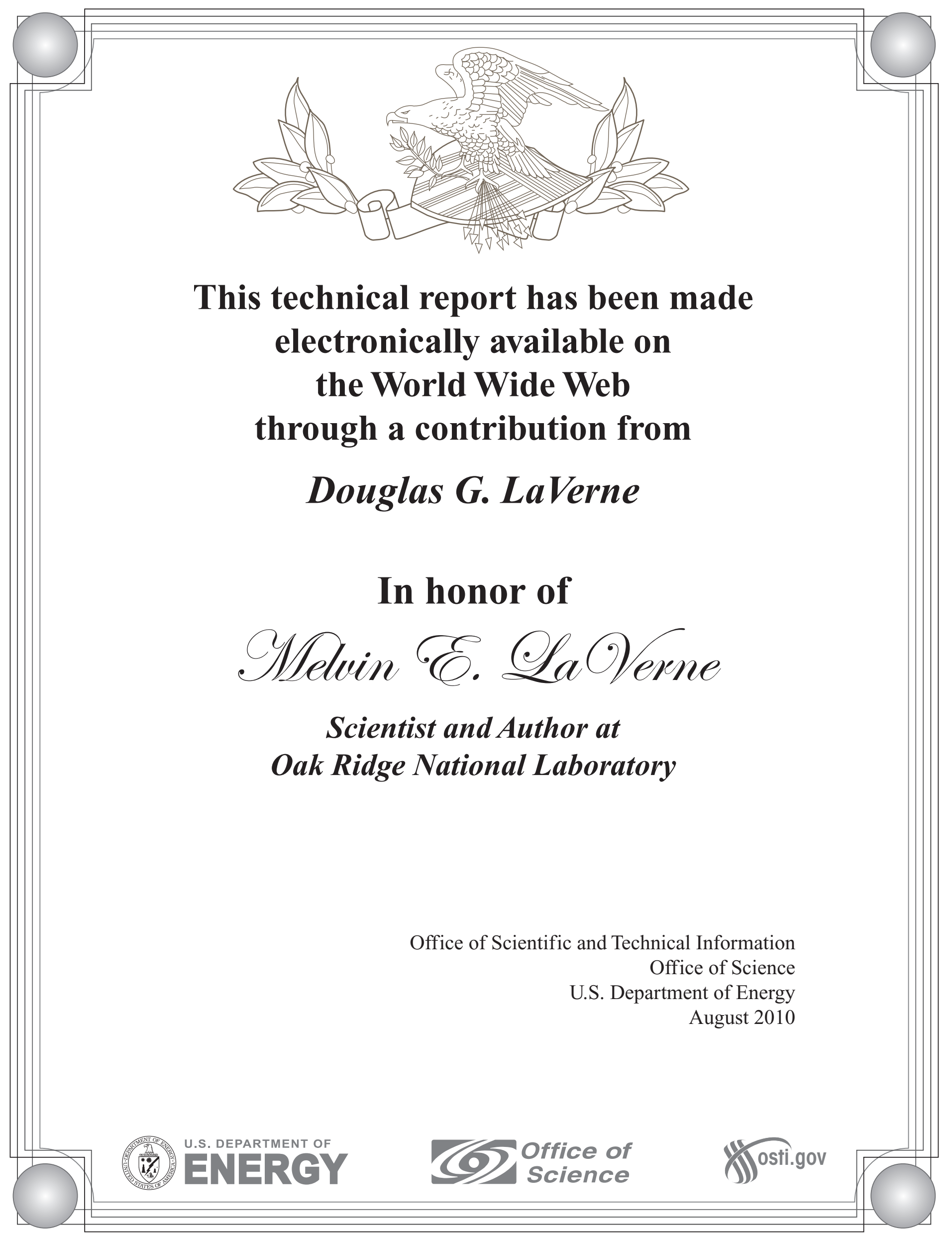




\title{
The Oak Ridge Fog and Drift Code (ORFAD) User's Manual
}

\author{
M. E. LaVerne
}




\section{Printed in the United States of America. Available from} National Technical Information Service

U.S. Department of Commerce

5285 Port Royal Road, Springfield, Virginia 22161

Price: Printed Copy $\$ 6.00$; Microfiche $\$ 3.00$

$$
5.30
$$

This report was prepared as an account of work sponsored by the United States Government. Neither the United States nor the Energy Research and Development Administration/United States Nuclear Regulatory Commission, nor any of their employees, nor any of their contractors, subcontractors, or their employees, makes any warranty, express or implied, or assumes any legal liability or responsibility for the accuracy, completeness or usefulness of any information, apparatus, product or process disclosed, or represents that its use would not infringe privately owned rights. 


\section{DISCLAIMER}

This report was prepared as an account of work sponsored by an agency of the United States Government. Neither the United States Government nor any agency Thereof, nor any of their employees, makes any warranty, express or implied, or assumes any legal liability or responsibility for the accuracy, completeness, or usefulness of any information, apparatus, product, or process disclosed, or represents that its use would not infringe privately owned rights. Reference herein to any specific commercial product, process, or service by trade name, trademark, manufacturer, or otherwise does not necessarily constitute or imply its endorsement, recommendation, or favoring by the United States Government or any agency thereof. The views and opinions of authors expressed herein do not necessarily state or reflect those of the United States Government or any agency thereof. 


\section{DISCLAIMER}

Portions of this document may be illegible in electronic image products. Images are produced from the best available original document. 
ORNL/TM-5201

Contract No. W-7405-eng-26

Energy Division

THE OAK RIDGE FOG AND DRIFT CODE (ORFAD) USER'S MANUAL

M. E. LaVerne

Date Published: January 1977

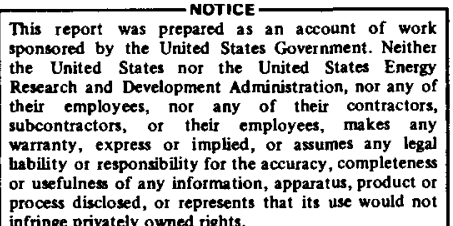

infringe privately owned rights.

Prepared by the OAK RIDGE NATIONAL LABORATORY

Oak Ridge, Tennessee 37830

operated by

UNION CARBIDE CORPORATION

for the

ENERGY RESEARCH AND DEVELOPMENT ADMINISTRATION 


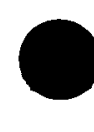

4

- 


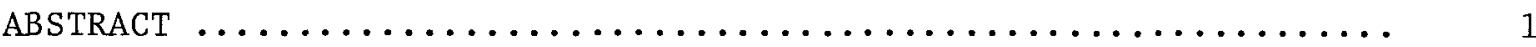

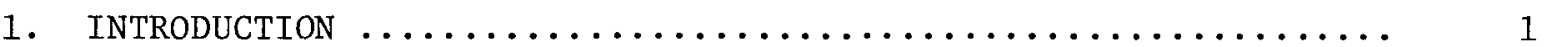

2. DESCRIPTION OF THE PHYSICAL MODEL $\ldots \ldots \ldots \ldots \ldots \ldots \ldots \ldots \ldots \ldots \ldots \ldots \ldots \ldots \ldots \ldots$

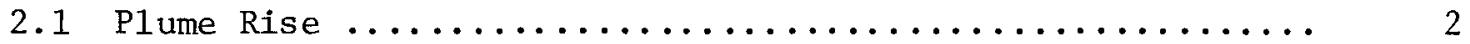

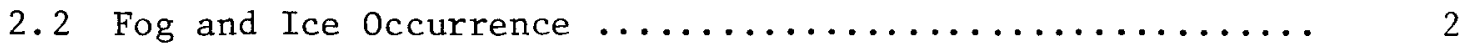

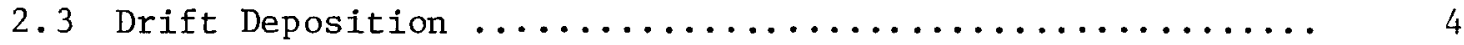

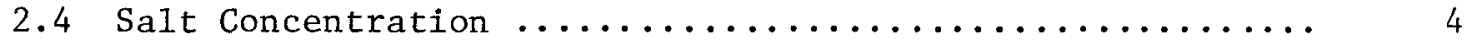

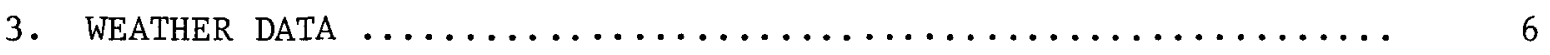

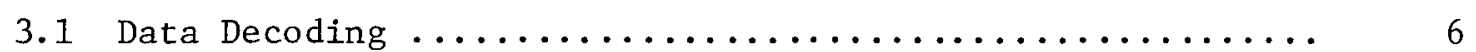

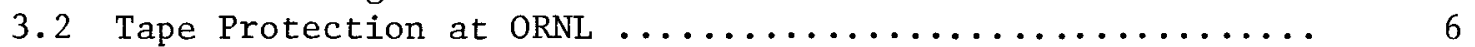

3.3 Special Handling of Data $\ldots \ldots \ldots \ldots \ldots \ldots \ldots \ldots \ldots \ldots \ldots \ldots \ldots \ldots$

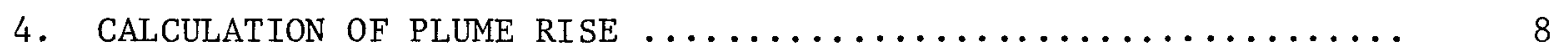

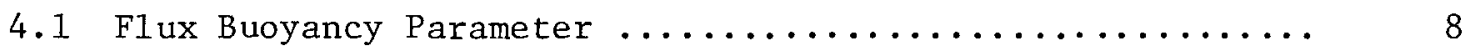

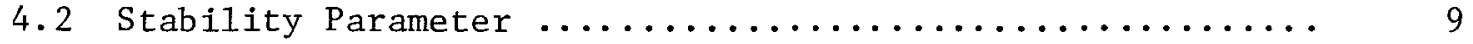

4.3 Plume Rise for a Single Tower ................... 10

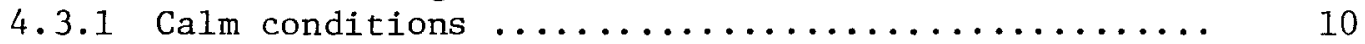

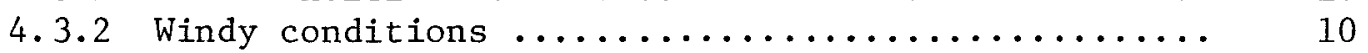

4.3.2.1 Pasquill stability class $<4 \ldots \ldots \ldots \ldots . . . .10$

4.3.2.2 Pasquill stability class $>4 \ldots \ldots \ldots \ldots \ldots . .11$

4.4 Plume Rise for Multiple Towers .................. 11

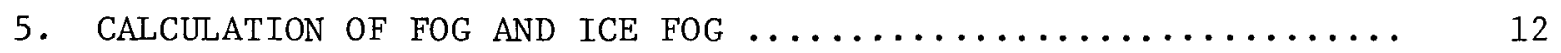

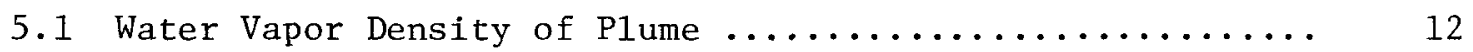

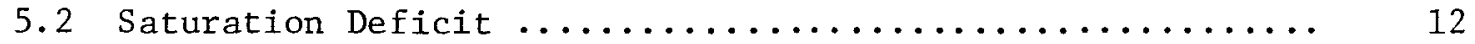

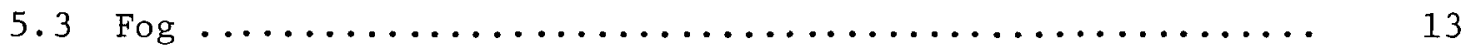

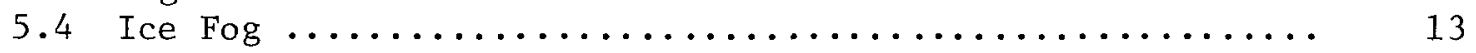

6. CALCULATION OF DRIFT DEPOSITION AND SALT CONCENTRATION ...... 14

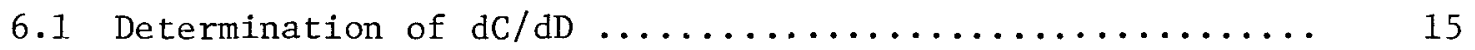

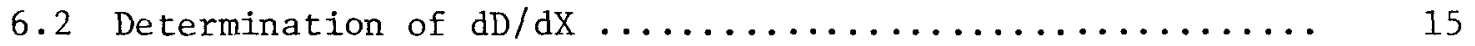

6.2 .1 No evaporation; relative humidity $\geq 76 \% \ldots \ldots \ldots \ldots$

6.2 .2 Evaporation; relative humidity $<76 \% \ldots \ldots \ldots \ldots \ldots . \ldots 19$

6.2.2.1 Evaporation distance ............... 19

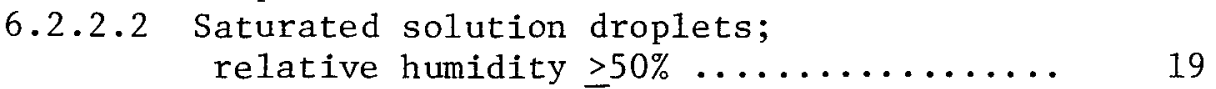

6.2.2.3 Dry particles; relative humidity $<50 \% \ldots . .21$

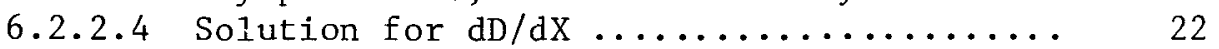

6.3 Drift Deposition and Salt Concentration ............. 22

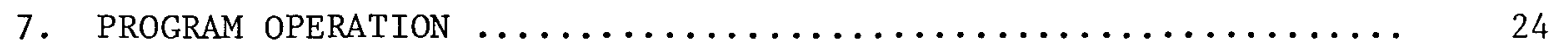

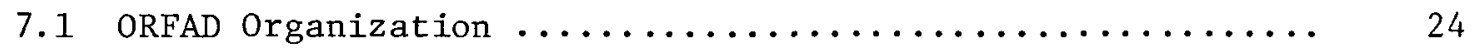

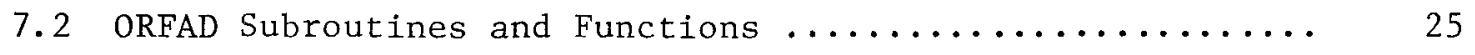

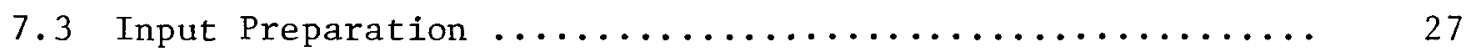


Page

7.3.1 Description of input quantities ............. 27

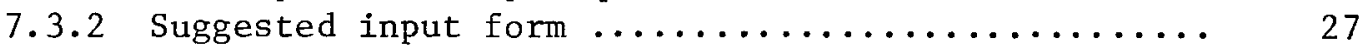

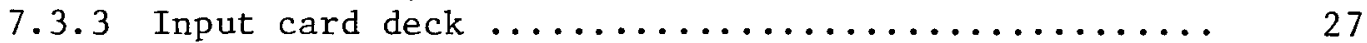

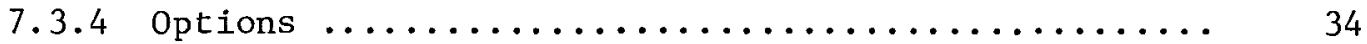

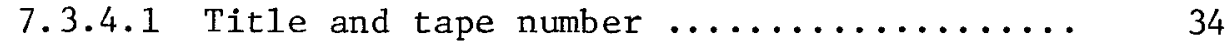

7.3.4.2 Dissolved solids concentration .......... 34

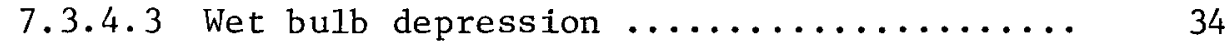

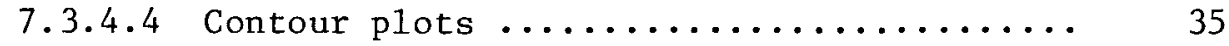

7.3.4.5 Condensed vapor fraction ............. 35

7.3.4.6 Elevation for salt concentration ........ 35

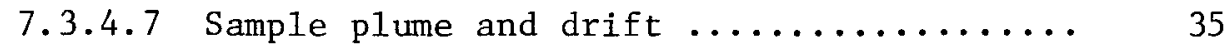

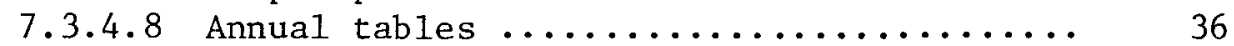

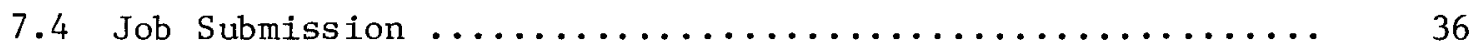

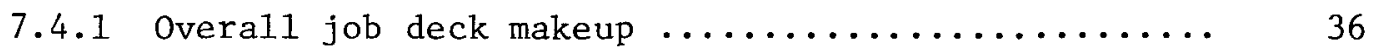

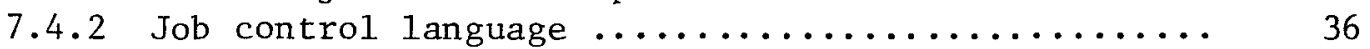

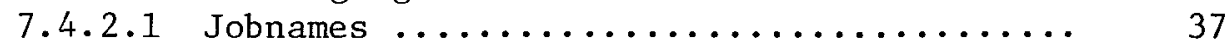

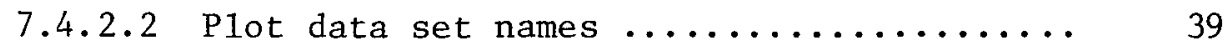

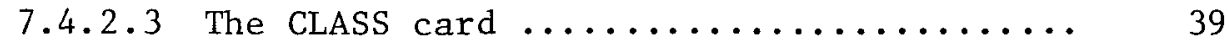

7.4.2.3.1 Execution time .............. 39

7.4.2.3.2 The "SPECIAL" parameter ...... 39

7.4.2.3.3 Output specifications ....... 39

7.4 .3 Overriding the disk programs ............... 40

7.4.4 Program checkout using the data cell ........... 40

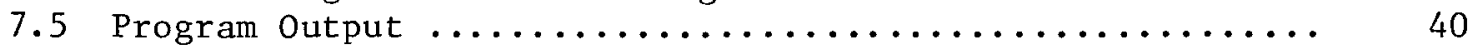

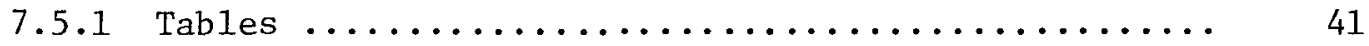

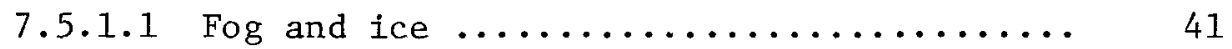

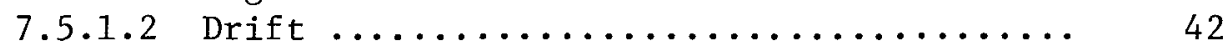

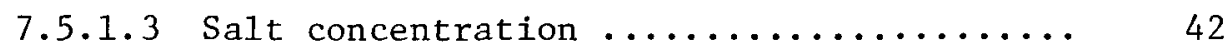

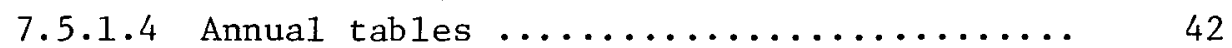

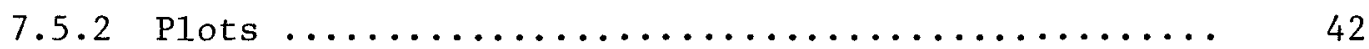

7.5.2.1 Horizontal plane ................ 42

7.5.2.2 Vertical plane ................. 42

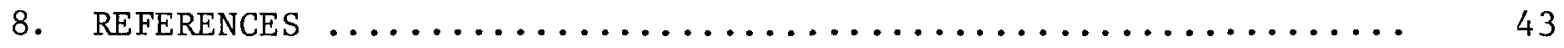

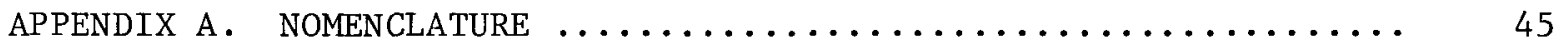

APPENDIX B. PASQUILL STABILITY CLASSES ................. 49

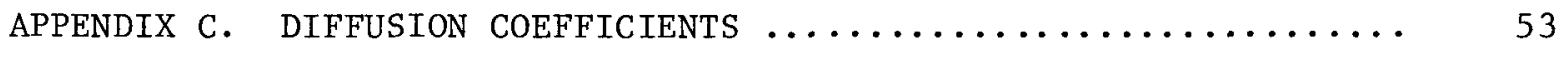

APPENDIX D. FALL DISTANCE OF EVAPORATING DROPLET $\ldots \ldots \ldots \ldots \ldots \ldots \ldots$

APPENDIX E. FORTRAN LISTING OF ORFAD PROGRAMS $\ldots \ldots \ldots \ldots \ldots \ldots \ldots$.

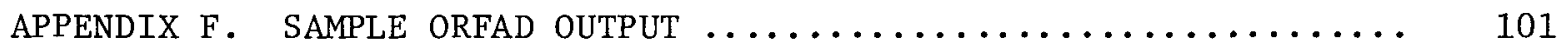

APPENDIX G. TRANSLATION OF CODED WIND DIRECTIONS TO DIRECTION

INDEXES .................................. 117 
THE OAK RIDGE FOG AND DRIFT CODE (ORFAD)

USERS' MANUAL

M. E. LaVerne

\section{ABSTRACT}

ORFAD is a computer program written for the purpose of providing estimates of fog and drift resulting from the operation of wet cooling towers. The program uses hourly weather data from tapes.

The physical and calculational models are described, and detailed instructions are given for input preparation and running the program. A program listing and sample output are appended.

\section{INTRODUCTION}

ORFAD is a computer program originally developed for use in the preparation of environmental statements for central station power plants. Its purpose was, and is, to provide reasonable estimates of the incremental amounts of fog chargeable to the operation of wet cooling towers and of the salt drift deposited in the vicinity of a power plant using such towers.

Since publication of the original report, 1 a number of modifications has been made in the program, most notably in the method employed for drift calculation. These modifications, coupled with changes in program input preparation and operating procedures, have generated a need for an updating and fuller explanation of ORFAD. This report is intended to fill that need by providing a current explanation of the basis for ORFAD and detailed instructions for running the program.

In the preparation of this report, I have consulted on numerous occasions with John $V$. Wilson, the originator of ORFAD, in order to clarify obscure points. His very considerable assistance is gratefully acknowledged. 
2. DESCRIPTION OF THE PHYSICAL MODEL

We assume that the effluent from a wet cooling tower forms a plume containing both pure water vapor and particulate matter, the latter con- . sisting of saline water droplets whose total mass is substantially smaller than that of the vapor. The initial concentration of the dissolved solids, assumed to be principally $\mathrm{NaCl}$, is equated to that in the cooling-tower water. The horizontal transport rate of the tower effluent is equated to wind speed, which is assumed to be independent of height.

The distribution of water vapor density is assumed to be Gaussian with respect to the plume centerline. Water droplets, on the other hand, are assumed to fall in distinct trajectories determined by droplet size and ambient conditions.

\subsection{Plume Rise}

The plume, because it will be warmer and will contain more water vapor than the surrounding air, will be buoyant and will rise from the tower. The wind will then bend the plume over toward the horizontal, forming a more or less gently rising curve downwind from the tower.

As the plume rises, it experiences shear forces along its edges as a result of the difference in velocity between the plume and the surrounding viscous air. Air is entrained into the plume, causing it to expand both laterally and vertically. The plume rise and air entrainment result in cooling and dilution of the contained moisture; as a consequence, the plume buoyancy is diminished, and the plume ultimately levels off at some maximum altitude.

Figure 1 illustrates the plume rise process schematically.

\subsection{Fog and Ice Occurrence}

The distribution of water vapor density about the plume centerline is assumed to be Gaussian, with greater lateral than vertical dispersion. (Refer to Fig. 1.) 


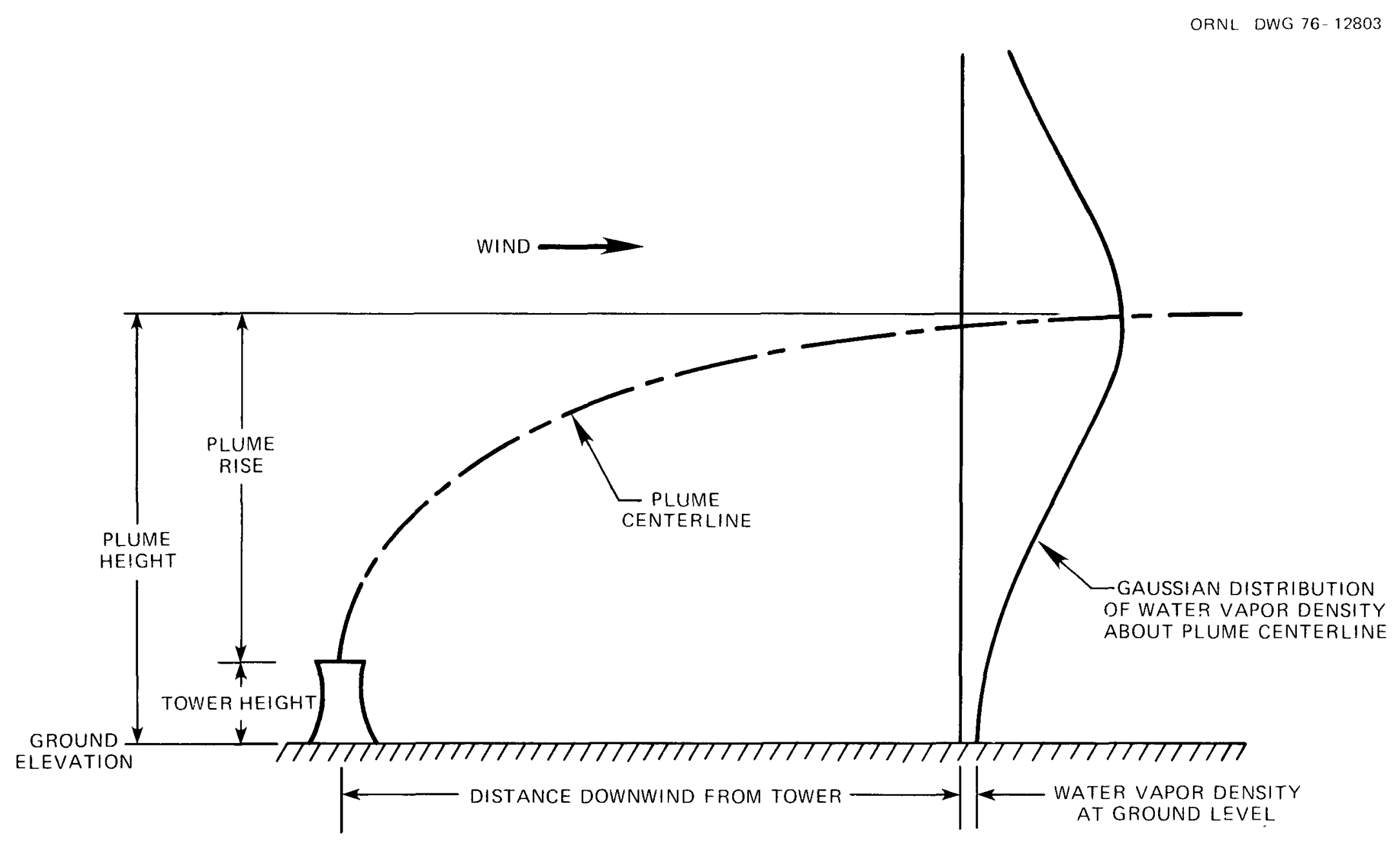

Fig. 1. Schematic of model for fog calculation. 
Condensation is presumed to occur if, at any point in the expansion of the plume, the vapor added by the plume causes the local vapor concentration to reach or exceed the saturation level; that is, if the plume adds enough moisture to overcome the saturation deficit of the entrained air, fogging occurs.

If fogging conditions exist and, in addition, the ambient temperature is below freezing, icing is assumed to occur.

\subsection{Drift Deposition}

The water droplets are assumed to travel in ballistic trajectories set by the rise velocity of the plume centerline and the fall velocity of a droplet relative to the plume centerline. Figure 2 is a schematic of the drift calculational model. The relative fall velocity, found from the relations of Hosler, Pena, and Pena, ${ }^{2}$ is determined from the droplet size and relative humidity range. Relative humidity determines whether the droplets fall without evaporation, or evaporate to a saturated solution, or evaporate to dry particles. Implicitly, all droplets and particles are taken to be spherical.

A specified distribution of fractional mass with respect to particle diameter is used to assign droplets to classes. Each class has a nominal diameter and represents a certain fraction of the total drift discharged from the tower. Separate calculations are made for each class, and the results are summed to get the total drift.

\subsection{Salt Concentration}

The salt concentration is determined by dividing the terminal fall velocity into the previously found drift deposition. 


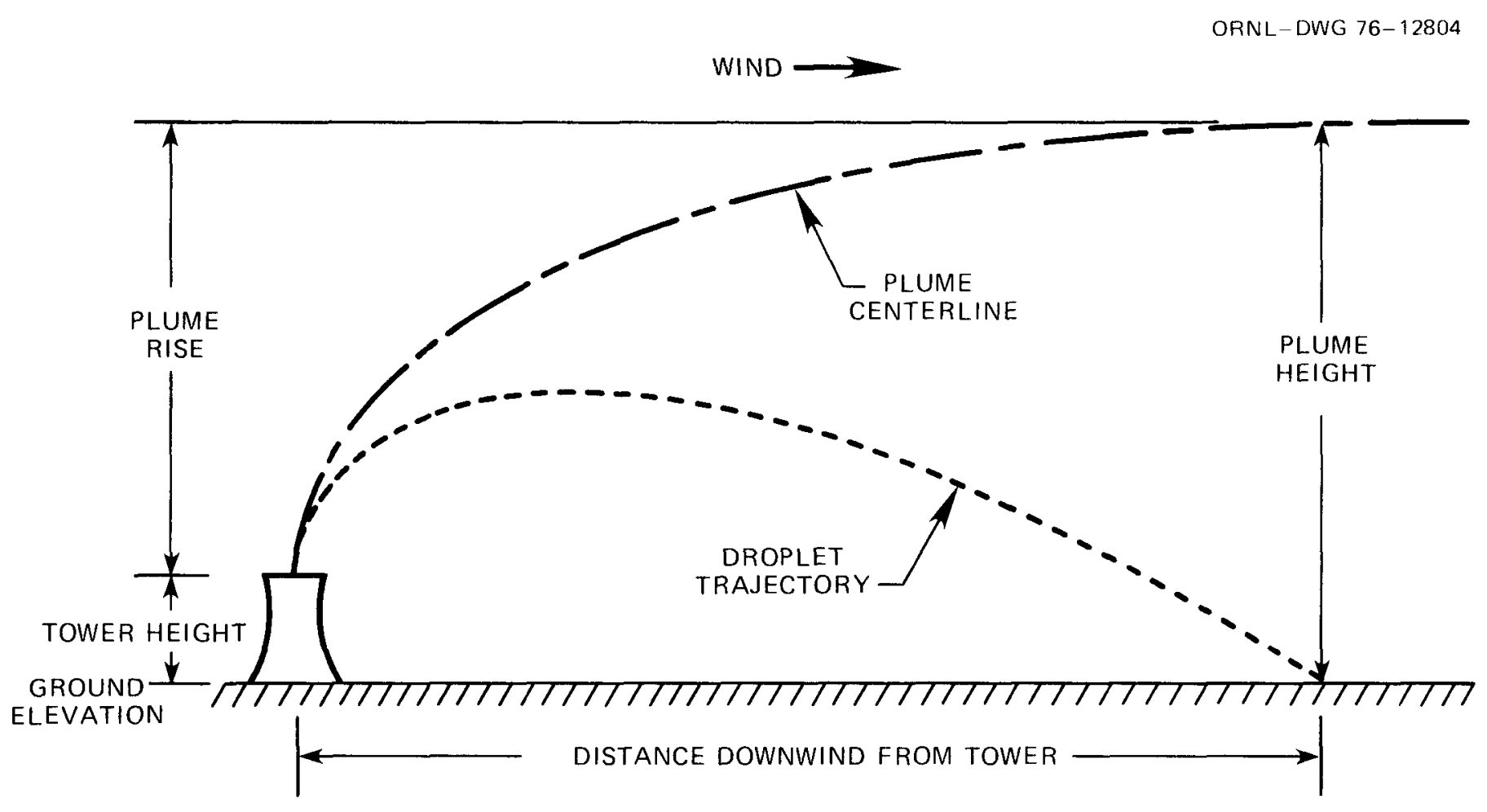

Fig. 2. Schematic of model for drift calculation. 


\section{WEATHER DATA}

The hourly or trihourly surface weather observations described in Ref. 3 are currently used by ORFAD. These observations are available on magnetic tape from the National Oceanographic and Atmospheric Administration (NOAA). 4 The periods covered by the data, depending on location, range up to 25 years. Any one tape will generally carry data for 10 years.

From the numerous items recorded, ORFAD uses wind speed and direction, dry and wet bulb temperatures, total cloud cover, cloud ceiling, and obstructions to vision, the last item being defined as smoke, haze, or a combination thereof.

\subsection{Data Decoding}

In order to fit large quantities of data onto one tape, NOAA has employed a special type of coding involving the overpunching of the numbers. As a result, these data cannot be read directly by the usual FORTRAN input statements, and, therefore, a special decoding subroutine, SIGNCK, has been incorporated in ORFAD to interpret the data from tape.

Through 1964, data were recorded at intervals of $1 \mathrm{hr}$; for later years, data were recorded at 3-hr intervals, beginning at $0 \mathrm{hr}$ Coordinated Universal Time (formerly Greenwich Mean Time). Hours having no data were left blank. Thus, tapes for 1965 and later are two-thirds empty, with the remaining third containing data similar to those for earlier years. ORFAD uses information on the geographic location of the towers to determine which hours on the tapes contain data.

In the tally after 1964, the program assumes that each reading applies to a 3-hr increment. If a period of several years spanning 1964 and 1965 is to be averaged, each hour through 1964 is given a weight of 1 , and each trihourly reading thereafter is given a weight of 3 .

\subsection{Tape Protection at ORNL}

In order to prevent accidental erasure or other damage to the original weather tapes purchased from NOAA, it is customary at ORNL to 
copy the originals onto "pool" tapes and to run the program with these copies. Occasionally, the utility program doing the copying encounters a faulty record or other difficulty and omits a record from the copy. Thus, the copied weather data may not cover all hours of the year.

\subsection{Special Handling of Data}

The original weather data tapes use special coding for entries that are invalid or missing for any reason. ORFAD tallies but does not analyze these entries. An exception is made where the datum is relative humidity; if valid dry and wet bulb temperatures are present, they are used to calculate a relative humidity.

The weather data tapes provide for reporting fog, ground fog, and ice fog. Sometimes, when these fogs are reported, the dry and wet bulb temperatures will differ. The program tallies these hours of natural fog but does not analyze them. Presumably, if fog already exists, the cooling tower will not increase its incidence. Conversely, fog may not be reported when dry and wet bulb temperatures are equal. In this case, since natural fog is not present, any calculated fog is charged to tower operation. However, we should note that the situation is somewhat ambiguous, the temperatures having been recorded only to the nearest degree.

The data tapes use CALM as a wind direction. However, even with CALM recorded, the wind speed is sometimes given as nonzero. ORFAD will analyze these hours, assigning them to directions in proportion to the relative frequencies of the winds in those directions. When the wind speed is recorded as zero, the program substitutes 1 knot, on the basis that there is always a slight wind aloft. 


\section{CALCULATION OF PLUME RISE}

The steps involved in finding the rise of the plume centerline consist of

1. determining a flux buoyancy parameter $\mathbf{F}$ for a single tower;

2. calculating a stability parameter $s$ for the atmosphere;

3. obtaining the plume rise $\Delta \mathrm{H}_{1}$ for a single tower;

4. applying a correction to obtain the plume rise $\Delta \mathrm{H}_{\mathrm{N}}$ for $\mathrm{N}$ towers, given that for one tower.

\subsection{Flux Buoyancy Parameter}

The flux buoyancy parameter as defined by Hanna ${ }^{5}$ is an extension of that given by Briggs, 6 incorporating an additional term to account for the release of latent heat from condensing moisture. For a moist plume in which a fraction $f$ of the vapor condenses,

$$
\mathrm{F}=\mathrm{W}_{\mathrm{o}} g \mathrm{R}_{\mathrm{o}}^{2}\left[1-\mathrm{T}_{\mathrm{eo}} / \mathrm{T}_{\mathrm{po}}+\left(\mathrm{q}_{\mathrm{po}}-\mathrm{q}_{\mathrm{eo}}\right)\left(0.61+\mathrm{fh}_{\mathrm{fg}} / \mathrm{C}_{\mathrm{p}} \mathrm{T}_{\mathrm{po}}\right)\right] \text {, }
$$

where

$$
\begin{aligned}
\mathrm{F} & =\text { the flux buoyancy parameter, } \mathrm{m}^{4} / \mathrm{sec}^{3}, \\
\mathrm{~W}_{0} & =\text { tower exit velocity, } \mathrm{m} / \mathrm{sec}, \\
g & =\text { acceleration of gravity, } 9.8066 \mathrm{~m} / \mathrm{sec}^{2}, \\
\mathrm{R}_{0} & =\text { tower inside radius at exit, } \mathrm{m}, \\
\mathrm{T}_{\mathrm{eo}} & =\text { environment temperature, } \mathrm{K}, \\
\mathrm{T}_{\mathrm{po}} & =\text { plume initial temperature, } \mathrm{K}, \\
\mathrm{q}_{\mathrm{po}} & =\text { plume initial mixing ratio, water vapor to dry air, } \mathrm{g} / \mathrm{g}, \\
\mathrm{q}_{\mathrm{eo}} & =\text { environment mixing ratio, water vapor to dry air, } \mathrm{g} / \mathrm{g}, \\
\mathrm{f} & =\text { fraction of vapor condensed, } \\
\mathrm{h}_{\mathrm{fg}} & =\text { latent heat of water vapor, cal } / \mathrm{g}, \\
\mathrm{C}_{\mathrm{p}} & =\text { specific heat of air at constant pressure, cal/g } \mathrm{K} .
\end{aligned}
$$

A complete 1isting of nomenclature may be found in Appendix A. 
The term $0.61\left(\mathrm{q}_{\mathrm{po}}-\mathrm{q}_{\mathrm{eo}}\right)$ represents the additional buoyancy resulting from the difference in molecular weight between water vapor and air. The final term gives the additional buoyancy resulting from release of latent heat by condensation of some fraction of the original water vapor. An estimate of $f=0$ is ordinarily used and will give conservative results in the sense of overestimating fog and drift.

The environmental temperature at the top of the cooling tower is determined from that at the base by using the temperature gradient corresponding to the Pasquill atmospheric stability class.

The water vapor in the plume is calculated on the basis that $25 \%$ of the heat is removed as sensible heat and $75 \%$ as latent heat. The initial temperature of the plume is then taken as the wet bulb temperature corresponding to the enthalpy of the air leaving the tower, which, in turn, is equated to the sum of the enthalpy entering the tower and the enthalpy increase inside the tower. The enthalpy increase is taken as the product of the circulating-water temperature range and the ratio of the water mass flow rate to the air mass flow rate. Enthalpy of the leaving air as a function of wet bulb temperature is calculated from

or

$$
h=\left(t_{w}+4.305\right) /\left(3.917-0.024846 t_{w}\right) \quad 10 \leq t_{w} \leq 80
$$
where

$$
h=\left(t_{w}-13.85\right) /\left(2.766-0.015652 t_{w}\right) \quad 80<t_{w},
$$

$$
\begin{aligned}
h & =\text { enthalpy, Btu/1b, } \\
t_{w} & =\text { wet bulb temperature, }{ }^{\circ} \mathrm{F} .
\end{aligned}
$$

\subsection{Stability Parameter}

The stability parameter is defined by

$$
s=g\left(\partial T_{e o} / \partial z+0.01\right) / T_{e o},
$$

where $\mathrm{s}$ is stability parameter, $\mathrm{sec}^{-2}$, and $\partial \mathrm{T}$ eo $/ \partial \mathrm{z}$ is atmospheric temperature gradient, $\mathrm{K} / \mathrm{m}$. The temperature gradient is that corresponding to the Pasquill stability class determined from the given weather data. An explanation of this atmospheric stability classification is given in 
Appendix $B$, together with a listing of the temperature gradients used in ORFAD.

\subsection{Plume Rise for a Single Tower ${ }^{5,6}$}

The plume rise is dependent on whether calm or windy conditions prevail and, for the windy case, on the stability of the atmosphere.

\subsubsection{Calm conditions}

For all stability classes, the plume rise in calm air is given by

$$
\Delta \mathrm{H}_{1}=5.0 \mathrm{~F}^{0.25} \mathrm{~s}^{-0.375}
$$

where $\Delta H_{1}$ is plume rise for a single tower, $m$, and $F$ and $s$ are as previously defined.

\subsubsection{Windy conditions}

Under windy conditions, plume rise is further dependent on the stability of the atmosphere.

\subsubsection{Pasquill stability class $\leq 4$}

For an unstable-to-neutral atmosphere, we calculate a quantity $X *$ defined by

$$
\mathrm{X}^{*}=2.16 \mathrm{~F}^{0.4} \mathrm{H}_{0}^{0.6}, \mathrm{~m},
$$

where $\mathrm{H}_{0}$ is the tower height or $304.8 \mathrm{~m}$, whichever is smaller, that is,

$$
\mathrm{H}_{0}=\min \left(\mathrm{H}_{\mathrm{T}}, 304.8\right) \text {. }
$$

The plume rise is then given by

$$
\Delta \mathrm{H}_{1}=1.6 \mathrm{~F}^{1 / 3} \mathrm{U}^{-1} \mathrm{X}^{2 / 3},
$$

where

$$
\mathrm{X}=\min \left(\mathrm{X}_{\mathrm{me}}, 3 \mathrm{X}^{*}\right) \text {, }
$$

$U$ is wind speed, $\mathrm{m} / \mathrm{sec}, \mathrm{X}_{\mathrm{me}}$ is downwind distance from the tower, $\mathrm{m}$, and $\mathrm{F}$ and $\mathrm{X}^{*}$ are as previously defined. 


\subsubsection{Pasquill stability class $>4$}

For a stable atmosphere, the plume rise is again given by Eq. (7) but with $\mathrm{X}$ now being determined from

$$
\mathrm{X}=\min \left(\mathrm{X}_{\mathrm{me}}, 2.4 \mathrm{U} \mathrm{s}^{-1 / 2}\right)
$$

\subsection{Plume Rise for Multiple Towers}

When a set of $\mathrm{N}$ towers forms a cluster with a maximum dimension $\mathrm{L}$, the following relations given by Briggs $^{7}$ are used to determine the plume rise for the cluster from that for a single tower:

$$
\Delta \mathrm{H}_{\mathrm{N}}=\left(\frac{\mathrm{N}+\mathrm{S}}{1+\mathrm{S}}\right)^{1 / 3} \Delta \mathrm{H}_{\mathrm{l}}
$$

with

$$
S=6\left(\frac{\mathrm{L}}{\mathrm{N}^{1 / 3} \Delta \mathrm{H}_{1}}\right)^{3 / 2}
$$

where

$$
\begin{aligned}
\mathrm{N} & =\text { number of towers in the cluster, } \\
\mathrm{L} & =\text { the maximum cluster dimension, } \mathrm{m}, \\
\Delta \mathrm{H}_{1} & =\text { the plume rise for a single tower, } \mathrm{m}, \\
\Delta \mathrm{H}_{\mathrm{N}} & =\text { the plume rise for the cluster, } \mathrm{m} .
\end{aligned}
$$

When several cooling towers are in the same general vicinity, it is a matter of judgment whether they should be analyzed as a single cluster or separately. Briggs has suggested that the effects be analyzed both ways and the more conservative result selected.

After the number of towers in the cluster has been determined, a further judgment is needed to find the maximum dimension L. Ordinarily, the diameter of the smallest circle that circumscribes all the towers is a good choice. 


\section{CALCULATION OF FOG AND ICE FOG}

In predicting the amount of ground-level fog induced by coolingtower operation, the ORFAD program holds the tower accountable only if (1) naturally occurring fog was not reported and (2) the moisture content of the plume was sufficient to equal or exceed that required to saturate the air during the data period considered. If fog was reported, the occurrence will be tallied, but the remainder of the fog and ice calculation will be bypassed on the basis that if a fog already exists, the cooling tower will not increase its incidence.

\subsection{Water Vapor Density of Plume}

Under the previously mentioned assumption of a Gaussian distribution of water vapor within the plume, the vapor concentration at ground level is given by

$$
x=\frac{Q}{\pi \sigma_{y} \sigma_{z} U} \exp \frac{-H^{2}}{2 \sigma_{z}^{2}},
$$

where

$$
\begin{aligned}
X & =\text { water vapor concentration at ground level, } \mathrm{g} / \mathrm{m}^{3}, \\
\mathrm{Q} & =\text { water vapor mass velocity at tower exit, } \mathrm{g} / \mathrm{sec}, \\
\mathrm{H} & =\text { plume centerline height above ground, } \mathrm{m}, \\
\sigma_{\mathrm{y}} & =\text { lateral diffusion coefficient, } \mathrm{m}, \\
\sigma_{\mathrm{z}} & =\text { vertical diffusion coefficient, } \mathrm{m}, \\
\mathrm{U} & =\text { wind speed, } \mathrm{m} / \mathrm{sec} .
\end{aligned}
$$

The diffusion coefficients are derived from the relations given by Briggs, ${ }^{8}$ as shown in Appendix $\mathrm{C}$.

\subsection{Saturation Deficit}

The saturation deficit, or the increment in water vapor density required in order to saturate the air at the same dry bulb temperature, is given by

$$
d_{s}=7345 \frac{p_{s}-p_{v}}{T_{a}} \text {, }
$$


where

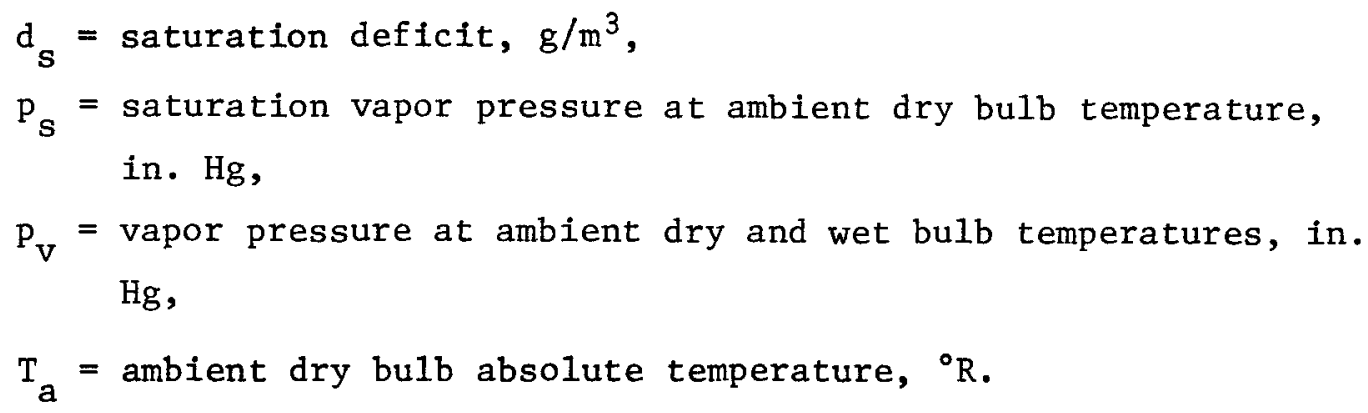

\subsection{Fog}

Fogging is assumed to occur if the added vapor concentration equals or exceeds the saturation deficit. We further assume that the fogging will occur over a distance of $1.25 \sigma_{y}$ on either side of the downwind vector. This distance corresponds to Briggs' plume half-width, ${ }^{8}$ which is determined by equating the integral of the Gaussian distribution in the lateral direction to that of a uniform distribution having the same centerline concentration. The result is $\sqrt{\pi / 2} \sigma_{y}$, that is, $1.25 \sigma_{y}$, as given above. At the same distance $X$ from the tower, the sector arc length is $\pi X / 8$ (each sector covering $221 / 2^{\circ}$ ). The hours of fog are then adjusted by multiplying by the ratio of the fogging width to the arc length, that is, by $2.500 \mathrm{y} /$ $(\pi \mathrm{X} / 8)$. For example, a fog in which $2.50 \sigma_{\mathrm{y}}$ corresponds to a $10^{\circ}$ sector would be tallied as $10 / 22.5$ or $4 / 9 \mathrm{hr}$ of fog on the average for each hour of clock time for that sector.

\subsection{Ice Fog}

The calculation for ice fog follows that for fogging. If the local moisture concentration exceeds the saturation deficit and, in addition, the temperature is below the freezing point, icing is assumed to occur. The hours of ice are adjusted, of course, in the same manner as the hours of fog. 
6. CALCULATION OF DRIFT DEPOSITION AND SALT CONCENTRATION

As originally written and as described in Ref. 1, the drift calculation assumed that all drift particles of a certain original size class formed a plume having a Gaussian distribution of particle concentration about its own centerline. The centerline of the particle plume was assumed to lie below that of the vapor plume by the distance through which the finite-size drift particles had fallen, as determined by the method of Hosler et a1.2 The drift deposition was then calculated as the product of the ground-level concentration and the velocity of the final fall.

The above procedure was modified about the time of publication of Ref. 1. The diffusion model described above was abandoned, and a ballistic trajectory model in which all particles of a given initial size reach the ground at the same distance from the tower was employed. The method of Hosler et al. ${ }^{2}$ was retained for computing the trajectories.

The trajectory model assumes that all droplets of a given original size fall to the ground at the same distance from the tower for the same conditions of wind, relative humidity, and atmospheric stability. This distance is that at which the total fall distance of the droplet just equals the local plume height above ground.

The fraction of droplets falling in the interval $\Delta \mathrm{X}$ spanning $\mathrm{X}$ is approximated in $\mathrm{ORFAD}$ by

$$
\Delta C=\Delta \mathrm{X} \frac{\mathrm{dC}}{\mathrm{dD}} \frac{\mathrm{dD}}{\mathrm{dX}}
$$

where $X(D)$ is the distance at which a droplet of diameter $D$ strikes the ground and $C(D)$ is the cumulative distribution function of the droplets.

The drift deposition can be determined from the fraction of drift falling at a given distance, the area of the corresponding $22.5^{\circ}$ sector, and the total salt emission from the tower.

The airborne salt concentration is then found as the drift deposition rate divided by the velocity of the final fall. 


\subsection{Determination of $\mathrm{dC} / \mathrm{dD}$}

The cumulative distribution function $\mathrm{C}$ is developed from the input data on droplet size distribution, as shown in Fig. 3. Integration of the basic input frequency function, shown in part (a) of the figure, is carried out over 25 subintervals spanning the droplet sizes given, resulting in the cumulative distribution function in part (b). Differencing of $\mathrm{C}$ at the boundaries of the 25 subintervals and dividing by the subinterval width yields $\mathrm{dC} / \mathrm{dD}$, as shown in part (c). Note that this function coincides with the original function except for scale unless a subinterval spans a boundary of the basic intervals. There, the derived function value is the weighted mean of the adjacent values. The weights are selected to be area preserving.

\subsection{Determination of $\mathrm{dD} / \mathrm{dX}$}

Hosler et al. ${ }^{2}$ classify droplets into three categories: (1) those that do not evaporate at a11, (2) those that evaporate to saturated solutions, and (3) those that evaporate to dry particles. In the first cate-

gory, the fall velocity $V_{f}$ is a constant dependent only on droplet diameter. Within categories 2 and 3 , the fall velocity of the evaporating droplet is determined by averaging an initial value dependent on the original size of the droplet and a final uniform value attained after some evaporation distance $\mathrm{H}_{\mathrm{e}}$. The residual droplet is assumed to strike the ground with this final velocity.

The assumption that all droplets and particles are spherical is implicit throughout the model.

\section{2 .1 No evaporation; relative humidity $\geq 76 \%$}

For the nonevaporating case, the quantity $\mathrm{dD} / \mathrm{dX}$ can be derived analytically. First, we note for convenience that

$$
\frac{d D}{d X} \equiv \frac{d V_{f}}{d X} \frac{d D}{d V_{f}}
$$




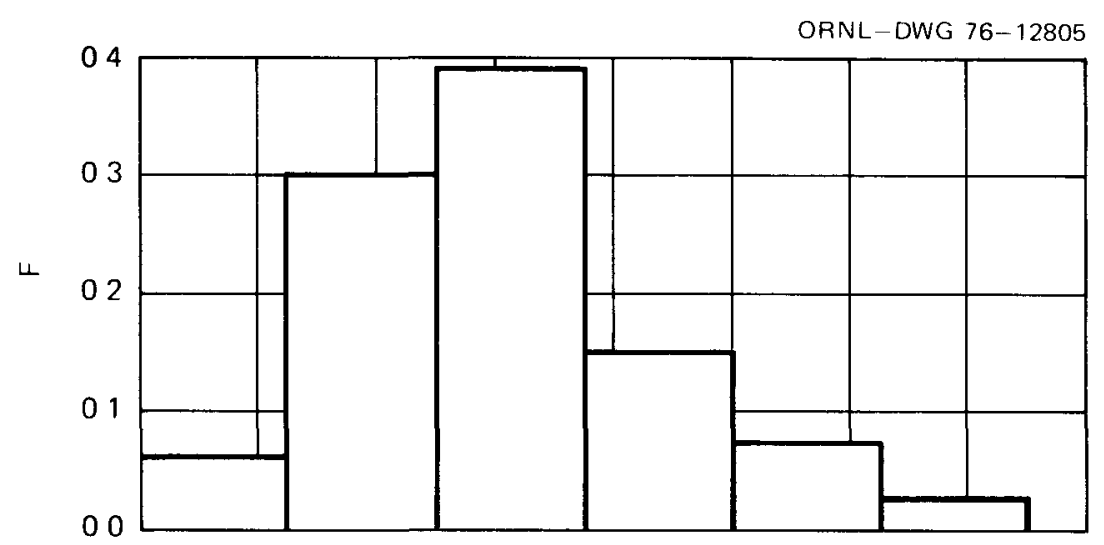

(a)

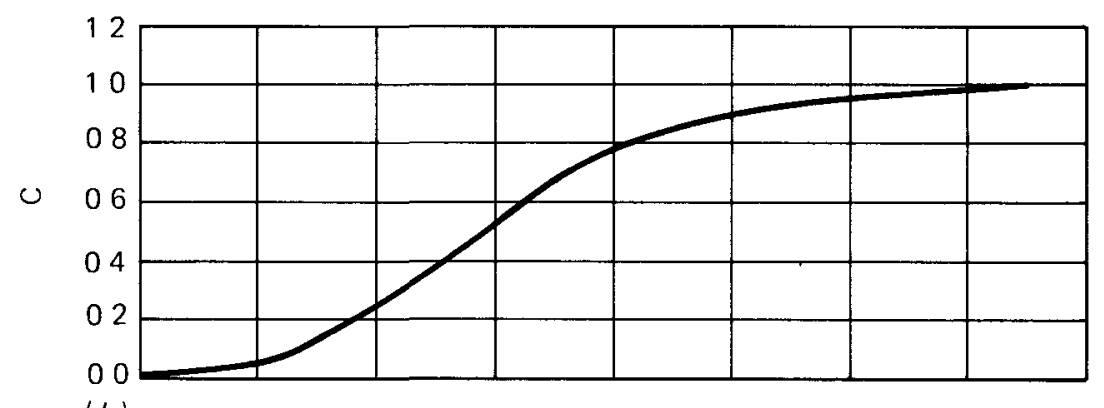

(b)

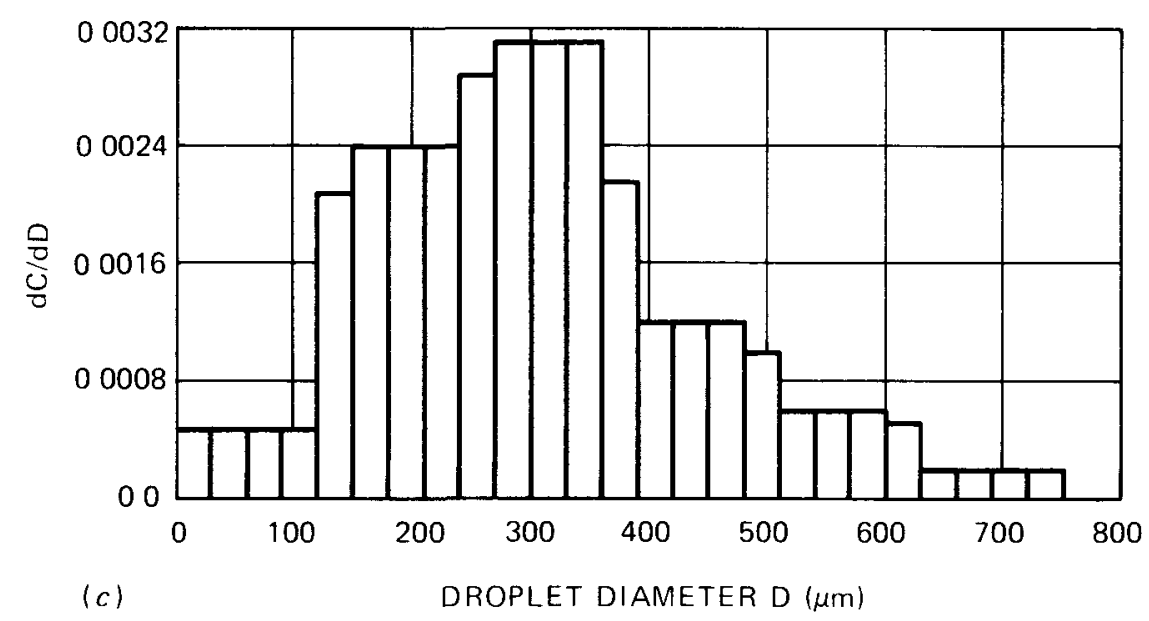

Fig. 3. Development of cumulative distribution function and its derivative from the basic input frequency function. 
From the relation

$$
\text { Time of fall = horizontal transport time }
$$

or

$$
\mathrm{H} / \mathrm{V}_{\mathrm{f}}=\mathrm{X} / \mathrm{U}
$$

we get

$$
v_{f}=\frac{U H}{X}
$$

so that

$$
\frac{d V_{f}}{d x}=\frac{1}{x}\left(V_{f}-U \frac{d H}{d X}\right)
$$

[Actually, the sign of the right-hand side of Eq. (18) has been changed so that the drift depositions will be positive.]

We now consider the second factor $d D / d v_{f}$, for which we require $v_{f}$ as a function of D. Because there is no evaporation, the droplets fall at uniform velocities characterized by their diameters, as shown in Fig. 4. Small droplets are assumed to follow Stokes' law, while medium and large droplets fall according to wind tunnel data ${ }^{9}$ reported in the International Meteorological Tables, 1966. The fall velocity $\mathrm{V}_{f}$ is given by the equations

$$
\begin{array}{ll}
\mathrm{V}_{f}=\mathrm{D}^{2} / 33414 & \mathrm{D} \leq 74.36 \mu \mathrm{m} \\
\mathrm{V}_{\mathrm{f}}=0.00445(\mathrm{D}-37.18) & \mathrm{D}>74.36 \mu \mathrm{m},
\end{array}
$$

where $V_{f}$ is fall velocity, $\mathrm{m} / \mathrm{sec}$, and $\mathrm{D}$ is original droplet diameter, $\mu \mathrm{m}$. Then, we have, for $\mathrm{D} \leq 74.36 \mu \mathrm{m}$,

$$
\frac{d D}{d v_{f}}=\frac{1}{2} \frac{D}{V_{f}}
$$




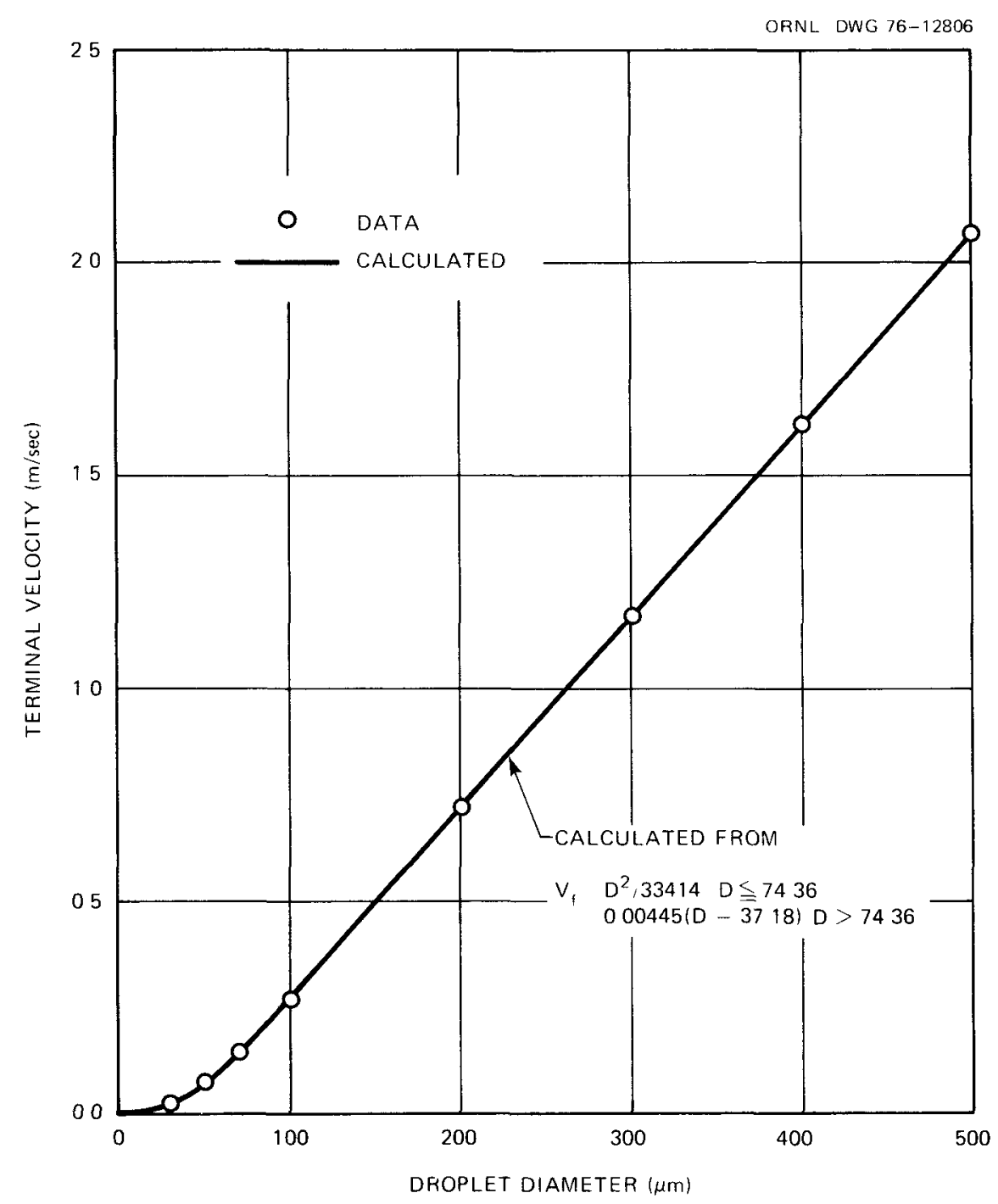

Fig. 4. Terminal fall velocity of water droplets. Data from International Meteorological Tables, 1966.

and

$$
\frac{d D}{d X}=\frac{D}{2 V_{f} X}\left(v_{f}-U \frac{d H}{d X}\right)
$$

For the larger droplets, we obtain

$$
\frac{d D}{d v_{f}}=\frac{1}{0.00445}
$$


Hence, for $\mathrm{D}>74.36 \mu \mathrm{m}$,

$$
\frac{d D}{d X}=\frac{1}{0.00445 X}\left(V_{f}-U \frac{d H}{X}\right) .
$$

\section{2 .2 Evaporation; relative humidity $<76 \%$}

For relative humidity below $76 \%$, evaporation is assumed to occur, with a droplet possibly attaining a saturated solution or becoming a dry particle. The fall velocity of the droplet or particle is found by averaging an initial velocity dependent on initial droplet size and a final velocity dependent on relative humidity. A repetitive solution now becomes necessary in order to determine the diameter of a droplet falling at a given distance.

\subsubsection{Evaporation distance}

The distance a droplet falls while evaporating depends on the initial droplet diameter and the ambient relative humidity. This distance has been given graphically by Hosler et al. ${ }^{2}$ and is approximated in ORFAD by the expression

$$
\mathrm{H}_{\mathrm{e}}=\frac{7.414610^{-6} \mathrm{D}^{2.667}}{(1-\mathrm{r})^{1.079}} \text {, }
$$

where $\mathrm{H}_{\mathrm{e}}$ is evaporation distance, $\mathrm{m}, \mathrm{D}$ is original droplet diameter, $\mathrm{m}$, and $r$ is relative humidity.

\subsubsection{Saturated solution droplets; relative humidity $\geq 50 \%$}

In the relative humidity range from 50 to $76 \%$, evaporation is assumed to occur until the droplets become saturated. The droplets then fall at a constant velocity dependent on their final diameter. The vertical distance the droplets fall before becoming saturated is given by Eq. (24). The initial velocity is that obtained from the appropriate one of $\mathrm{Eq} .(19)$. 
A mass balance gives the diameter of the saturated droplet as

$$
D_{s}=D\left[\frac{\rho_{w} c}{\rho_{s} c_{s}}\right]^{1 / 3},
$$

where

$$
\begin{aligned}
D_{s} & =\text { diameter of the saturated droplet, } \mu \mathrm{m}, \\
D & =\text { diameter of the original droplet, } \mu \mathrm{m}, \\
\rho_{\mathrm{w}} & =\text { initial water density, } \mathrm{g} / \mathrm{cc}, \\
& =1.0+0.7 \mathrm{c}, \text { for } \mathrm{c} \leq 0.05 \mathrm{~g} / \mathrm{g}, \\
\rho_{s} & =\text { saturated solution density, } 1.197 \mathrm{~g} / \mathrm{cc}, \\
\mathrm{c} & =\text { initial concentration, } \mathrm{g} / \mathrm{g}, \\
\mathrm{c}_{s} & =\text { saturated solution concentration, } 0.26 \mathrm{~g} / \mathrm{g} .
\end{aligned}
$$

The final fall velocity is given by

$$
v_{s}=v_{s} \rho_{s} / \rho
$$

where $v_{s}$ is final fall velocity of the saturated droplet, $\mathrm{m} / \mathrm{sec}, v_{s}$ is fall velocity of a droplet of diameter $D_{s}$ [from Eq. (19)], m/sec, and $\rho$ is density of pure water, $1.0 \mathrm{~g} / \mathrm{cc}$.

The average fall velocity $\overline{\mathrm{V}}_{\mathrm{e}}$ during evaporation (i.e., while falling through the distance $H_{e}$ ) is then found as the mean of the initial and final fall velocities.

$$
\bar{v}_{e}=\left(v_{f}+v_{s}\right) / 2
$$

where $v_{f}$ is the initial fall velocity of a droplet of orlginal diameter D [from Eq. (19)], in $\mathrm{m} / \mathrm{sec}$. An evaporation time is computed from

$$
t_{e}=\frac{H_{e}}{\bar{V}_{e}},
$$

where $\mathrm{H}_{e}$ is found from Eq. (24). 
The droplet falls a distance $H$ in time $t$, where

$$
H=V_{f} t-\frac{1}{2} \frac{V_{f}^{2}-v_{s}^{2}}{2 H_{e}} t^{2} \quad t<t_{e}
$$

or

$$
\mathrm{H}=\mathrm{H}_{\mathrm{e}}+\left(\mathrm{t}-\mathrm{t}_{\mathrm{e}}\right) \mathrm{v}_{\mathrm{s}} \quad \mathrm{t} \geq \mathrm{t}_{\mathrm{e}}
$$

The time $t$ is the horizontal distance divided by the wind speed, as indicated in Eq. (16), and $\mathrm{H}$ must equal the plume height above ground at the same distance. The origin of the second term on the right-hand side of Eq. (29a) is explained in Appendix D.

\subsubsection{Dry particles; relative humidity $<50 \%$}

For relative humidities below $50 \%$, the droplets are assumed to evaporate to dry particles. The particles then fall at a constant velocity dependent on their final diameters. Except for differing velocities, this category is handled in the same manner as the saturated solution droplets.

A mass balance gives the diameter of the dry particle as

$$
D_{d}=D\left[\frac{\rho_{w} c}{\rho_{d}}\right]^{1 / 3}
$$

where $\mathrm{D}_{\mathrm{d}}$ is diameter of the dry particle, $\mathrm{m}, \rho_{\mathrm{d}}$ is dry particle density, $2.165 \mathrm{~g} / \mathrm{cc}$, and the remaining quantities are as previously defined.

The final fall velocity is given by

$$
v_{d}=v_{d} \rho_{d} / \rho
$$

where $v_{d}$ is final fall velocity of the dry particle, $\mathrm{m} / \mathrm{sec}$, and $v_{d}$ is fall velocity of a particle of diameter $D_{d}[$ from $E q .(19)], \mathrm{m} / \mathrm{sec}$. 
The average fall velocity $\bar{v}_{e}$ during the drying out period (i.e., while falling through the distance $H_{e}$ ) is then found as the mean of the initial and final fall velocities:

$$
\bar{v}_{e}=\left(v_{f}+v_{d}\right) / 2
$$

The particle falls a distance $H$ in the time $t$, where

$$
H=V_{f} t-\frac{1}{2} \frac{V_{f}^{2}-v_{d}^{2}}{2 H_{e}} t^{2} \quad t<t_{e}
$$

or

$$
H=H_{e}+\left(t-t_{e}\right) v_{d} \quad t \geq t_{e} \text {. }
$$

\subsubsection{Solution for $\mathrm{dD} / \mathrm{dX}$}

Starting from the largest size, the program selects a drop size from the droplet distribution function. The distance from the tower at which this selected drop will strike the ground is then found from Eqs. (25) through (29) for saturated drops or from Eqs. (30) through (33) for dry particles, depending on the relative humidity.

This calculation, using successively smaller drops, is repeated until two consecutive drop sizes yield fall distances spanning the current deposition distance. The slope $\mathrm{dD} / \mathrm{dX}$ of the diameter vs distance curve is then approximated by the ratio of the difference in the two drop sizes to the difference in the corresponding fall distances.

\subsection{Drift Deposition and Salt Concentration}

We calculate a source term $Q_{1}$ from

$$
Q_{1}=\frac{q F_{w} c}{C_{p w} \Delta t} \text {, }
$$


where

$$
\begin{aligned}
\mathrm{Q}_{1} & =\text { total salt from the tower, } \mathrm{g} / \mathrm{sec}, \\
\mathrm{q} & =\text { heat rejection, cal/sec, } \\
\mathrm{F}_{\mathrm{W}} & =\text { fraction of circulating water as drift, } \\
\mathrm{C} & =\text { concentration of salt in circulating water, } \mathrm{g} / \mathrm{g}, \\
\mathrm{C}_{\mathrm{pw}} & =\text { specific heat of circulating water, } 1.0 \mathrm{cal} / \mathrm{g} \cdot{ }^{\circ} \mathrm{C}, \\
\Delta \mathrm{t} & =\text { circulating-water temperature range, }{ }^{\circ} \mathrm{C} .
\end{aligned}
$$

Then

$$
X_{2}=Q_{1} \Delta \mathrm{C} / \mathrm{A}
$$

where $x_{2}$ is salt deposition rate, $\mathrm{g} / \mathrm{sec} \cdot \mathrm{m}^{2}$, A is area of deposition sector, $\mathrm{m}^{2}$, and $\Delta \mathrm{C}$ is fraction of total output salt deposited in sector. The area, radial width, and mean radius of a $22.5^{\circ}$ sector are related by

$$
\Delta \mathrm{X}=\frac{8 \mathrm{~A}}{\pi \mathrm{X}}
$$

where $\Delta \mathrm{X}$ is radial width of sector, $\mathrm{m}, \mathrm{X}$ is mean radius of sector, $\mathrm{m}$. Finally, using the definitions of $\Delta \mathrm{C}$ from Eq. (14) and of $\Delta \mathrm{X}$ from Eq. (36) we obtain

$$
x_{2}=\frac{8}{\pi} \frac{Q_{1}}{X} \frac{d C}{d D} \frac{d D}{d X}
$$

as the equation for drift deposition rate $\left(\mathrm{g} / \mathrm{sec} \cdot \mathrm{m}^{2}\right)$. The equation applies whether droplet evaporation occurs or not, evaporation entering only into the determination of $\mathrm{dD} / \mathrm{dX}$.

Salt concentration $\left(\mathrm{g} / \mathrm{m}^{3}\right)$ is then found from the deposition by dividing by the final fall velocity, that is,

$$
c_{s}=x_{2} / v \text {, }
$$

where $v$ is final fall velocity, $\mathrm{m} / \mathrm{sec}$. The velocity $\mathrm{v}$ is found from Eqs. (19), (26), or (31), as appropriate to a nonevaporating droplet, a saturated solution droplet, or a dry particle, respectively. 


\section{PROGRAM OPERATION}

This section presents a brief description of the organization of the ORFAD program and the subroutines and functions employed (exclusive of plotting and system-supplied routines), instructions on input preparation and job submission, and the program output. Some knowledge of the computer procedures is presumed; for example, the user is assumed to have appropriate computer charge numbers and jobname initials for use at ORNL.

\subsection{ORFAD Organization}

The overall organization of ORFAD is illustrated in Fig. 5, which shows the calling sequences for the subroutines and functions used by the program. A complete listing of the FORTRAN programs used may be found in Appendix E.

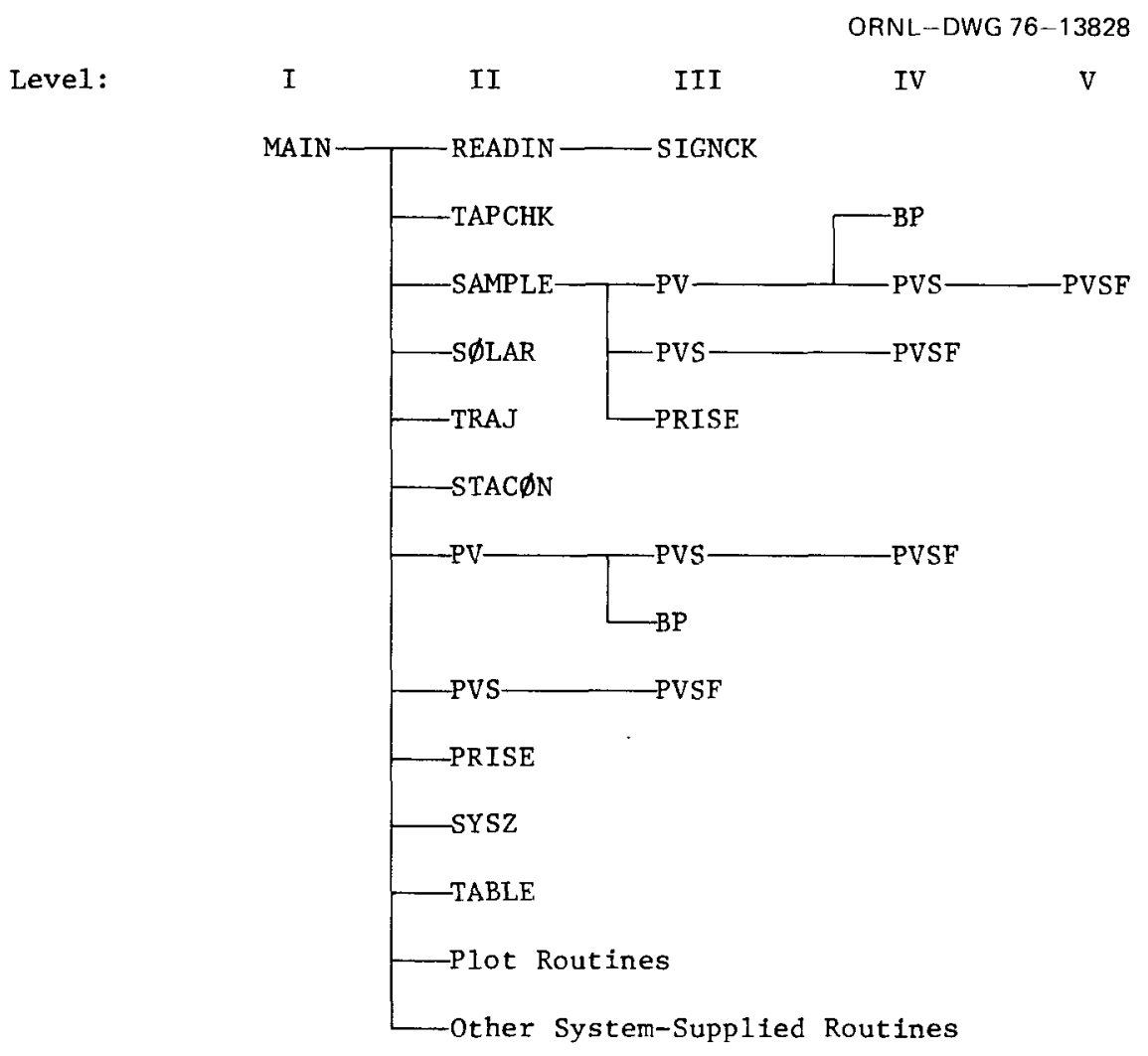

Fig. 5. Overall organization of ORFAD, showing the calling sequences for subroutines and functions. 
Table 1 shows the intercommunication among the subprograms through the medium of $C \emptyset M M \emptyset N$ storage, both labeled and blank.

\subsection{ORFAD Subroutines and Functions}

The main program calls, directly or indirectly, a number of subprograms that perform the functions described below. The plotting routines have not been included

\begin{tabular}{|c|c|}
\hline Name & Function \\
\hline READIN & Reads hourly weather data from tapes obtained from NOAA. \\
\hline SIGNCK & $\begin{array}{l}\text { Tests the validity of weather data and supplies the } \\
\text { proper signs. }\end{array}$ \\
\hline TAPCHK & $\begin{array}{l}\text { Verifies that proper tape was mounted, checks tape } \\
\text { data period and start date against requested values. }\end{array}$ \\
\hline SAMPLE & $\begin{array}{l}\text { Provides sample values of plume rise and drift for } \\
\text { program verification. }\end{array}$ \\
\hline PV & $\begin{array}{l}\text { Calculates atmospheric vapor pressure from wet and dry } \\
\text { bulb temperatures and elevation above sea level. }\end{array}$ \\
\hline PVS & $\begin{array}{l}\text { Calculates pressure of saturated vapor, in. } \mathrm{Hg} \text {, at a } \\
\text { given wet bulb temperature, }{ }^{\circ} \mathrm{F} \text {. }\end{array}$ \\
\hline PVSF & $\begin{array}{l}\text { Calculates pressure of saturated vapor, psi, at a } \\
\text { given wet bulb temperature, } k \text {. }\end{array}$ \\
\hline $\mathrm{BP}$ & $\begin{array}{l}\text { Determines the standard barometric pressure, in. } \mathrm{Hg} \text {, } \\
\text { at a given altitude in feet above sea level. }\end{array}$ \\
\hline SøLAR & $\begin{array}{l}\text { Provides equation of time and declination of sun for } \\
\text { use in subroutine } \operatorname{STAC} \emptyset \mathrm{N} \text {. }\end{array}$ \\
\hline PRISE & $\begin{array}{l}\text { Calculates plume rise above stack top as a function of } \\
\text { downwind distance. }\end{array}$ \\
\hline TRAJ & $\begin{array}{l}\text { Calculates various quantities used for drift calcula- } \\
\text { tion in main program, such as evaporation distances } \\
\text { and fall velocities for saturated and dry particles. }\end{array}$ \\
\hline STAC $\emptyset \mathrm{N}$ & Calculates the Pasquill atmospheric stability class. \\
\hline SYSZ & $\begin{array}{l}\text { Calculates the diffusion coefficients } \sigma_{y} \text { and } \sigma_{z} \text { as } \\
\text { functions of downwind distance and stability class. } \\
\text { Prints output tables. }\end{array}$ \\
\hline
\end{tabular}


Table 1. Blank and labeled C $\emptyset \mathrm{MM} \emptyset \mathrm{N}$ storage in ORFAD

\begin{tabular}{|c|c|c|c|c|c|c|c|c|c|c|c|c|c|c|}
\hline \multirow{2}{*}{$\begin{array}{c}\text { Program } \\
\text { name }\end{array}$} & \multicolumn{12}{|c|}{$C \emptyset M M \emptyset N$ storage names ${ }^{\mathbf{a}}$} & \multirow[b]{2}{*}{ SCANC } & \multirow[b]{2}{*}{ IBREAK } \\
\hline & $\overline{\text { MAINC }}$ & TAPE & SAMP & DRØPS & STAB & Blank & TABUL & TITLER & LGND & $\mathrm{C} \emptyset \mathrm{NT}$ & Q7QUAD & SUB & & \\
\hline MAIN & $\mathrm{X}$ & $\mathrm{X}$ & $\mathrm{X}$ & $\mathbf{x}$ & $x$ & $\mathrm{X}$ & $\mathrm{X}$ & $\mathrm{X}$ & $\mathrm{X}$ & & & & & \\
\hline READIN & & $\mathrm{X}$ & & & & & & & & & & & & \\
\hline TAPCHK & & $\mathrm{X}$ & & & & & & & & & & & & \\
\hline SAMPLE & & & $\mathrm{X}$ & $\mathrm{X}$ & & $\mathrm{X}$ & & & & & & & & \\
\hline TRAJ & & & $X$ & $\mathrm{X}$ & & & & & & & & & & \\
\hline $\operatorname{STAC} \emptyset \mathrm{N}$ & & & & & $\mathrm{X}$ & & & & & & & & & \\
\hline PRISE & & & & & & $\mathrm{X}$ & & & & & & & & \\
\hline SYSZ & & & & & & $\mathrm{X}$ & & & & & & & & \\
\hline TABLE & & & & & & & $\mathrm{X}$ & & & & & & & \\
\hline BL $\emptyset \mathrm{CK}$ DATA & & & & & & & & $\mathrm{X}$ & $\mathrm{X}$ & & & & & \\
\hline RC $\emptyset \mathrm{NTR}$ & & & & & & & & & & & $\mathrm{X}$ & & & \\
\hline LTRIS & & & & & & & & & & $\mathrm{X}$ & & & & \\
\hline UTRIS & & & & & & & & & & $\mathrm{X}$ & & & & \\
\hline Q7PL $\emptyset \mathrm{T}$ & & & & & & & & & & & $\mathrm{x}$ & & & \\
\hline CONTUR & & & & & & & & & & $\mathrm{X}$ & & $\mathrm{X}$ & & \\
\hline SUBPLT & & & & & & & & & & $\mathrm{X}$ & & $\mathrm{X}$ & & \\
\hline BøUNDS & $\mathrm{X}$ & & & & & & & & & & & & & \\
\hline SCAN & $\mathrm{x}$ & & & & & & & $\mathrm{X}$ & & & & & $\mathrm{X}$ & $\mathrm{X}$ \\
\hline PLTINT & $\mathrm{x}$ & & & & & & & & & & & & & \\
\hline PL $\emptyset \mathrm{TT} 1$ & $\mathrm{X}$ & & & & & & & $\mathrm{X}$ & & & & & $\mathrm{X}$ & $\mathrm{X}$ \\
\hline
\end{tabular}

${ }^{a}$ S $\emptyset$ LAR, SIGNCK, PREP, PV, PVS, PVSF, and BP have no C $\emptyset \mathrm{MM} \emptyset \mathrm{N}$ storage. Programs from C $\emptyset \mathrm{NPLT}$ down are plotting routines. PREP is also a plotting routine. 


\subsection{Input Preparation}

This section discusses the preparation of input for ORFAD, starting with descriptions of the input quantities required, together with their names and locations within the input deck, and followed by a suggested input form for convenient organization of the data. Sample numbers have been inserted. An example of an input deck, as it might be punched on cards from the sample input, is given next. Finally, the use of available options is discussed, together with some of their consequences.

\subsubsection{Description of input quantities}

Table 2 lists all the input quantities required for a computer run with program ORFAD, giving location in the card deck, the FORTRAN name, and a short description of each quantity. Some comments relative to the use (or misuse) of the quantities have been included.

\subsubsection{Suggested input form}

Figure 6 shows a suggested input form for use with ORFAD, complete with a set of sample input numbers. Note that, where relevant, units have been specified at the extreme right. The monthly concentration array C $\emptyset$ NM has been labeled with the months to which the respective numbers apply.

\subsubsection{Input card deck}

The input card deck for ORFAD contains, for each case, 12 cards giving the tower dimensions and operating parameters, miscellaneous output instructions such as the distance at which calculations will be performed, the number and type of contours to be plotted, etc. Figure 7 shows the input quantities from Fig. 6 as they could be punched on cards.

All input cards, except the first of each set of 12, are read with an $8 \mathrm{E} 10.3$ format. With a decimal point present, the numbers may be punched anywhere within their assigned columns. However, proofreading is easier if numbers are started in columns $1,11,21$, etc. Very small or very large numbers may be punched in an E-format, but care must be taken to avoid misinterpretation by the program. For example, the 0.0000001 in 
Table 2. Locations, names, and descriptions of input quantities

\begin{tabular}{|c|c|c|c|}
\hline $\begin{array}{l}\text { Card } \\
\text { No. }\end{array}$ & Column & $\begin{array}{l}\text { FORTRAN } \\
\text { name }\end{array}$ & Description \\
\hline \multirow[t]{2}{*}{1} & $1-72$ & $L \emptyset \mathrm{C}$ & $\begin{array}{l}\text { Any descriptive title may be inserted in } \\
\text { these columns. The title will be printed } \\
\text { on the first page of the output, on the } \\
\text { first page of each set of annual tables, and } \\
\text { on the first page of the overall-average } \\
\text { tables. CAUTION: Do not allow the title } \\
\text { to extend into any of columns } 73-80 \text {. Any } \\
\text { nonnumeric characters that appear in these } \\
\text { columns will cause the operating system to } \\
\text { terminate the program with a note to the } \\
\text { effect that you have used an "illegal decimal } \\
\text { character." Be warned. }\end{array}$ \\
\hline & $73-80$ & TAPEN & $\begin{array}{l}\text { The weather tape number is optional; if it } \\
\text { is supplied, subroutine TAPCHK will do vari- } \\
\text { ous things for you, such as verifying that } \\
\text { the correct tape was mounted, that the } \\
\text { data period requested is compatible with } \\
\text { that actually on the tape, etc. It is the } \\
\text { user's responsibility to see that the } \\
\text { TAPCHK arrays contain information covering } \\
\text { the requested tape. If TAPEN is omitted, } \\
\text { no checking is done, but a note to that } \\
\text { effect is printed. }\end{array}$ \\
\hline \multirow[t]{7}{*}{2} & $1-10$ & $\mathrm{HT}$ & $\begin{array}{l}\text { This is the height of the stack top above } \\
\text { local ground level, } \mathrm{m} \text {. }\end{array}$ \\
\hline & $11-20$ & RA & $\begin{array}{l}\mathrm{RA} \text { is the temperature range, } i . e ., \text { the } \\
\text { temperature of the circulating water enter- } \\
\text { ing the tower minus the temperature of that } \\
\text { leaving. Temperatures are in }{ }^{\circ} \mathrm{F} \text {. }\end{array}$ \\
\hline & $21-30$ & APP & $\begin{array}{l}\text { This is the ratio of the circulating-water } \\
\text { mass flow rate to the air mass flow rate } \\
\text { through the tower. }\end{array}$ \\
\hline & $31-40$ & $\mathrm{R} \emptyset$ & Inside radius of the top of the tower, $\mathrm{m}$. \\
\hline & $41-50$ & $w \emptyset$ & Exit velocity of the stack gases, $\mathrm{m} / \mathrm{sec}$. \\
\hline & $51-60$ & HEATT & $\begin{array}{l}\text { Total heat rejected, Mcal/sec. If there } \\
\text { are several towers in the cluster, use the } \\
\text { sum for all. }\end{array}$ \\
\hline & $61-70$ & LAT & $\begin{array}{l}\text { Latitude of the tower, in degrees } N \text {. If the } \\
\text { latitude is south, enter the latitude as a } \\
\text { negative number. Note that the entry must } \\
\text { be in decimal degrees, not degrees, minutes, } \\
\text { and seconds. }\end{array}$ \\
\hline
\end{tabular}


Table 2 (continued)

\begin{tabular}{|c|c|c|c|}
\hline $\begin{array}{l}\text { Card } \\
\text { No. }\end{array}$ & Columns & $\begin{array}{l}\text { FORTRAN } \\
\text { name }\end{array}$ & Description \\
\hline 2 & $71-80$ & $L \emptyset N G$ & $\begin{array}{l}\text { Longitude of the tower, in degrees } W \text {. If the } \\
\text { longitude is east, enter the longitude as a } \\
\text { negative number. Use decimal degrees. }\end{array}$ \\
\hline \multirow[t]{8}{*}{3} & $1-10$ & ELEV & $\begin{array}{l}\text { Elevation of tower base above mean sea level, } \\
\text { ft. }\end{array}$ \\
\hline & $11-20$ & FRACDR & $\begin{array}{l}\text { Mass fraction of circulating water carried out } \\
\text { of the tower as drift. }\end{array}$ \\
\hline & $21-30$ & DRCLAS & $\begin{array}{l}\text { Number of size classes of drift particles. } \\
\text { The number of entries on cards } 6 \text { and } 7 \text { should } \\
\text { agree with this number. Failure to agree can } \\
\text { lead either to a terminated computer run or } \\
\text { erroneous results. The maximum value for DRCLAS } \\
\text { is currently } 8 \text {. }\end{array}$ \\
\hline & $31-40$ & $\mathrm{C} \emptyset \mathrm{NC}$ & $\begin{array}{l}\text { Concentration of dissolved solids in the cool- } \\
\text { ing tower water, mass fraction. }\end{array}$ \\
\hline & $41-50$ & YRS & $\begin{array}{l}\text { Number of years for which data are to be } \\
\text { analyzed. }\end{array}$ \\
\hline & $51-60$ & $Z \emptyset \mathrm{NE}$ & $\begin{array}{l}\text { Time zone of cooling tower. Eastern Standard } \\
\text { Time Zone is 5; Central Standard is } 6 \text {, etc. } \\
\text { Z } \emptyset \mathrm{NE} \text { is used by the program to determine which } \\
\text { hours should have data on the tapes for the } \\
\text { years after } 1964 \text {. }\end{array}$ \\
\hline & $61-70$ & START & $\begin{array}{l}\text { Last two digits of the first year to be } \\
\text { analyzed. This number is used in conjunction } \\
\text { with YRS to determine the period to be } \\
\text { analyzed. For example, to analyze the years } \\
1959 \text { through } 1967 \text {, enter } 9 \text { in columns } 41-42 \\
\text { and } 59 \text { in columns } 61-63 \text {. }\end{array}$ \\
\hline & $71-80$ & WBD & $\begin{array}{l}\text { This quantity, the wet bulb depression, in }{ }^{\circ} \mathrm{F} \text {, } \\
\text { may be used to resolve the ambiguous cases where } \\
\text { wet and dry bulb temperatures have been reported } \\
\text { equal on the weather tape but natural fog was } \\
\text { not reported. If a greater-than-zero value is } \\
\text { entered for WBD, it is used for calculating } \\
\text { the saturation deficit in the ambiguous cases. }\end{array}$ \\
\hline 4 & $1-80$ & $\mathrm{C} \emptyset \mathrm{NCM}$ & $\begin{array}{l}\text { Monthly concentration array, January through } \\
\text { August. These eight months are entered in } \\
\text { the eight } 10 \text {-digit fields on the card, columns } \\
1-10 \text {, } 11-20 \text {, etc. }\end{array}$ \\
\hline
\end{tabular}


Table 2 (continued)

\begin{tabular}{|c|c|c|c|}
\hline $\begin{array}{c}\text { Card } \\
\text { No. }\end{array}$ & Columns & $\begin{array}{l}\text { FORTRAN } \\
\text { name }\end{array}$ & Description \\
\hline 5 & $1-40$ & $\mathrm{C} \emptyset \mathrm{NCM}$ & $\begin{array}{l}\text { Month1y concentration array, September through } \\
\text { December. The last four months are entered in } \\
\text { the first four 10-digit fields. }\end{array}$ \\
\hline 6 & $1-80$ & DIAM & $\begin{array}{l}\text { Enter the characteristic diameters, } \mu \mathrm{m} \text {, of the } \\
\text { drift particles in each of the DRCLAS size } \\
\text { classes. As before, the numbers are entered } \\
\text { in up to eight 10-digit fields, columns } 1-10 \text {, } \\
11-20 \text {, etc. }\end{array}$ \\
\hline 7 & $1-80$ & DRFRAC & $\begin{array}{l}\text { Weight fractions for the drift particles in } \\
\text { each of the DRCLAS classes. Enter in up to } \\
\text { eight 10-digit fields, as before. }\end{array}$ \\
\hline \multirow[t]{8}{*}{8} & $1-10$ & DNUM & $\begin{array}{l}\text { Number of drift contours to be plotted. The } \\
\text { actual values used are selected by the program. } \\
\text { The program starts with the highest value that } \\
\text { can be plotted, and succeeding contour values } \\
\text { are decreased by a factor of } 2 \text { until DNUM con- } \\
\text { tours have been plotted. }\end{array}$ \\
\hline & $11-20$ & $\mathrm{~T} \emptyset \mathrm{TTWR}$ & Total number of cooling towers. \\
\hline & $21-30$ & TØWERS & Number of cooling towers in a single cluster. \\
\hline & $31-40$ & CLUSIZ & $\begin{array}{l}\text { Maximum dimension of a single cluster, m. This } \\
\text { will ordinarily be the diameter of the smallest } \\
\text { circle enclosing all the towers of a cluster. }\end{array}$ \\
\hline & $41-50$ & FRAC $\emptyset \mathrm{N}$ & $\begin{array}{l}\text { Fraction of the plume vapor that condenses. } \\
\text { The fraction determines the added buoyancy } \\
\text { resulting from release of latent heat in the } \\
\text { plume. A value of zero should yield conserva- } \\
\text { tive fogging and drift estimates (conservative } \\
\text { in the sense of overestimation). }\end{array}$ \\
\hline & $51-60$ & XNDIS & $\begin{array}{l}\text { Number of distances at which calculations of } \\
\text { fog, drift, etc., will be made. The maximum } \\
\text { number currently is } 19 \text {. }\end{array}$ \\
\hline & $61-70$ & HSALT & $\begin{array}{l}\text { The height above ground, } \mathrm{m} \text {, at which the air- } \\
\text { borne salt concentration is to be calculated. }\end{array}$ \\
\hline & $71-80$ & SAMP & $\begin{array}{l}\text { This parameter is used to trigger a calcula- } \\
\text { tion of a sample plume rise and drift. If } \\
\text { SAMP }=0 \text {. (or, equivalently, is left blank), } \\
\text { the sample calculation is bypassed. If SAMP }= \\
1 ., \text { the sample calculation is performed, but } \\
\text { the computer run is terminated immediately } \\
\text { thereafter. SAMP = } 2 \text {. (or greater) produces } \\
\text { the sample calculation and continues the } \\
\text { computer run. }\end{array}$ \\
\hline
\end{tabular}


Table 2 (continued)

\begin{tabular}{|c|c|c|c|}
\hline $\begin{array}{l}\text { Card } \\
\text { No. }\end{array}$ & Columns & $\begin{array}{l}\text { FORTRAN } \\
\text { name }\end{array}$ & Description \\
\hline 9 & $1-80$ & $\mathrm{X} M I$ & $\begin{array}{l}\text { Distance array, miles. These are the distances } \\
\text { downwind from the towers at which calculations } \\
\text { for fog, drift, etc., will be made. This card } \\
\text { contains the first eight distances in the } \\
\text { standard 10-digit fields. }\end{array}$ \\
\hline 10 & $1-80$ & $\mathrm{XMI}$ & $\begin{array}{l}\text { This card continues the distance array, assum- } \\
\text { ing more than elght values are used. If XNDIS } \\
\text { is } \leq 8 \text {, leave this card blank. }\end{array}$ \\
\hline 11 & $1-30$ & $\mathrm{XMI}$ & $\begin{array}{l}\text { This card completes the distance array. If } \\
\text { XNDIS is } \leq 16 \text {, leave this card blank. }\end{array}$ \\
\hline \multirow[t]{3}{*}{12} & $1-10$ & XNUM & $\begin{array}{l}\text { Number of fog, ice, and salt contours to be } \\
\text { plotted. Values on the contours are selected } \\
\text { by the program, as explained for DNUM (card } 8 \text { ). }\end{array}$ \\
\hline & $11-20$ & VPLT & $\begin{array}{l}\text { Enter any positive number to get plots in the } \\
16 \text { compass directions in vertical planes. } \\
\text { Contour values are selected as previously } \\
\text { explained. }\end{array}$ \\
\hline & $21-30$ & ANNUM & $\begin{array}{l}\text { Enter any positive number to get annual fog, } \\
\text { drift, ice, and salt tables. If ANNUM is } \\
\text { entered as zero (or left blank), no annual } \\
\text { tables but only the overall averages will be } \\
\text { printed. This provides for considerable sav- } \\
\text { ing in lines printed. }\end{array}$ \\
\hline
\end{tabular}


ORNL OWG $76-13829$

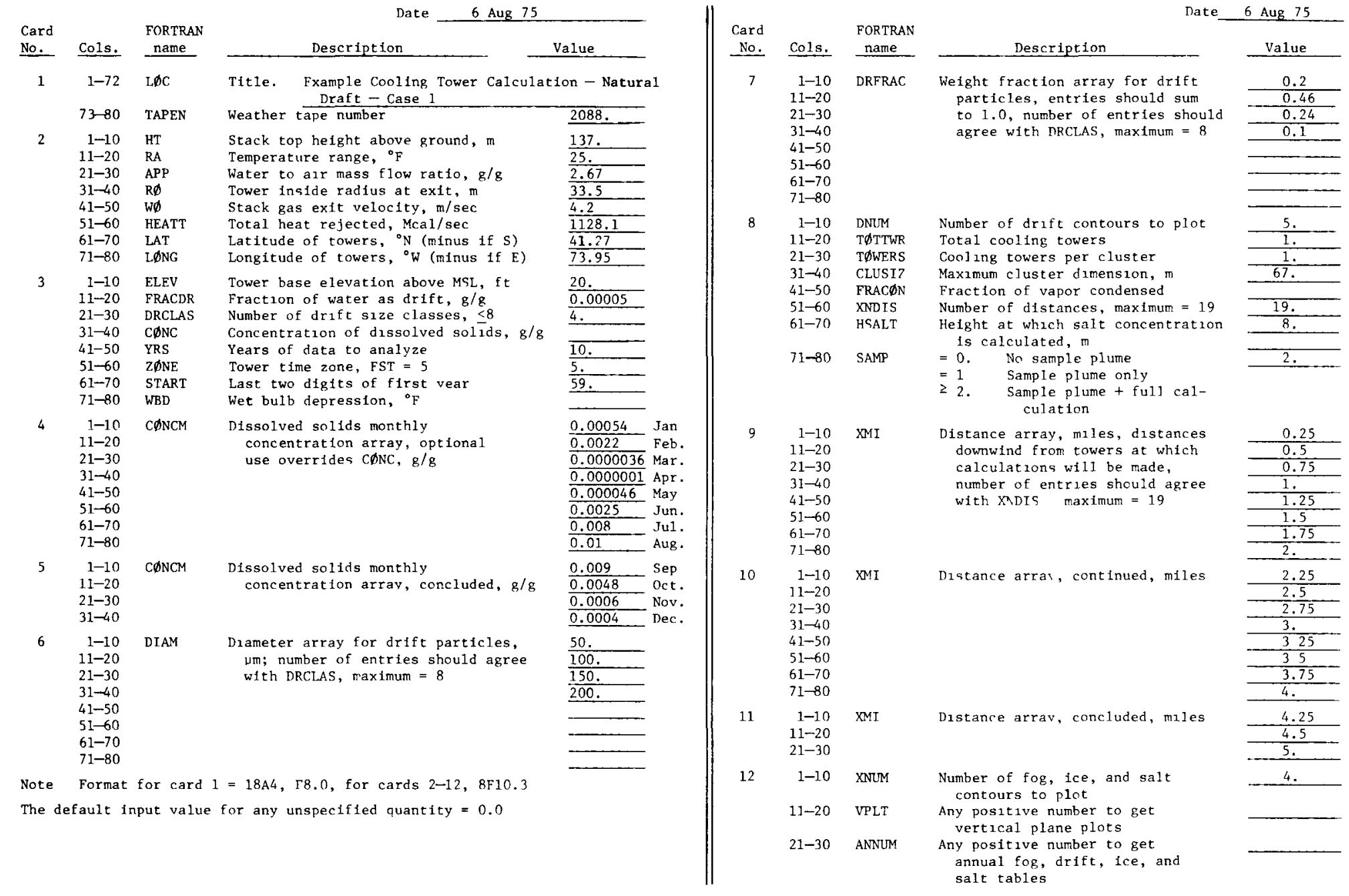

Fig. 6. Suggested input form for ORFAD with sample values inserted. 
ORNL-OWG 76-12807

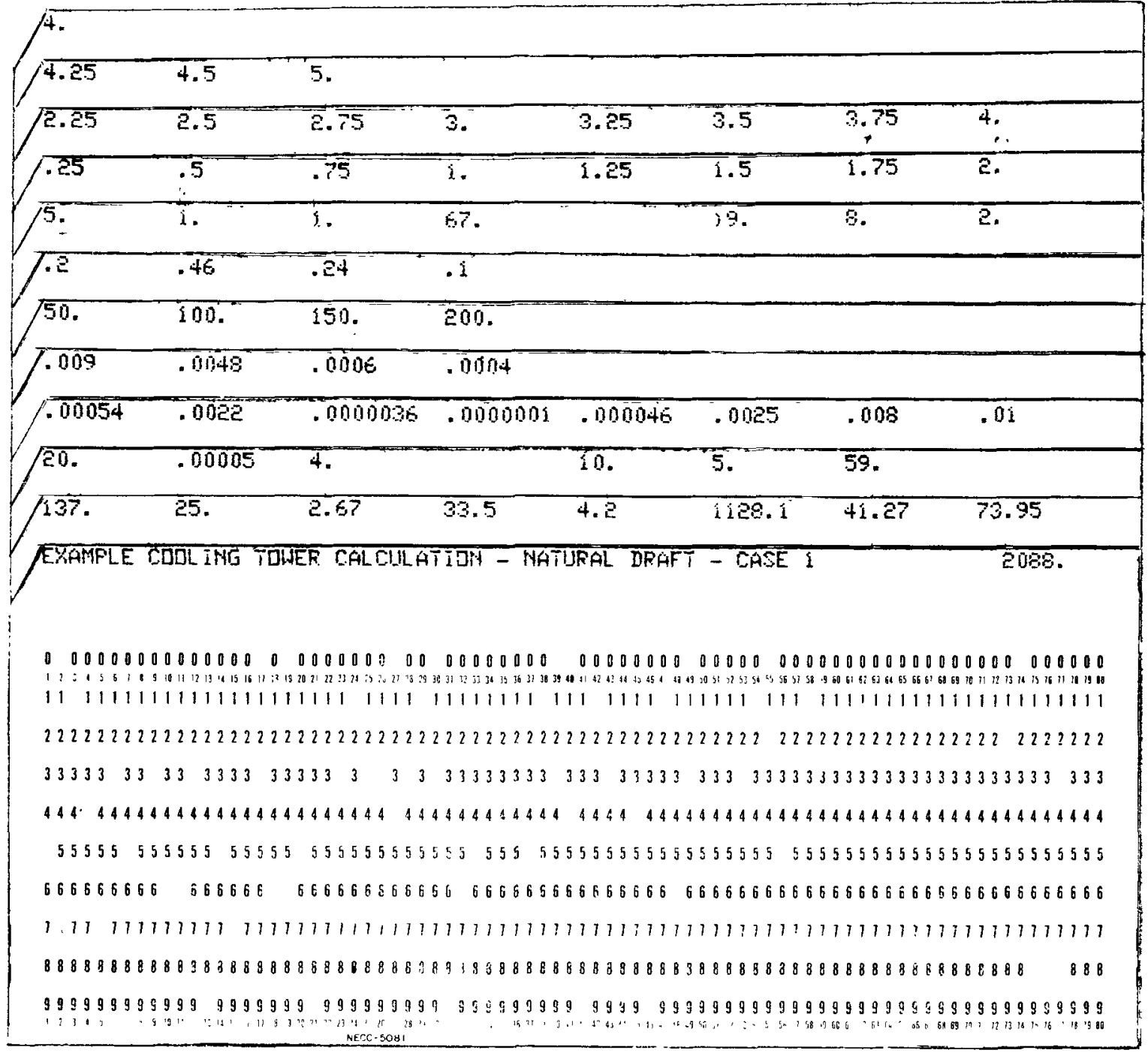

Fig. 7. ORFAD input deck as punched from the data of Fig. 6.

columns $31-40$ of card 4 could have been punched as $1.0 \mathrm{E}-7$. However, if the exponent ended in a column other than 40, the number would be misinterpreted by the program. If the 7 were to be punched in, say, column 38 , the blanks in columns 39 and 40 would cause the number to be read as 1.0E-700, which is not what was intended.

The first card of each set is read with an 18A4, F8.0 format; as a result, the title must not extend past column 72 . Information other than numeric (or blanks) in columns 73-80 will cause immediate termination of the computer run. 


\subsubsection{Options}

Some of the input items in ORFAD are optional in the sense that the program will function with or without them. However, the output, and, to some extent, the calculation will depend on whether the options are exercised.

In general, any unspecified input number will be taken as zero. This means that if an option requires a number in order to be activated, leaving the quantity blank (or, equivalently, inserting zero) omits the option. The general principle is that optional items must be requested.

\subsubsection{Title and tape number}

Both items on this card are optional. A title need not be given, although it is certainly convenient for output identification. The tape number similarly may be omitted with no untoward effects. If the tape number is omitted, no checking is done, and a message to that effect is printed in the case output. If a tape number is given for a tape on which the checking subroutine has no data, a warning message is also printed In the output.

\subsubsection{Dissolved solids concentration}

The dissolved solids concentration may be specified as a single quantity to be used for the entire year or as a set of monthly values. The program determines which to use by examining the $\varnothing \emptyset \mathrm{NCM}$ array. If the array is empty, C $\emptyset \mathrm{NC}$ (the yearly concentration) is used; otherwise, C $\emptyset \mathrm{NCM}$ is used. Hence, one or the other must be specified. If the array is nonzero, $\varnothing \emptyset \mathrm{NC}$ is irrelevant and will be ignored (actually, ORFAD, for various reasons, will take it to be 1.0 ).

\subsubsection{Wet bulb depression}

In the normal course of events, if the wet and dry bulb temperatures are reported as equal (on the weather tape) and fog has not been reported, ORFAD will calculate a period of additional fog induced by the tower irrespective of the amount of added vapor. Unfortunately, the situation is ambiguous; the weather tape temperatures are reported to whole 
degrees only, so that the real difference could be up to $1^{\circ}$ when the two temperatures are reported equal. The wet bulb depression (WBD) permits the user to resolve the ambiguity, if desired, by stating what difference to use in place of zero. WBD is then used in setting the saturation deficit utilized in determining whether fog occurs, but only when wet and dry bulb temperatures have been reported equal. Lacking anything better, 0.5 could be used for WBD on the basis that this is the mean of the zero minimum and the 1.0 maximum.

\subsubsection{Contour plots}

DNUM and XNUM specify the number of contours to be plotted in the horizontal plane. Specifying any nonzero value for VPL $\emptyset \mathrm{T}$ generates a set of vertical plane plots, one for each of the 16 compass directions used. About 135 cards are punched per case if horizontal plane plots only are called for, and roughly five times that many are punched if vertical plane plots are also requested. Since the default limit on punched cards is 1000 , this option can cause trouble unless the user is watchful.

\subsubsection{Condensed vapor fraction}

FRAC $\emptyset N$, the fraction of vapor condensed, affects the plume rise through release of latent heat. Ordinarily, this quantity will be left blank. However, if the user has reason to believe that condensation is occurring or if he just wants to determine the effect of the condensation, the parameter may be set to some positive fraction.

\subsubsection{Elevation for salt concentration}

The parameter HSALT determines the height above ground at which concentration of airborne salt will be computed. Ground level is obtained if the quantity is left blank.

\subsubsection{Sample plume and drift}

Setting SAMP to some nonzero value directs the computer to calculate a sample plume and drift for program-generated combinations of distance, wind speed, stability class, relative humidity, etc. If only the sample 
calculation is wanted, use 1.0 for SAMP; this will terminate the calculation immediately after the sample output. Setting SAMP $=2.0$ or more will yield the sample values and continue the calculation.

\subsubsection{Annual tables}

If ANNUM is specified, annual tables of fog, ice, drift, and salt will be produced. For a calculation covering a 10-year period, this results in the generation of 89 pages of output; leaving ANNUM blank reduces the output to about 9 pages. The annual averages over the entire period are produced in any event, so that, unless results for individual years are required, leaving ANNUM blank is strongly recommended.

\subsection{Job Submission}

Job submission is treated here only to the extent necessary for the running of ORFAD jobs at ORNL. The job deck makeup and job control language will be covered only in that detail felt necessary for a reasonable chance of successful operation. Some variations are provided for the benefit of the experimentally minded.

\subsubsection{Overall job deck makeup}

The current version of ORFAD is stored on the on-1ine disk at ORNL, and the sample job deck shown in Table 3 is set up to use that version. Note that hexadecimal decks may be incorporated to supplant any of the routines on disk. Table 4 is a more general job deck, in which both FORTRAN and hexadecimal-level card decks may be used to replace any disk versions of programs. Note the differences between Tables 3 and 4; in particular, note that the cataloged procedure FøRTHLG is called for in Table 3, whereas FØRTHCLG is required in Table 4.

\subsubsection{Job contro1 language}

The job control language (JCL) portions required for using ORFAD are set forth in Tables 3 and 4. This section discusses a few of the more commonly experienced stumbling blocks encountered in their use. Any greater treatment of the rather esoteric subject of JCL would be neither appropriate nor feasible here. 
Table 3. Sample job deck with ORFAD on the on-line disk at ORNL ${ }^{a}$

//MELF JøB (98765), 'Y-12 9204-1 LA VERNE'

$/ / *$ CLASS CPU9 $1=20 \mathrm{M}$, SPECIAL $=$ TAPE, I $\emptyset=15$

// EXEC F $\emptyset$ RTHLG, PARM. $G \emptyset==^{\prime} \mathrm{EU}=-1, \mathrm{DUMP}=\mathrm{H}^{\prime}, \mathrm{REGI} \emptyset \mathrm{N} . \mathrm{G} \emptyset=250 \mathrm{~K}$

//LKED.SYSLIB DD

$/ / \quad \mathrm{DD}$

$/ / \quad \mathrm{DD}$

// DD DSNAME=LABLIB, DISP=SHR

// DD DSNAME=A8.G1,P31394.C10207. CHANDLER . GRAPHICS,

$/ / \mathrm{V} \varnothing \mathrm{L}=\mathrm{REF}=\mathrm{ZZZZZZ}, \mathrm{DISP}=\mathrm{SHR}$

//LKED.PL $\emptyset \mathrm{TSUBS}$ DD DISP=(SHR, PASS), DSN=JGSPL $\emptyset \mathrm{TH}$

//LKED.FT33F001 DD DISP=SHR, UNIT $=2314, \mathrm{~V} \emptyset \mathrm{L}=\mathrm{SER}=\mathrm{ZZZZZZ,}$

$/ /$ DSNAME $=\varnothing$ NLINEA. MELHF $235 . \emptyset$ RFAD

//LKED.SYSIN DD *

(Any hexadecimal decks go here. Use is optional.)

INCLUDE PL $\emptyset$ TSUBS

INCLUDE FT33F001

$/ *$

$/ / G \emptyset . F T 49 F 001$ DD UNIT $=I N 2 \emptyset U 2, \mathrm{DCB}=(\mathrm{RECFM}=\mathrm{VS}, \mathrm{LRECL}=3204, \mathrm{BLKSIZE}=3208)$, $/ / \mathrm{DISP}=(\mathrm{NEW}, \mathrm{KEEP}), \mathrm{SPACE}=(3208,(30,10), \mathrm{RLSE}), \mathrm{DSN}=\mathrm{PL} \emptyset \mathrm{T} 00 . \mathrm{MELF}$

$/ / G \emptyset$.FT51F001 DD SYS $\emptyset \mathrm{UT}=\mathrm{A}$

$/ / G \emptyset . F T 07 F 001$ DD SYS $\emptyset \mathrm{UT}=\mathrm{B}, \mathrm{DCB}=(\mathrm{RECFM}=\mathrm{FB}, \mathrm{LRECL}=80, \mathrm{BLKSIZE}=3520)$

$/ / \mathrm{G} \emptyset . \mathrm{FT} 08 \mathrm{F001}$ DD UNIT=TAPE9, $\mathrm{\emptyset \textrm {L }}=\mathrm{SER}=8, \mathrm{LABEL}=(1, \mathrm{NL}), \mathrm{DISP}=\varnothing \mathrm{LD}$,

$/ / \mathrm{DCB}=(\mathrm{RECFM}=\mathrm{F}, \mathrm{BLKSIZE}=495)$

$/ /$ GØ.FT05F001 DD *

(Input decks go here)

$/ *$

$1 /$

${ }^{\mathrm{a}}$ Caution: If hexadecimal decks are used, remember that they will supersede any routines with the same names occurring on the disk.

\section{4 .2 .1 Jobnames}

The computer operating system at ORNL views dimly any attempt to run more than one job with a given jobname at one time. At best, such an attempt delays execution of the second job until the first one has left the system; at worst, cancellation could result. The solution is to use a series of jobnames when multiple runs are anticipated, say, MEL1, MEL2, 
Table 4. Sample job deck using FORTRAN decks with ORFAD on the on-line disk at ORNL ${ }^{\mathrm{a}}$

//MEL1 JøB (98765), 'Y-12 9204-1 LA VERNE'

$/ / *$ CLASS CPU91=20M, SPECTAL=TAPE, I $\emptyset=15$

// EXEC F $\emptyset$ RTHCLG, PARM. $G \emptyset='$ EU $=-1, D U M P=H^{\prime}$, REGION. $G \emptyset=250 \mathrm{~K}$

//FØRT.SYSIN DD *

(FORTRAN decks go here)

$1 *$

//LKED.SYSLIB DD

$1 / \quad \mathrm{DD}$

$1 / \quad \mathrm{DD}$

// DD DSNAME=LABLIB, DISP $=$ SHR

/ $/$ DD DSNAME=A8.G1.P31394.C10207. CHANDLER. GRAPHICS,

// $\mathrm{V} \varnothing \mathrm{L}=\mathrm{REF}=\mathrm{ZZZZZZ}, \mathrm{DISP}=\mathrm{SHR}$

//LKED. PL $\emptyset$ TSUBS DD DISP=(SHR, PASS), DSN=JGSPL $\emptyset \mathrm{TH}$

//LKED . FT33F001 DD DISP=SHR, UNIT $=2314, \mathrm{~V} \emptyset \mathrm{L}=\mathrm{SER}=\mathrm{ZZZZZZ,}$

$/ /$ DSNAME $=\varnothing$ NLINEA.MELHF $235 . \emptyset$ RFAD

//LKED.SYSIN DD *

(Hexadecimal decks, if used, go here)

INCLUDE PL $\varnothing$ TSUBS

INCLUDE FT33F001

/*

//GØ.FT49F001 DD UNIT=IN2 ØU2, DCB=(RECFM=VS, LRECL=3204, BLKSIZE=3208),

$/ / \mathrm{DISP}=(\mathrm{NEW}, \mathrm{KEEP}), \operatorname{SPACE}=(3208,(30,10), \mathrm{RLSE}), \mathrm{DSN}=\mathrm{PL} \emptyset \mathrm{T} 00 . \mathrm{MEL} 1$

$/ /$ GØ.FT51F001 DD SYS $\emptyset \mathrm{UT}=\mathrm{A}$

$/ / G \emptyset . F T 07 F 001$ DD SYS $\emptyset \mathrm{UT}=\mathrm{B}, \mathrm{DCB}=(\mathrm{RECFM}=\mathrm{FB}, \mathrm{LRECL}=80, \mathrm{BLKSIZE}=3520)$

$/ / \mathrm{G} \emptyset$. FT08F001 DD UNIT=TAPE9, $\mathrm{V} \emptyset \mathrm{L}=\mathrm{SER}=8, \mathrm{LABEL}=(1, \mathrm{NL}), \mathrm{DISP}=\emptyset \mathrm{LD}$,

// $\mathrm{DCB}=(\mathrm{RECFM}=\mathrm{F}, \mathrm{BLKSIZE}=495)$

$/ / G \emptyset$. FT05F001 DD *

(Input decks go here)

$/ *$

$1 /$

a Caution: If hexadecimal decks are used, remember that they will supersede any routines of the same names occurring on the disk. Similarly, FORTRAN decks will take precedence over both hexadecimal decks and routines on the disk. 
etc., and never reuse any jobname unti] that particular job has been returned.

\subsubsection{Plot data set names}

Similar considerations apply to the plot data set name on the

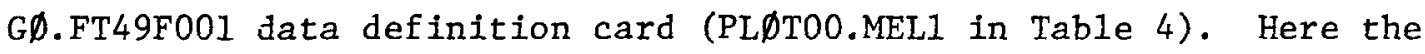
probable result is operator cancellation of the run because the plot data set will be reported as "unavailable." One simple solution is (1) to follow the recommendation in the immediately preceding paragraph and (2) to make the plot data set qualifier (in the example, MEL1) and the jobname equal.

\subsubsection{The CLASS card}

The $/ / *$ CLASS card is essential for running ORFAD at ORNL. If the CLASS card is absent, the system will assign parameters appropriate to a class $B$ job, but since ORFAD is inherently a class F job, the job will fail.

\subsection{Execution time}

Execution time is specified in the CPU91 parameter of the CLASS card. Running time for ORFAD is 15 to $20 \mathrm{~min}$; 15 may be marginal and 20 should be adequate for one case. For multiple cases, allow 20 min each to be safe, that is, set CPU91=40M for two cases, etc. In most cases, you will use less time.

\subsection{The "SPECIAL" parameter}

The SPECIAL=TAPE entry must be present. Leaving it out will cause cancellation of the job.

\subsection{Output specifications}

As mentioned previously, output will depend on the options exercised. Reasonable "guesstimates" seem to be about 3200 lines, 600 to 700 cards, and 15,000 input-output (I $\emptyset)$ operations per case. System assigned (default) values at ORNL are 10,000 lines, 1000 cards, and 10,000 I $\emptyset$. 
Thus, a CLASS card for four cases with most options in use might read: $1 / *$ CLASS CPU9I=80M, LINES $=15, \mathrm{CARDS}=30, I \emptyset=60, \mathrm{SPECIAL}=\mathrm{TAPE}$. Note that lines and $I \emptyset$ are given in thousands, cards in hundreds.

\subsubsection{Overriding the disk programs}

It is inevitable that, sooner or later, some ORFAD user will find that he prefers a different way of performing some calculation in the program. Figure 5 and Table 1 have been presented previously in order to assist in making such changes. For further assistance, Appendix $E$ contains a complete listing of ORFAD, both the main program and all subprograms except for system-supplied routines.

The disk programs may be overridden by using either hexadecimal decks with the job deck of Table 3 or a combination of FORTRAN and hexadecimal decks with the job deck of Table 4.

\subsubsection{Program checkout using the data cell}

As an aid in checking out program modifications, two sets of weather data, each for one year, have been placed on a data cell at ORNL. Use of the data cell removes the necessity for mounting a tape and leads to faster turnaround of debugging runs.

Necessary changes in the JCL for data cell use are as follows. The CLASS card reduces to $/ / *$ CLASS CPU91 $=5 \mathrm{M}$ (note that SPECIAL=TAPE has been deleted). Other items on the card will generally be within the default ranges and need not be specified. The FT08F001 card (including its continuation) must be replaced, as shown in Table 5 .

\subsection{Program Output}

The output from ORFAD consists of both tabular and graphical presentations of additional hours of fog and ice, drift deposition, and salt concentration resulting from cooling tower operation. A sample set of output may be found in Appendix $\mathrm{F}$. 
Table 5. Job control language changes required for data cell use at ORNL ${ }^{a}$

(A) Data period prior to 1965; data at 1 -hr intervals

//* HøUST $\emptyset \mathrm{N}$ TX. WEATHER DATA $1 / 59$ - 12/59 ( NE-H $\emptyset \mathrm{UR}$ INTERVALS)

$/ / \mathrm{G} \emptyset . \mathrm{FT} 08 \mathrm{~F} 001$ DD UNIT=2321, VøL=SER=DCZZZZ,

$/ / \mathrm{DSN}=\emptyset \mathrm{NLINEA} . \mathrm{ECLDE} 818 . \mathrm{HOUSTON}, \mathrm{DISP}=\mathrm{SHR}$

(B) Data period in 1965 or later; data at 3-hr intervals //* NASHVILLE, TN. WEATHER DATA 1/65 - 12/65 (THREE-HøUR INTERVALS)

$/ / G \emptyset . F T 08 F 001$ DD UNIT=2321, VøL=SER=DCZZZZ,

$/ / \mathrm{DSN}=\emptyset \mathrm{NLINEA} . \mathrm{ECLDE} 818 . \mathrm{NASHVLE}, \mathrm{DISP}=\mathrm{SHR}$

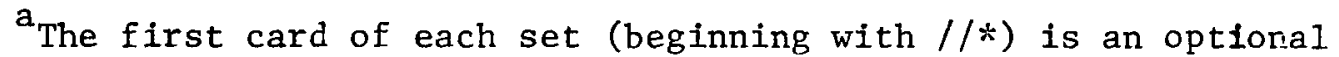
comment card and may be omitted.

\subsubsection{Tables}

Four types of tables are produced: one for additional fog, one for additional ice fog, one for drift, and one for salt concentration at a selected height.

\subsubsection{Fog and ice}

For fog and ice, the program prints out the annual number of additional hours of fog (not counting naturally occurring fogs) and ice that would be experienced as a result of full-time operation of the cooling tower. These values are printed for specified discrete distances from the tower for each of the 16 wind directions (points) used. The occurrences of "calms" are distributed among the 16 points in proportion to the relative frequencies of winds in those directions. 


\subsubsection{Drift}

For drift, the program prints, for the same locations and hours as used for fogs, the annual rate of deposition per unit area of the dissolved solids from the drift in grams per year per square metre of horizontal surface. The amount of drift deposited in liquid form is neither calculated nor printed.

\subsubsection{Salt concentration}

The salt concentration is printed as grams per cubic metre at a preselected altitude above ground level. The arrangement and arguments for the tables are similar to those for drift.

\subsubsection{Annual tables}

If annual tables are requested, the above tables are printed for each of the years in the specified period. In any event, the annual averages for the entire period are printed as the last set of tables.

\section{5 .2 Plots}

Optionally, the printed tables may be supplemented by contour maps plotted in either the horizontal or the vertical plane or in both.

\subsubsection{Horizontal plane}

Contour maps for each of the four quantities in the printed tables may be plotted in the horizontal plane for the overall period averages. Points on the contour maps are located as on an ordinary geographical map, and the numerical value on the contour line indicates the amount of fog, drift, etc., occurring thereon. Since the directions are true directions, when the wind is, say, from the north, the drift will fall south of the tower and will be plotted there.

\subsubsection{Vertical plane}

Optionally, contour maps of hours of fog may also be plotted in the vertical plane for each of the 16 compass directions from the tower. 
8. REFERENCES

1. J. V. Wilson, ORFAD, A Computer Program to Estimate Fog and Drift from Wet Cooling Towers, ORNL/TM-4568 (January 1975).

2. C. L. Hosler, J. Pena, and R. Pena, Determination of Salt Deposition Rates from Drift from Evaporative Cooling Towers, Department of Meteorology, Pennsylvania State University, University Park, Pa. (May 1972).

3. Tape Reference Manual, Airways Surface Observations, TDF 14, U.S. Weather Bureau (now National Oceanographic and Atmospheric Administration), undated.

4. Weather data tapes from NOAA, National Weather Records Center, Federal Office Building, Asheville, N.C. 28801.

5. S. R. Hanna, Meteorological Effects of Cooling Tower P1umes, NOAA-ATDL Report, ATDL Contribution No. 48 (January 1971).

6. G. A. Briggs, Jr., Plume Rise, AEC Critical Review Series, TID-25075 (November 1969).

7. G. A. Briggs, Jr., Plume Rise from Multiple Sources, NOAA-ATDL Report, ATDL Contribution No. 91 (March 1974).

8. G. A. Briggs, Jr., Diffusion Estimation for Small Emissions, NOAAATDL Draft Report, ATDL Contribution File No. 79 (May 1973).

9. S. Letestu (ed.), International Meteorological Tables, WMO-No. 188.TP. 94, Secretariat of the World Meteorological Organization, Geneva, Switzerland, 1966. 


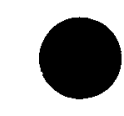

d

•

- 
Appendix A

NOMENCLATURE

\begin{tabular}{|c|c|c|}
\hline a & Acceleration & $\mathrm{m} / \mathrm{sec}^{2}$ \\
\hline$a_{\mathbf{s}}$ & Solar altitude & $\operatorname{deg}$ \\
\hline A & Sector area & $\mathrm{m}^{2}$ \\
\hline B & Diffusion coefficient parameter & \\
\hline c & Concentration of salt in circulating water & $g / g$ \\
\hline$c_{s}$ & Salt concentration in saturated droplet & $g / g$ \\
\hline $\mathrm{C}$ & Cumulative distribution function for droplets & \\
\hline $\mathrm{C}_{\mathrm{s}}$ & Salt concentration in air & $\mathrm{g} / \mathrm{m}^{3}$ \\
\hline$\Delta \mathrm{C}$ & Incremental droplet deposition & \\
\hline $\mathrm{C}_{\mathrm{p}}$ & Specific heat of air & $\mathrm{cal} / \mathrm{g} \cdot{ }^{\circ} \mathrm{C}$ \\
\hline $\mathrm{C}_{\mathrm{pW}}$ & Specific heat of water & $\mathrm{cal} / \mathrm{g} \cdot{ }^{\circ} \mathrm{C}$ \\
\hline$d_{s}$ & Saturation deficit & $\mathrm{g} / \mathrm{m}^{3}$ \\
\hline $\mathrm{D}$ & droplet diameter & $\mu \mathrm{m}$ \\
\hline $\mathrm{D}_{\mathrm{d}}$ & Diameter of dry particle & $\mu \mathrm{m}$ \\
\hline $\mathrm{D}_{\mathbf{s}}$ & Diameter of saturated solution droplet & $\mu \mathrm{m}$ \\
\hline $\mathrm{f}$ & Fraction of condensation in plume & \\
\hline $\mathrm{F}$ & Flux buoyancy parameter & $\mathrm{m}^{4} / \mathrm{sec}^{3}$ \\
\hline $\mathrm{F}_{\mathrm{W}}$ & Fraction of circulating water as drift & \\
\hline$g$ & Acceleration of gravity & $\mathrm{m} / \mathrm{sec}^{2}$ \\
\hline $\mathrm{h}$ & Enthalpy of air at tower exit & $\mathrm{Btu} / \mathrm{Ib}$ \\
\hline$h_{f g}$ & Latent heat of water & $\mathrm{cal} / \mathrm{g}$ \\
\hline $\mathrm{H}$ & Plume height & $\mathrm{m}$ \\
\hline$\Delta \mathrm{H}_{1}$ & Plume rise for one tower & $\mathrm{m}$ \\
\hline$\Delta \mathrm{H}_{\mathrm{N}}$ & Plume rise for $\mathrm{N}$ towers in a cluster & $\mathrm{m}$ \\
\hline $\mathrm{H}_{\mathrm{e}}$ & Evaporation distance & $\mathrm{m}$ \\
\hline $\mathrm{L}$ & Maximum dimension of a tower cluster & $\mathrm{m}$ \\
\hline $\mathbf{P}_{\mathrm{S}}$ & $\begin{array}{l}\text { Saturation vapor pressure at dry bulb } \\
\text { temperature }\end{array}$ & in. $\mathrm{Hg}$ \\
\hline $\mathrm{p}_{\mathrm{v}}$ & Vapor pressure at ambient temperature & in. $\mathrm{Hg}$ \\
\hline$q$ & Tower heat rejection & $\mathrm{cal} / \mathrm{sec}$ \\
\hline$q_{e o}$ & $\begin{array}{l}\text { Environment mixing ratio (water vapor to } \\
\text { dry air) }\end{array}$ & $g / g$ \\
\hline
\end{tabular}




\begin{tabular}{|c|c|c|}
\hline$q_{p o}$ & $\begin{array}{l}\text { Initial plume mixing ratio (water vapor to } \\
\text { dry air) }\end{array}$ & $g / g$ \\
\hline Q & Water vapor mass velocity at tower exit & $\mathrm{g} / \mathrm{sec}$ \\
\hline$Q_{1}$ & Total salt from tower & $\mathrm{g} / \mathrm{sec}$ \\
\hline $\mathrm{r}$ & Relative humidity & \\
\hline $\mathrm{R}_{\mathrm{O}}$ & Tower inside radius at exit & $\mathrm{m}$ \\
\hline$R_{y}$ & Lateral plume radius & $\mathrm{m}$ \\
\hline $\mathrm{R}_{z}$ & Vertical plume radius & $\mathrm{m}$ \\
\hline s & Stability parameter & $\sec ^{-2}$ \\
\hline $\mathrm{S}$ & Briggs parameter for multiple plume rise & \\
\hline$t$ & Evaporating droplet fall time & $\mathrm{sec}$ \\
\hline$\Delta t$ & Circulating-water temperature range & ${ }^{\circ} \mathrm{C}$ \\
\hline$t_{w}$ & Wet bulb temperature for enthalpy $h$ & ${ }^{\circ} \mathrm{F}$ \\
\hline $\mathrm{T}_{\mathrm{a}}$ & Ambient dry bu1b temperature & ${ }^{\circ} \mathbf{R}$ \\
\hline $\mathrm{T}_{\text {eo }}$ & Environment temperature & $\mathrm{K}$ \\
\hline$T_{\text {po }}$ & Plume initial temperature & $\mathrm{K}$ \\
\hline$\partial T_{e o} / \partial z$ & Atmospheric temperature gradient & $\mathrm{K} / \mathrm{m}$ \\
\hline $\mathrm{U}$ & Wind speed & $\mathrm{m} / \mathrm{sec}$ \\
\hline $\mathrm{v}$ & Final velocity of a droplet & $\mathrm{m} / \mathrm{sec}$ \\
\hline$v_{d}$ & Final velocity of a dry particle & $\mathrm{m} / \mathrm{sec}$ \\
\hline$v_{s}$ & $\begin{array}{l}\text { Final velocity of a saturated solution } \\
\text { droplet }\end{array}$ & $\mathrm{m} / \mathrm{sec}$ \\
\hline $\mathrm{V}_{\mathrm{d}}$ & Initial velocity of droplet of diameter $D_{d}$ & $\mathrm{~m} / \mathrm{sec}$ \\
\hline$\overline{\mathrm{V}}_{\mathrm{e}}$ & Average fall velocity during evaporation & $\mathrm{m} / \mathrm{sec}$ \\
\hline$V_{f}$ & Initial velocity of droplet of diameter $D$ & $\mathrm{~m} / \mathrm{sec}$ \\
\hline $\mathrm{V}_{\mathrm{s}}$ & Initial velocity of droplet of diameter $D_{s}$ & $\mathrm{~m} / \mathrm{sec}$ \\
\hline$W_{0}$ & Tower exit velocity & $\mathrm{m} / \mathrm{sec}$ \\
\hline$x^{*}, x_{m e}, x$ & Downwind distance from tower & $\mathrm{m}$ \\
\hline$\Delta \mathrm{X}$ & Width of sector in downwind direction & $\mathrm{m}$ \\
\hline$\rho$ & Density of pure water & $\mathrm{g} / \mathrm{cm}^{3}$ \\
\hline$\rho_{\mathrm{d}}$ & Density of dry particle & $\mathrm{g} / \mathrm{cm}^{3}$ \\
\hline$\rho_{s}$ & Density of saturated solution & $\mathrm{g} / \mathrm{cm}^{3}$ \\
\hline$\rho_{w}$ & Density of initial droplet & $\mathrm{g} / \mathrm{cm}^{3}$ \\
\hline$\sigma_{\mathrm{y}}$ & Plume lateral diffusion coefficient & $\mathrm{m}$ \\
\hline$\sigma_{2}$ & Plume vertical diffusion coefficient & $\mathrm{m}$ \\
\hline
\end{tabular}


$x$

$x_{2}$
Water vapor density at ground level

Salt deposition rate $\mathrm{g} / \mathrm{m}^{3}$

$\mathrm{g} / \mathrm{sec} \cdot \mathrm{m}^{2}$ 


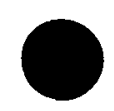

I

,

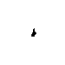

.

$+$

,

$\bullet$ 
Appendix B

\section{PASQUILL STABILITY CLASSES}

The following explanation of the derivation of the Pasquill stability classes, as used in ORFAD, is adapted from Exhibit 3 of Ref. 1 . This system for classifying atmospheric stability is based on work accomplished by F. Pasquill of the British Meteorological office in 1961. Stability near the ground is dependent primarily on net radiation and wind speed. Without the influence of clouds, insolation (incoming radiation) during the day is dependent upon solar altitude, which is a function of time of day and time of year. When clouds are present, their cover and thickness decrease incoming and outgoing radiation; in this case insolation is estimated by solar altitude and modified for existing conditions of total cloud cover and cloud ceiling height. At night, estimates of outgoing radiation are made by considering cloud cover.

This stability classification system has been made completely objective for computer determination of stability class. The stability classes are as follows: (1) extremely unstable, (2) unstable, (3) slightly unstable, (4) neutral, (5) slightly stable, (6) stable, and (7) extremely stable. Classes 6 and 7 are combined in ORFAD and identified as class 6 , as suggested in Ref. 1 .

Table B-1 gives the stability classes as functions of wind speed and net radiation. The net radiation index (NRI) ranges from 4 , the highest

Table B.1. Stability class as a function of net radiation and wind speed

\begin{tabular}{cccccccr}
\hline \multirow{2}{*}{$\begin{array}{c}\text { Wind speed } \\
\text { (knots) }\end{array}$} & \multicolumn{6}{c}{ Net radiation index } \\
\cline { 2 - 8 } & 4 & 3 & 2 & 1 & 0 & -1 & -2 \\
\hline 0,1 & 1 & 1 & 2 & 3 & 4 & 6 & 7 \\
2,3 & 1 & 2 & 2 & 3 & 4 & 6 & 7 \\
4,5 & 1 & 2 & 3 & 4 & 4 & 5 & 6 \\
6 & 2 & 2 & 3 & 4 & 4 & 5 & 6 \\
7 & 2 & 2 & 3 & 4 & 4 & 4 & 5 \\
8,9 & 2 & 3 & 3 & 4 & 4 & 4 & 5 \\
10 & 3 & 3 & 4 & 4 & 4 & 4 & 5 \\
11 & 3 & 3 & 4 & 4 & 4 & 4 & 4 \\
12 & 3 & 4 & 4 & 4 & 4 & 4 & 4 \\
\hline
\end{tabular}


positive net radiation (directed toward the ground), to -2 , the highest negative net radiation (directed away from the ground). Instability occurs with high positive net radiation and low wind speed; stability occurs with high negative net radiation and light winds; and a neutral condition occurs with cloudy skies or high wind speeds.

The NRI used with wind speed to obtain stability class is determined by the following procedure.

1. If the total cloud cover is $10 / 10$ and the ceiling is less than $7000 \mathrm{ft}, \mathrm{NRI}=0$ (day or night).

2. At night (night being defined as the period from $1 \mathrm{hr}$ before sunset to $1 \mathrm{hr}$ after sunrise),

a) NRI $=-2$ for total cloud cover $\leq 4 / 10$;

b) NRI $=-1$ for total cloud cover $>4 / 10$.

3. During the day, use the following procedure:

a) Determine the insolation class number as a function of solar altitude from Table B-2.

b) If total cloud cover is $\leq 5 / 10$, use the NRI in Table B-1 corresponding to the insolation class number.

c) If total cloud cover is $\geq 5 / 10$, modify the insolation class number by following these six steps:

(1) Subtract 2 for ceiling $<7000 \mathrm{ft}$.

(2) Subtract 1 for ceiling $\geq 7000$ but $<16,000 \mathrm{ft}$.

(3) Subtract 1 if total cloud cover is $10 / 10$. This will apply only to ceilings $\geq 7000 \mathrm{ft}$, since cases with $10 / 10$ coverage below $7000 \mathrm{ft}$ are considered in the first step of the procedure.

(4) If the insolation class number has not been modified by the immediately preceding steps 1,2 , or 3 , assume the modified class number equal to the class number.

(5) If the modified insolation class number is less than 1 , set it equal to 1 .

(6) Use the NRI in Table B-1 corresponding to the modified insolation class number. 
Table B-3 shows the temperature gradients, $\partial \mathrm{T}$ eo $/ \partial z$, as used by ORFAD, as a function of the Pasquill stability class. The gradients are expressed in $\mathrm{K} / \mathrm{m}$.

Table B-2. Insolation and insolation class number as functions of solar altitude

\begin{tabular}{lll}
\hline$a_{\mathbf{s}}$ solar altitude & Insolation & Insolation class No. \\
\hline $60^{\circ}<a_{s}$ & Strong & 4 \\
$35^{\circ}<a_{s} \leq 60^{\circ}$ & Moderate & 3 \\
$15^{\circ}<a_{\mathbf{s}} \leq 35^{\circ}$ & Slight & 2 \\
$a_{s} \leq 15^{\circ}$ & Weak & 1 \\
\hline
\end{tabular}

Table B-3. Atmospheric temperature gradient as a function of Pasquill stability class

\begin{tabular}{cc}
\hline $\begin{array}{c}\text { Pasquil1 stability } \\
\text { class }\end{array}$ & $\begin{array}{c}\partial \mathrm{T} \text { eo } \\
\text { gradient }(\mathrm{K} / \mathrm{m})\end{array}$ \\
\hline 1 & -0.0263 \\
2 & -0.0173 \\
3 & -0.01457 \\
4 & -0.01 \\
5 & +0.00455 \\
6 & 0.0263 \\
\hline
\end{tabular}




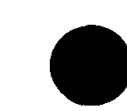

,

•

0 


\section{Appendix C \\ DIFFUSION COEFFICIENTS}

The following expressions, which are used in ORFAD for the diffusion coefficients $\sigma_{y}$ and $\sigma_{z}$, are derived from Briggs' expressions ${ }^{8}$ for the plume half-width and half-depth, $R_{y}$ and $R_{z}$, respectively. The diffusion coefficients (in metres) are related to $R_{y}$ and $R_{z}$ by

$$
\sigma_{y}=0.8 R_{y}
$$

and

$$
\sigma_{z}=0.8 \mathrm{R}_{z}
$$

Both the downwind distance $X$ and the diffusion coefficients are in metres. In Table $\mathrm{C}-1, \mathrm{~B}=\sqrt{1+0.0001 \mathrm{X}}$.

Table C-1. Diffusion coefficients as functions of stability class and downwind distance

\begin{tabular}{cll}
\hline $\begin{array}{c}\text { Stability } \\
\text { class }\end{array}$ & $\sigma_{\mathrm{y}}(\mathrm{m})$ & \multicolumn{1}{c}{$\sigma_{\mathrm{z}}(\mathrm{m})$} \\
\hline 1 & $0.22 \mathrm{X} / \mathrm{B}$ & $0.20 \mathrm{X}$ \\
2 & $0.16 \mathrm{X} / \mathrm{B}$ & $0.12 \mathrm{X}$ \\
3 & $0.11 \mathrm{X} / \mathrm{B}$ & $0.08 \mathrm{X} / \sqrt{1+0.0002 \mathrm{X}}$ \\
4 & $0.08 \mathrm{X} / \mathrm{B}$ & $0.06 \mathrm{X} / \sqrt{1+0.0015 \mathrm{X}}$ \\
5 & $0.06 \mathrm{X} / \mathrm{B}$ & $0.03 \mathrm{X} /(1+0.0003 \mathrm{X})$ \\
6 & $0.04 \mathrm{X} / \mathrm{B}$ & $0.02 \mathrm{X} /(1+0.0003 \mathrm{X})$ \\
\hline
\end{tabular}

$a_{B}=\sqrt{1+0.0001 X} ; x$ is in metres. 


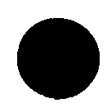

,

,

^

'

$\bullet$ 


\section{Appendix D}

FALL DISTANCE OF EVAPORATING DROPLET

From elementary mechanics, the distance $H$ that an object (in this case, an evaporating droplet) will fall in a time $t$ under constant acceleration $a$ and with an initial velocity $\nabla_{f}$ is given by

$$
H=V_{f} t+\frac{1}{2} a t^{2}
$$

The evaporating droplet attains the velocity $v$ after some evaporation time $t_{e}$, so that

$$
a=-\frac{v_{f}-v}{t_{e}} .
$$

The evaporation time is

$$
\mathrm{t}_{\mathrm{e}}=\frac{\mathrm{H}_{\mathrm{e}}}{\overline{\mathrm{V}}_{\mathrm{e}}},
$$

where $\mathrm{H}_{e}$ is the evaporation distance defined by Eq. (24) of the text and

$$
\bar{v}_{e}=\frac{1}{2}\left(V_{f}+v\right)
$$

Then

$$
a=-\frac{v_{f}^{2}-v^{2}}{2 H_{e}}
$$

and

$$
H=V_{f} t-\frac{1}{2} \frac{V_{f}^{2}-v^{2}}{2 H_{e}} t^{2}
$$

which becomes Eq. (29a) of the text when $v=v_{s}$, the final fall velocity of a saturated droplet, and Eq. (33a) when $v=v_{d}$, the final velocity of a dry particle. 
○

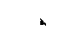

$\bullet$ 
Appendix E

FORTRAN IISTING OF ORFAD PROGRAMS 
LEVEL 21.6 IOEC 721

OS/360 FORTRAN H

COMPILER DPTIONS - NAME = MAIN, OPT $=02, L I N E C N T=60, S I Z E=0000 \mathrm{~K}$,

SOURCE, EBCDIC, NOLIST, NO OE CK, LOAD, MAP, NOEOIT, NOID, NOXREF

PRTGRAM ORFAD

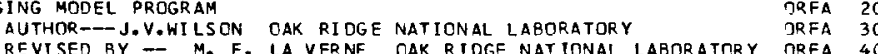

M. LA VERNE OAK RIDGE NATIONAL LABORATORY

ELEV = GROUND ELEVATION, FT

$X M I=$ DOWNHIND DISTANCES, MILES

HT = STACK HEIGHT, MEIERS

QO = STACK INSIDE RADIUS, METERS

WO = STACK EXIT VELOCITY, METERS/SEC

ADP = WLTER FLOW RATE I AIR FLOW RATE IN COOLING TOWER ORFA 100

TRFA 110

$R H=$ PELATTVE HUMIOLTY

DRT = AMBIENT DRY GULB TEMPERATURE, DEG F

TS = STACK GAS TEMPERATUPE AT TOWER EXIT, DEG F

HEATT = TOTAL HEAT DISSIPATED. MEGA CALISEC

CHI = PLUME YAPOR CONCENTRATION, GMICU M

TEO = MMBIENT TEMPERATURE AT GROUND LEVEL, DEG K TRFA 190

$S D=$ SATURATION DEFICIT, GMICU M ORFA 210

ORFA 210

ORFA 230

REAL*8 TDDAY, JOBNO

REAL \#4 ICE, ICETOT

RFAL\#4 IFR, IFRTOT

COMMON HT,WD,RO, ICON,TEO,U,XME, TPO, DELO, FRACON, TOWERS, CLUSIZ TRFA 270

COMMIN/TABULIXMIR2OI,NH, NDIS

COMMON/STAB /LAT,LONG, ICC, ICL, IDAY S, THS, IHR, KGO, EDABCI5I GRFA 310

CIMMMON/MAINCJXDIM,YOIM, IDUM, JDUM, ID ,NUMBER, FF (75),JQ ORFA 320

COMMON/SAMP/O1, IORCL, FLEV, DI AMC 201, DRFRAC(20), SD(20), SDH(20) TRFA 330

COMMON/TITLER/LOC 1181 ORFA 340

COMMON/OROPSI VF(25,2),DF(25,21,C UMUL $(25), V I(25)$ ORFA 350

COMMON ITADEI KSTAT, KYEAR, KMONTH, KOAY ORFA 360

DTMENSION SALTI17,191,SALTOT(17,191 ORFA 370

DIMENSION TE(20), HE(20) ORFA 380

DIMENSION TH(17),X(20),F(20,17) DRFA 390

DIMENSION DRTFT(17,19), VFALI8) DRFA 400

DIMENSION VFAL4(201,DCONT201 DRFA 410

DTMENSTON TGI (6) DRFA 420

OTMENSTON FOG $10,19,17)$, ALTI 10$),$ BPELEVIIO),FOGTOT(10,19,171 JRFA 430

DIMENS ION JHR (6), JWS (6), JDB(6), JWB(6), JAT (6), JCL (6), BAR(6), JWO(6) DRFA 440

DIMENS ION QUFF (3000)

DIMENSION CPF(I7),AREAS(19) DRFA 460

DIMENSION CP(17), AREAS(19) ORFA 470

DIMENSION ICOUNT(5), LOIR(17), IFR(17,19)

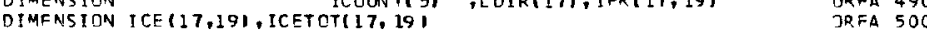

DIMENSION JCOUNT(5) ORT

DTMENS ION TOTIRF $(17,19)$, IFRTOT $(17,19)$, CPTCT $(17)$

DIMENSION GOF $(19,10,16)$, BUFFER $(3000)$ TRFA 530

EQUIVALENCF (GOF $(1,1,1)$, FOG $(1,1,1)\}$ GRFA 540

C ARRAYS CONCM AND PF PROVIDE FOR MONTHLY VARIATION OF CONCENTRATION ORFA 550

AND PLANT FACTOR. EITHER CONC DR THE ENTIRE CONCM ARRAY MUST $=1.0 .0$ ORFA 570

DATA TGI/ $-0.0263,-0.0173,-0.01457,-0.01,0.00455,0.0263 /$

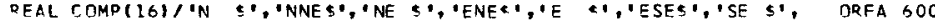

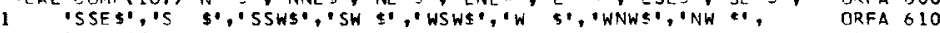

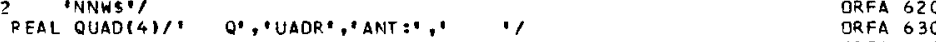

$A B(F)=255.38+F / 1.8 \quad$ TRFA 640

FUNCTION ABIFI CONVERTS FAHRENHEIT TO KELVIN DRFA 660

CALL CRTIBUFF, 3000, 'WILSONS', O) TRFA 670

jRFa 680
orfaga 690

CALL ERRSET $(214,257,0,0,1) \quad$ ORFA 710 CALL ERRSET $\{215\}$
CARFA 720

c * * InPUT CARD 1. *********************** O*RFA 740

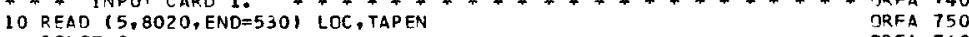

DRFA 760

DRFA 770

ZERO TEN-YEAR TOTALS ORFA 790

MALT $=10$ TRFA BOO

0020 IOIR $=1,17$

CDTOT(YOIRI $=0$.

90 20 IX $X=1,19$

TITDRF (IDIR, IXI=0.

ICETOT(IOIR, I $X)=0$.

SAL TOT(IDIR, $[X]=0$.

IFRTDT (IOIR, $|X|=0$

in $20 \mathrm{M}=1, \mathrm{NAL} T$

FOG TOT $(M, I X, I D I R)=0$. ORFA 890

20 CANTINUE INPUT DATA

PDINT 8030

PRINT 8230, LOC

CALL IOAY TTOCAY

IHA SP $=$ IGTJTOI

CALL JCBNUM(JCBNOS

$M \cap O 360=M D O F L(O)$

TRFA 930

DREA 940

ORFA 950

ORFA 960

ORFA 980 


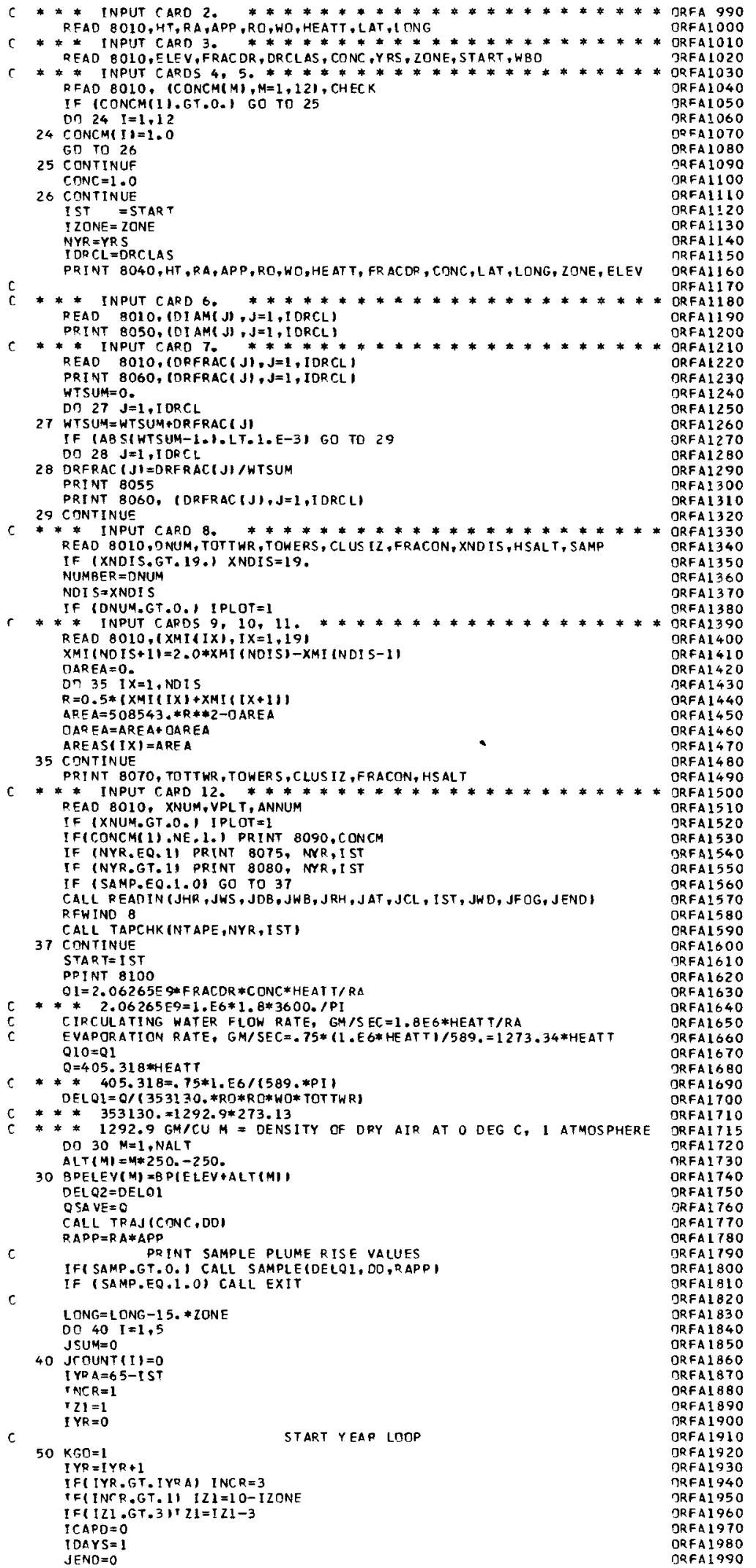




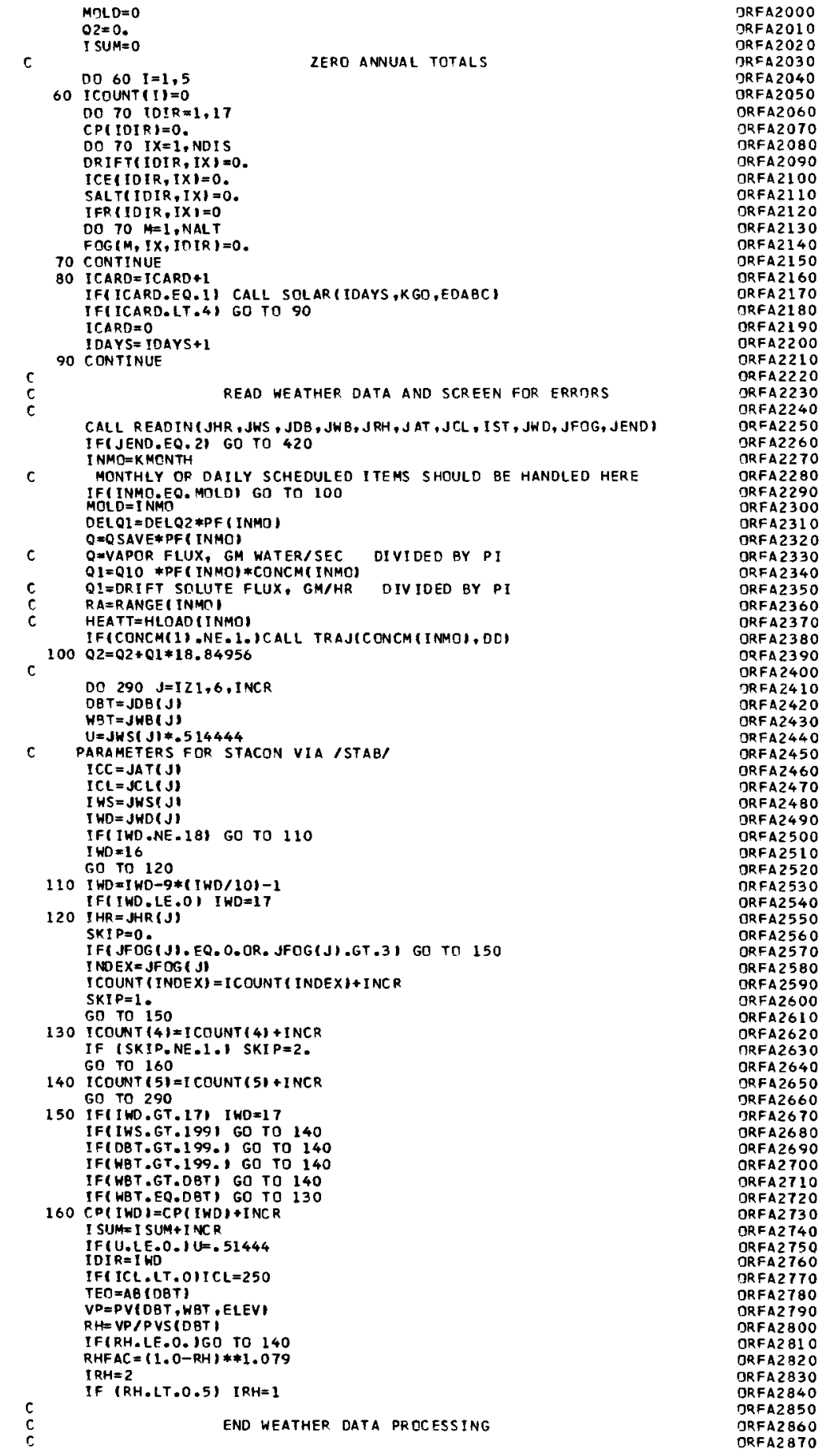


Calculate saturat ton deficit

ORFA 2880
ORFA2 890

ORFA2900

JRFA2910

ORFA2930

ORFA2930

ORFA2950

ORFA2950

DRFA2960

JRFA2 980

DRFA2990

ORFA 3000

DRFA 3010

ORFA 3020

ORFA3030

ORFA 3040

ORFA 3050

ORFA 3060

ORFA 3070

JRFA3080

TRFA3090

ORFA3110

ORFA 1120

ORFA 3130

ORFA3140

ORFA 3150

ORFA 3160

ORFA3170

DRFA 3180

ORFA 3190

DRFA3200

ORFA3210

ORFA 3220

ORFA 3230

ORFA 3240

ORFA 3250

ORFA3260

ORFA 3270

ORFA3280

DRFA329Q

ORFA 3300

ORFA 3320

ORFA3320

ORFA3340

DRFA3350

ORFA3350

ORFA 3370

ORFA 3370

DRFA 3390

ORFA 3390

ORFA3410

ORFA 3420

ORFA 3430

ORFA 3440

ORFA3450

ORFA3460

ORFA 3470

ORFA 3480

ORFA3490

DRFA3500

DRFA3510

ORFA

ORFA 3550

ORFA350

ORFA3570

ORFA3580

ORFA 3580

ORFA3590

ORFA 3600

ORFA 3620

DRFA3630

DRFA3640

ORFA 3650

ORFA 3660

DRFA 3670

DRFA3680

ORFA3690

ORFA3700

ORFA3710

ORFA 3720

ORFA 3730

DRFA 740

ORFA3760

ORFA 3770

JRFA3780

JRFA 3780

ORFA 3800

ORFA 3810

ORFA3820

ORFA3830

ORFA 3840

DRFA 3850

ORFA3860

ORFA3870

ORFA3880 
PRINT 8130, ICOUNT (3)

PRINT 8140, ICOUNT (4)

c

04 CDNTINUF

STRIBUTE RESULTS FOR CALMS TO WIND OIRECTIONS

IFIIYR.GT.NYR I GO TO 360

SUMCP $=0$.

310 SUMCP $=$ SUMCP + CP 16

CP17=1.+CP(17) SUMCP

DO 350 I $X=1$, NDIS

IFR $X=$ IFR(1],I $X$ I

DRIX $=$ DRIFT $(17, I X \mid$

ICEX $=I C E(17, I X)$

SALX $=S A L T(17, I X)$

DO 330 IDIR=1,16

CPOSUM $=C P($ IOIR $) / S U M C P$

IFR (IOIR, IX $\mid=$ IFR(IOIR, IX) +CPOSUM* IFRX

DRIFTIIDIR, IX $)=D R I F T I I D I R, I X]+C$ POSUM*DRIX

ICE $(I D I R, I X)=$ ICE $(I O I R, I X)+C P O S U M * I C E X$

SALTIIDIR, IX) =1.E6* (SALTIIDIR, IXI +CPOSUM *SALX)/I SUM

DO $320 \quad M=1$, NALT

320 FOG $(M, I X, I D I R)=F O G(M, 1 X, I D I R)+C$ POSUM*FOG $(M, I X, 17)$

330 CONTINUE

IFR $(17, I X)=0$

DRIFTI $17, I X \mid=0$

ICE $117,1 X)=0$

DO $340 \quad M=L, N A L$

$340 \mathrm{FDG}(M, 1 \mathrm{X}, 17)=0$.

350 CONTINUE

PRINT TABLES OF RESULTS

360 CONTINUE

OO 370 IDIR $=1,16$

[DIR] $*[P 17$

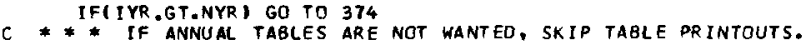
IF (ANNUM. LE. O.) GO TO 385

PRINT 8240, START

372 CONTINUE

PRINT 8160

IFOG $=1$ SU4-I COUNT (1)-I COUNT (2)-I COUNT (3)

PRINT 8180, IFOG

GO TO 376

374 PRINT 8170, NYR

60 TO 372

376 CONTINUE

PRINT 8220

IFIIYR.GT.NYRI PRINT 8170,NYR

IFIIYR.LE.NYRI PRINT 8240,START

PRINT B190

CALL TABLEIDRIFTI

SUMDRF $=0$.

DO 380 I $X=1$, NDIS

$\triangle R E A=A R E A S(I X)$

380 SUMDRF = SUMDRF

PRINT BODO, SUMDRF,Q2

PRINT BO00,

PRINT 8220 STMB PRINT 8170 , NYR

IFIIYR.GT.NYRI PRINT 8170, NYR

PRINT 8200

CALL TABLEIICEI

PRINT 8220

IF(IYR.GT.NYR, PRINT 8170, NYR

IF(IYR LE NYR) PRINT 8240, START

PRINT 8210,HSALT

CALL TABLEISALT:

PRINT 8180 . ISUM

385 CONTINUF

CP $(17)=0$
START $=$ START +1

IF(IYR.GT.NYR) GO TO 460

ACCUMULATE NYR TOTALS

DO 400 IDIR $=1,17$

CPTOT (IDIR) =CPTOT (IOIR) +CP(IDIR )

DO 400 IX=1, NDIS

TOTDRF (IDIR, IX) =TOTDRF(IDIR, IX I+OR IFT (IDIR, IX)

ICE TOT (IDIR, $I X)=$ ICETOT (IDIR, $I X)+$ I CE (IOIR, IX)

SALTOT (IDIR, IX) =SALTOT (IDIR, IX) +SALTIIDIR, IX)

DO $390 \mathrm{M}=1$, NALT

390 FOGTOT IM, IX, DOIRI=FOGTOTIM,IX,IOIRI +FOCIM,IX, IDIRI

400 CONTINUE

DO $410 \mathrm{I}=1.5$

410 JCOUNTII $=$ JCOUNTIII+I COUNT (I)

J $U M=J$ SUM+ I SUM

$\begin{array}{ll}c & \text { IFIIYR -NYRI } 50,420,460 \\ c & \text { END YEAR LOOP } \\ c & \text { OBTAIN AVERAGE FOR NYR YEARS }\end{array}$

420 FAC $1=J$ JSUM+JCOUNT (5)

$F A C 2=J$ JUM

$F A C 3=F A C 1 / F A C 2 / N Y R$

Oก 440 IDIR $=1$ I 16

CPI IDI R) = CPTOT (IDIR) $* F A C 3$

DO 440 I $X=1$, NDIS

DRIFTIIDIR, IX] =TOTORF IIDIR, IXI IFAC3

ORFA3890

ORFA3900

ORFA3910

ORFA3930

ORFA3 940

ORFA3950

ORFA3960

DRFA3970

JRFA 3980

ORFA3990

ORFA3990

TRFA4 4010

ORFA4020

ORFA4030

RFA4040

ORFA4050

DRFA4060

JRFA4070

ORFA4080

ORFA4090

ORFA4100

ORFA4110

ORFA4 120

ORFA4130

ORFA4140

DRFA4150

ORFA4160

ORFA41 70

DRFA 4180

(ORFA4200

(ORFA4220

DRFA4230

ORFA4260

ORFA42 70

ORFA4280

ORFA4280

ORFA4300

ORFA4310

DRFA4320

ORFA 4330

ORFA4340

JRFA4 350

ORFA4360

ORFA4370

ORFA4380

ORFA4390

ORFA4400

ORFA4410

ORFA4420

ORFA4430

ORFA4440

ORFA 4450

ORFA4460

ORFA4470

DRFA4480

ORFA4500

DRFA4510

ORFA45?

ORFA4530

ORFA4540

ORFA4550

ORFA4560

GRFA 4570

ORFA 4580

ORFA4590

DRFA4600

ORFA4610

ORFA4 620

ORFA4630

DRFA4640

DRFA4650

DRFA4660

ORFA4670

DRFA4680

ORFA4690

DRFA4700

ORFA 710

ORFA4720

ORFA4730

DRFA4740

ORFA4 750

ORFA4760

ORFA4780

ORFA4790

ORFA4BDO

ORFA4B1O

ORFA482

ORFA4 430

ORFA4840

DRFA4850

ORFA4860

DRFA4870

ORFA4980
ORFA4890 


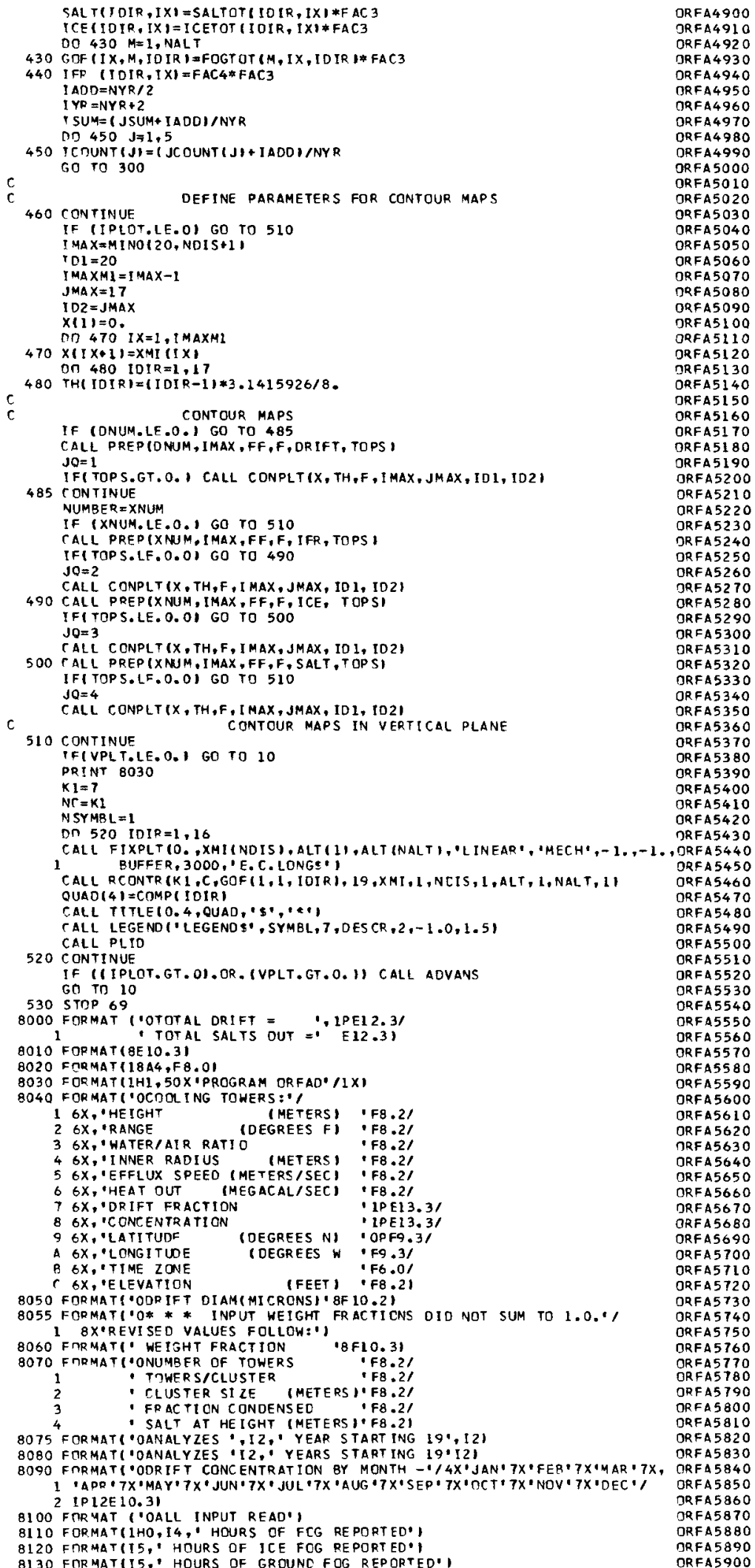


8140 FORMATII5,: HOURS WHEN ORY BULB=WET BULB'

8160 FORMATI1HO, 39X."HOURS OF ADOITIONAL FOG PER YEAR 1

8160 FORMATIHO, 39X. HOURS OF ADOITI ONAL

BI 80 FORMATIO $37 x_{0}$

8190 FORMAT $44 x$,

ihours analy zeo

-ORIFT, GMYYR PER SO METER'

8200 FORMATI1HO, 39X, 'HOURS OF ADOITIONAL ICE PER YEAR',I

8210 FORMAT $(40 X$,

8230 FORMAT (1X, 2 ,

B240 FORMAT (IHO, 49X, 'YEAR $19,, F 3.01$

8250 FORMAT IIH+, $82 X$, , DATE: ",AB,"

1 END
ORFA5910

ORFA5920

ORFA 5930

ORFA5950

ORFA5960

ORFA5970

DRFA5980

ORFA 5990

ORFAG010

ORFAG010

ORFA 6020
ORFA 6030
ORFA 6040
, MAIN ,

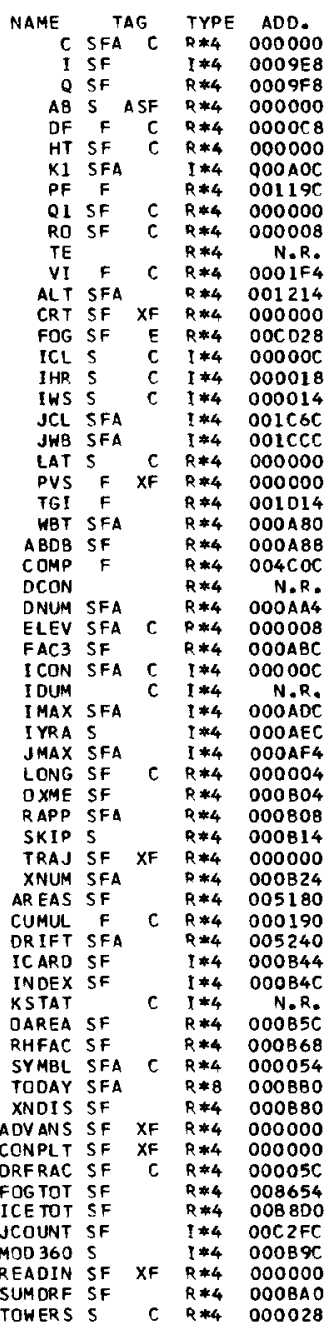

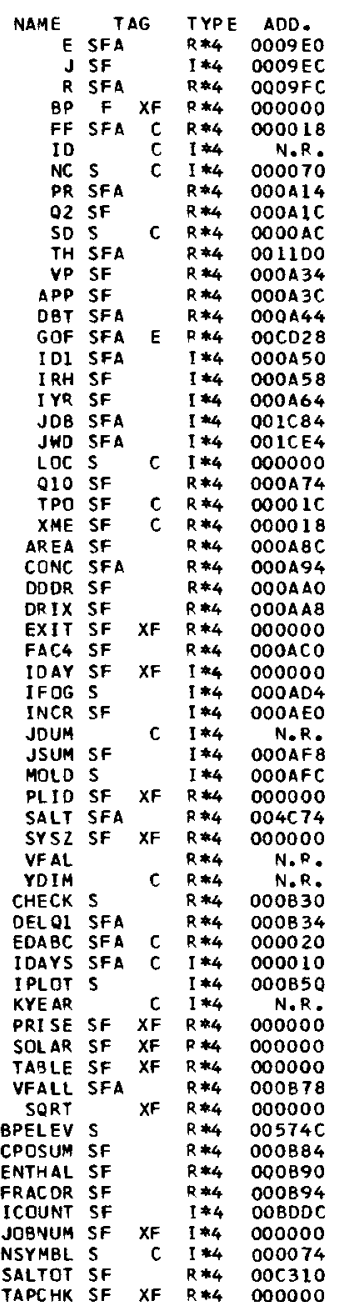

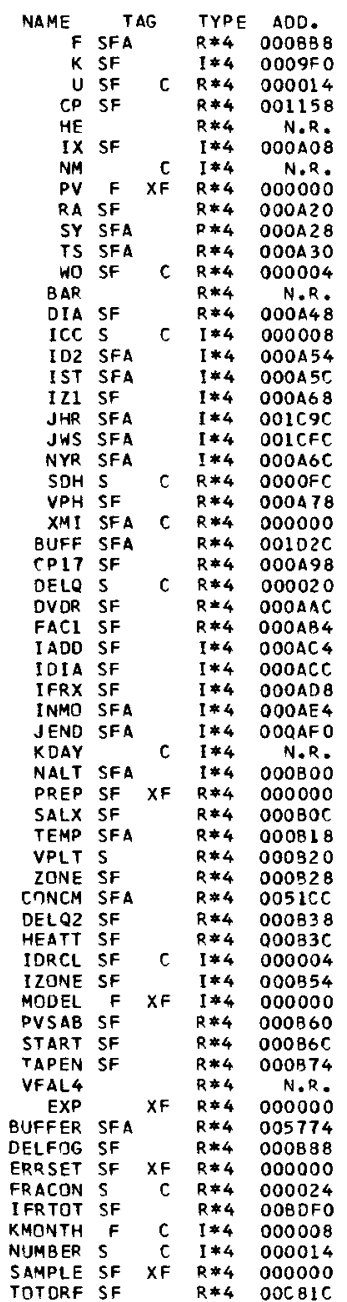

$\begin{array}{lll}R * 4 & 000000 \\ \text { RIC } & & \end{array}$

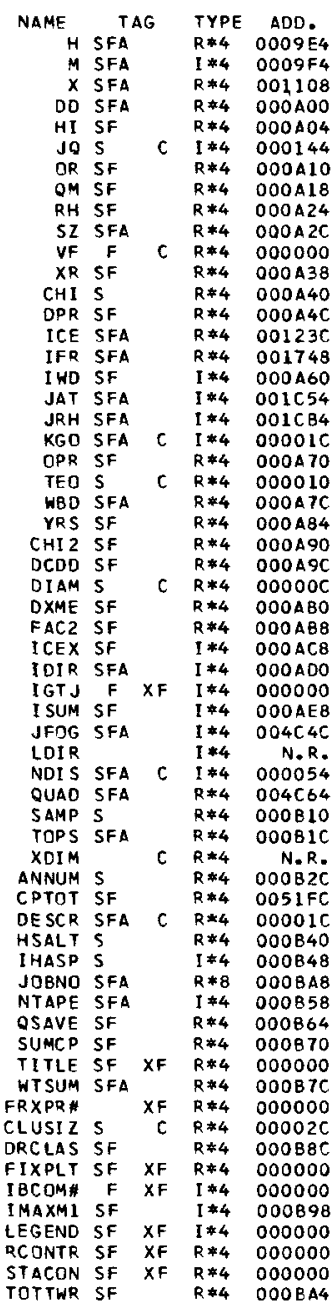

***** COMMON INFORMATION

SIZE OF PRCGRAM O1249C HEXAOECIMAL BYTES

name of COMMON block * * SIZE of block ooo030 hexadecimal bytes

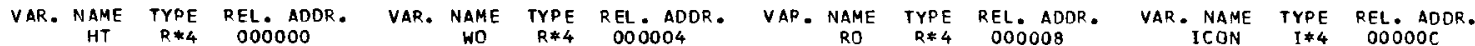




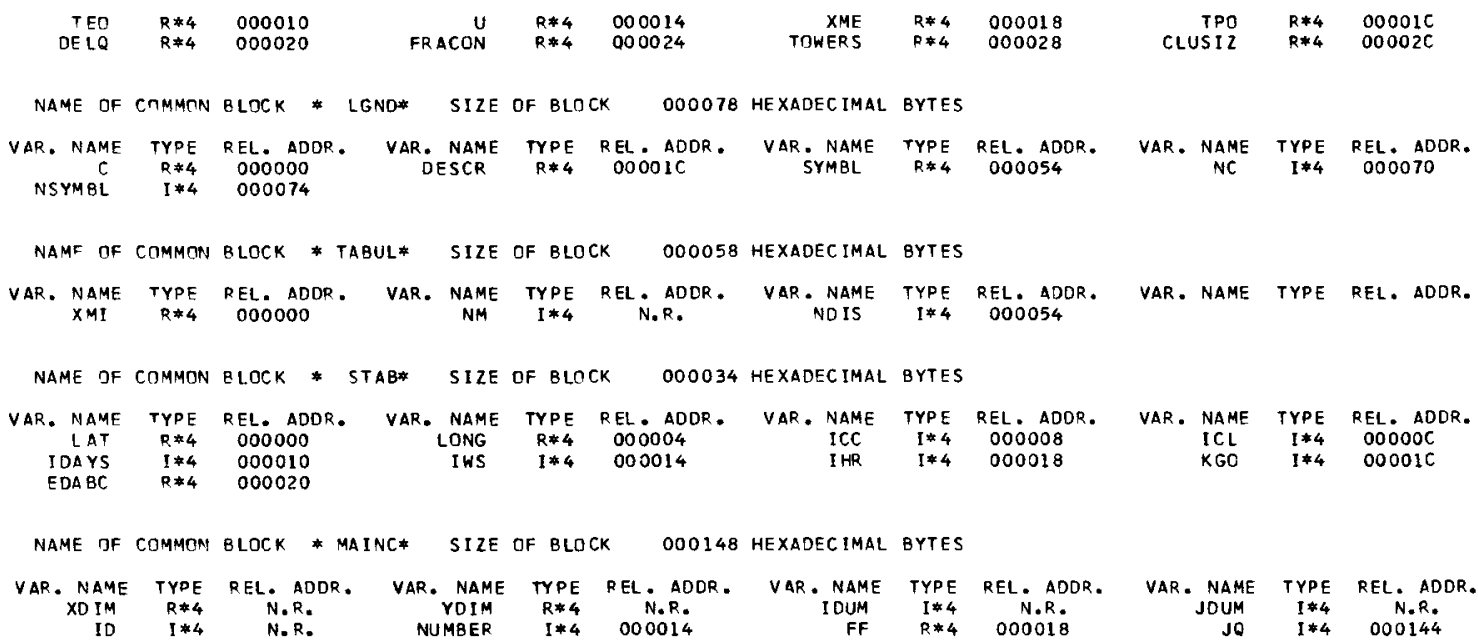

NAME OF COMMON BLOCK * SAMP* S1ZE OF BLOCK OOO14C HEXADECIMAL BYTES

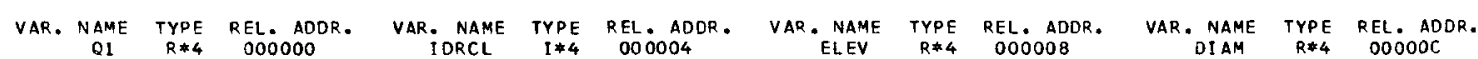

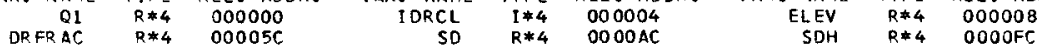

NAME JF COMMNN BLOCK *T ITLER* SIZE OF BLOCK 000048 HeXADECIMAL BYTES

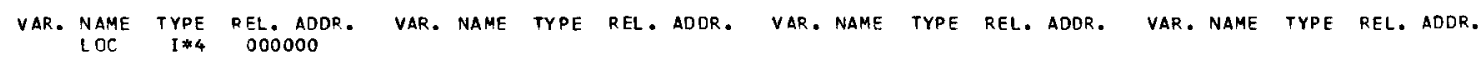

name of common block * Drops* Size of black 000258 hexadecimal bytes

VAR. NAME TYPE REL. ADDR. VAR. NAME TYPE REL. ADDR. VAP. NAME TYPE REL. ADDR. VAR. NaME TYPE REL. ADDR. name of commin block * tape* Size of block 000010 hexadecimal bytes

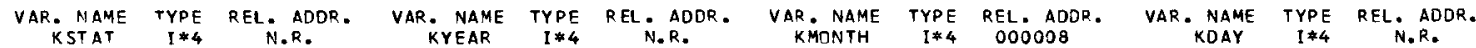

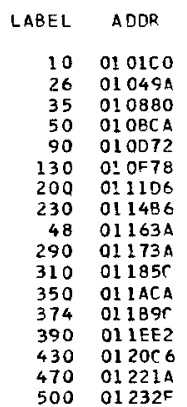

*CPTIIONS IN EFFECT*

* OPTIONS IN EFFECT*

* Statistics*

STURCE STATEMENTS *

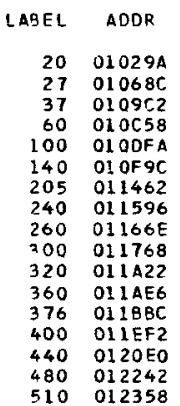

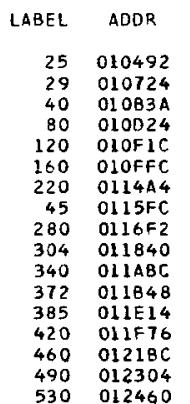

NAME $=$ MAIN, OPT $=02, L I N E C N T=50$, SI ZE $=0000 \mathrm{~K}$,

SOURCE, EBCDIC, NOLIST, NODECK, LO $\triangle D$, MAP, NOEDIT, NOID, NOXREF

* statistics* no diagnostics generateo

******* END OF COMPILATIINA ******* 
LEVEL 21.6 (DEC 721

OS/360 FORTRAN H

COMPILER OPTIONS - NAME $=$ MAIN, OPT $=02$, L I NE CNT $=60,5$ I $Z E=0000 \mathrm{~K}$,

SOURC E, EBCOIC, NOLIST, NODE CK, LDAD, MAP, NOEDIT, NOID, ND XREF

SUBROUTINE READINIIHR, IWS, IDB, IWB, IRH, IAT, ICL, IST, IWD, IFOG, IENDI READ

C * * XREF DATE $=28$ AUG $1975 * *$ *

COMMON /TAPE/ KSTAT, KYEAR, KMONT H, KDAY

L1 DBY 6 , , IOBC (6), IWB(6), IWBC (6), I AT (6)

100 PEAD $(8,8000, E N D=115$, ERR $=120) \mathrm{KST}$ AT, KYEAR, KMONTH, KDAY, (IHR (I),

1 ICLIII,ICLCII\}, IWDII\}, IHOCII)

2 IWS(I), IHSC(I), IOBCII, IDBC(II),

8000 FORMAT $14 X, 15,312,6(12,1 X, 12,41,4 X$,

$1 \mathrm{I} 1, \mathrm{Al}, 3(12, \mathrm{~A} 1), 4 \mathrm{X}, 12, \mathrm{Al}, 14 \mathrm{X}, \mathrm{Al}, 29 \mathrm{X}, \mathrm{Al}, 7 \mathrm{X})$

IFIKYEAR.LT.ISTIGO TO 100

DO $105 \quad I=1,6$

CALL SIGNCK (IHD(I), I WDCII)

CALL SIGNCK (IWS(I), IWSCII)

CALL SIGNCKIIDBCII, IOBCIII,

CALL SIGNCK (IWBCI, IWBCIII

CALL SIGNCK (IRH(I), TRHCII)

CALL SIGNCKIICL(I), ICLCII)

CALU $=0$

CALL SIGNCKITDUM, IATIII)

IAT I I I = IDUM

IOUM $=0$

ALL SIGNCKIIDUM, IFOGIII)

IFOG II I=IDUM

IFIKMONTH.EQ.12. AND. KDAY.EQ.311 GO TO 110

$$
\text { IFIKMONTH.EQ.12.AND.KDAY.EQ.311 GO TO } 110
$$

T. T. 18I RETURN

I END $=1$

115 TEND $=2$

RETURN

120 READ $(8,8000)$

DO $125 \quad I=1,6$

125 I $W$ S $111=9999$

RETURN

END
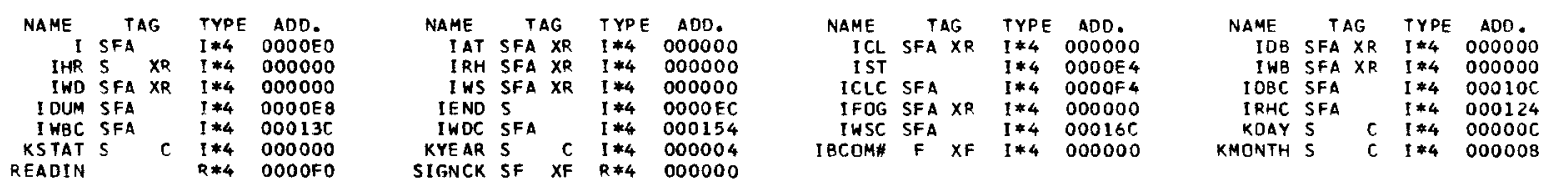

**\#* COMMCN INFORMATION **\#**

NAME OF COMMON BLOCK * TAPE* SIZE OF BLOCK 000010 HEXADEC IMAL BYTES

\begin{tabular}{|c|c|c|c|c|c|c|c|c|c|c|c|}
\hline $\begin{array}{l}\text { VAR. NAME } \\
\text { KSTAT }\end{array}$ & $\begin{array}{r}T Y P E \\
I \neq 4\end{array}$ & $\begin{array}{c}\text { REL. } A D D R \text {. } \\
000000\end{array}$ & $\begin{array}{l}\text { VAR. ' } \\
\text { KY }\end{array}$ & AME & $\begin{array}{r}\text { TYPE } \\
I * 4\end{array}$ & 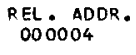 & $\begin{array}{r}\text { VAR } \\
K \text { K }\end{array}$ & $\begin{array}{l}\text { NAME } \\
\text { DNTH }\end{array}$ & $\begin{array}{r}\text { TYPE } \\
\text { I*4 }\end{array}$ & $\begin{array}{l}\text { REL. ADDF. } \\
000008\end{array}$ & $\begin{array}{l}\text { VAR. NAME } \\
\text { KDAY }\end{array}$ \\
\hline LABEL & $\triangle D D R$ & & $\angle A B E L$ & $A D$ & & & $\angle A B E L$ & ADDR & & LABEL & $A O O R$ \\
\hline $\begin{array}{l}100 \\
120\end{array}$ & $\begin{array}{l}0001 F 8 \\
000472\end{array}$ & & $\begin{array}{l}105 \\
125\end{array}$ & $\begin{array}{l}000 \\
000\end{array}$ & $\begin{array}{l}40 C \\
49 C\end{array}$ & & 110 & $00043 A$ & & 115 & 000462 \\
\hline
\end{tabular}

*OP TIONS IN EFFECT* NAME $=$ MAIN,OPT $=02, L I N E C N T=60$, SI ZE $=0000 \mathrm{~K}$,

\#OPTIONS IN EFFECT SOURCE, EBCDIC, NOLIST, NODECK, LO $\triangle 0$, MAP, NOEDIT, NOID, NOXREF

*STATISTICS* SOURCE STATEMENTS $=36$, PROGRAM SIZE $=1458$

*STATISTICS* no diagnostics generated 


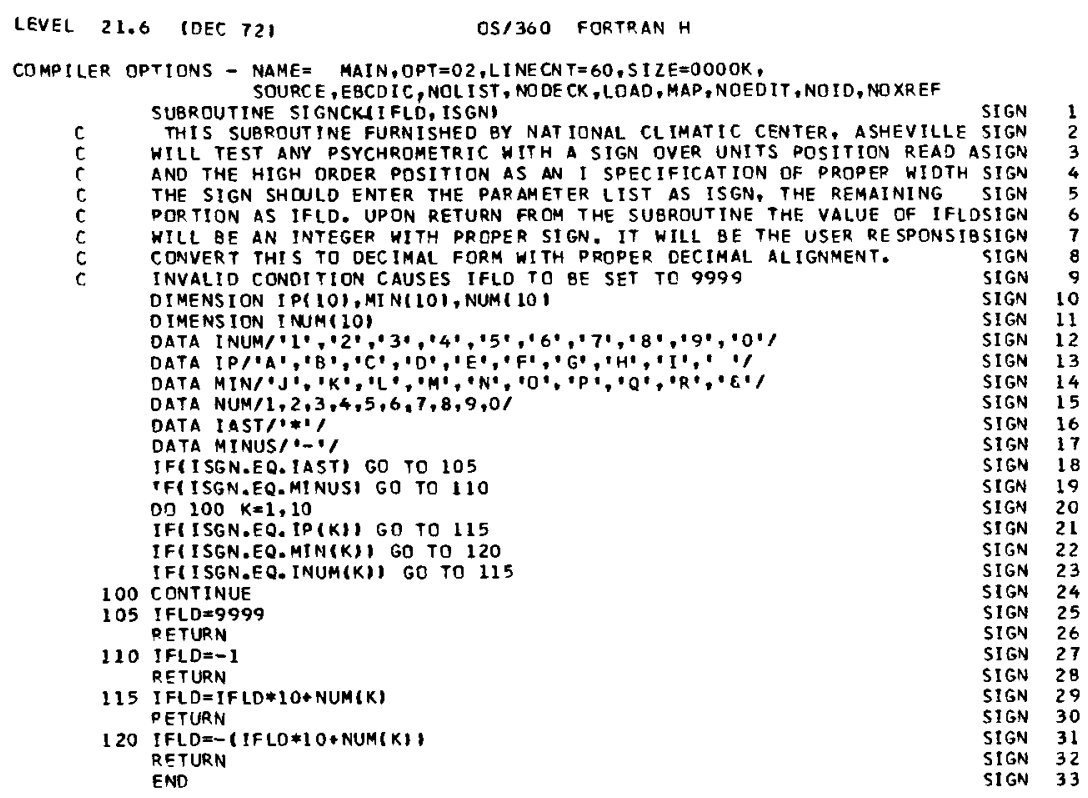

, SIGNCK , SIZE OF PROGRAM 000254 HEXADECIMAL BYTES

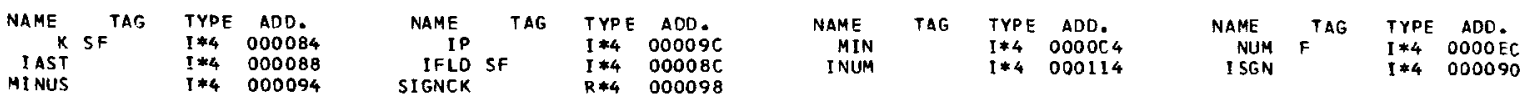

\begin{tabular}{|c|c|c|c|c|c|c|c|}
\hline LABEL & $\triangle D D R$ & $\angle A B E L$ & $A D D R$ & $\angle A B E L$ & ADDR & LABEL & AODR \\
\hline $\begin{array}{l}100 \\
120\end{array}$ & $\begin{array}{l}0001 \mathrm{B2} \\
0001 \mathrm{FB}\end{array}$ & 105 & $0001 B C$ & 110 & $0001 C c$ & 115 & 0001DA \\
\hline
\end{tabular}

*DPTIONS IN EFFECT* NAME $=$ MAIN,OPT $=02, L I N E C N T=60$, SI ZE $=0000 K$,

* OPTIONS IN EFFECT* SOURCE, EBCDIC, NOL IST, NODECK, LO AD, MAP, NOEDIT, NOID, NOXREF

* STATISTICS* SOURCF STATEMENTS = 30 , PROgRAM SIZE = 596

* STATISTICS* no diagnDSTICS generated

****** END OF COMPILATION *******

133K BYTES OF CORE NOT USED 
LEVEL 21.6

OS/360 FOPTRAN H

COMPILER OPTIONS - NAME $=$ MAIN, OPT $=02, L I N E C N T=60,5 ! Z E=0000 \mathrm{~K}$, NAME $=$ MAIN,OPT $=02, L 1 N E C N T=60,5 I Z E=0000 K$,
SOURCE, EBCD IC, NOL IST, NO DE CK, LOAD, MAP, NOEDIT, NOID, NOXREF SUBROUTINE TAPCHKINTAPE, NYR, I ST,
CIMMON JTAPF' KSTAT, KYEAR, KMONT H, KDAY

* * TAPCHK ARRAYS AS OF 4 NOV 75 OATA NOSTAT $13891,14703,14714,14735,14922,11641,14719,14768$, $13743,13897,13881,93807,93814,0,0 /$
DATA NOTAPE $/ 9987,967,2088,15900,13404,4184,9427,11498,14139$, 1 14619,14781,14782,11595,0,01 DATA NOIST/55,58,59,65,49,65,60,59,55,65,55,55,65,0,01

DATA NOLAST/64,67,68,74,58,73,69,68,64,74,64,64,74,0,01

* * LIST IS THE CURRENT NUMBER of VALID ENTRIES IN NOTAPE. * * * DATA LIST/13/

IF (NTAPE.GT.O) GO TO 10

PRINT 100

RFTURN

10 CANTINUE

DD $20 \quad I=1$, LIST

IF INTAPE.NE. NOTAPE II) GO TO 20

$\mathrm{N}=\mathrm{I}$

GO $P O{ }^{30}$

CONTINUE
PRINT 110 , NTAPE

RETURN

30 CONTINUE

NSTAT = NOSTAT(N)

NOI =NOTSTCH

$N O D=0$
$10 L$

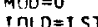

MOLD $=I S T$
MOL $=N Y R$

IF (KSTAT. NE. NSTAT) PRINT 120, NTAPE, NSTAT,KSTAT

IF IST.GE.NOI) GO TO 40

$M \cap C=1$

40 CONTINUE

IF IIIST+NYR-U) -LE. NOLI GO TO 50

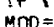

$M \cap O=1$
NYP $=$ NOL $-I S T+1$

50 CONTINUE

IF (MOO.GT.0) PRINT 130, NOLD, IOLD, NYR, IST

100 FORMATI 'OTAPE CHECK NOT REQUESTED.", 11

110 FORMAT TOTADE $X-1,15,{ }^{\circ}$ NOT IN CHECKLIST.",1

120 FTRMATI 'OTAPE $X-1,15, "$ STATION ' 15,1 REQUESTED."

130 FORMATI ODATES CORRECTED TO CONFDRM TO TAPE DATA:,

1 REQUESTEO: $\because 12,0$ YEARS STARTING IN $19 \%, 12 \%$

2 ' WILL USE: "II," YEARS STARTING IN $19 \circ, 12$ RETURN
ENO

TAPC 10

TAPC 20

TAPC 40

TAPC 50

TAPC 60

$\begin{array}{ll}\text { TAPC } & 60 \\ \text { TAPC } & 70\end{array}$

TAPC 80

$\begin{array}{rr}T A P C & 90 \\ \text { TAPC } 100\end{array}$

TAPC, 110

TAPC 1.20

TAPC 130

TAPC 140

TAPC 150

TADC 160

TAPC 170

TAPC 180

TAPC 190

TAPC 200

TAPC 210

TAPC 220

TAPC 230

TAPC 240

TAPC 250

TAPC 260

TAPC 280

TAPC 280

TAPC 300

TAPC 310

TAPC 320

TAPC 330

TAPC 340

TAPC 350

TAPC 360

TAPC 370

TAPC 380

TAPC 390

TAPC 400

TAPC 410

TAPC 420

TAPC 430

TAPC 440

TAPE 450

TAPC 460

TAPC 470

TAPC 480 


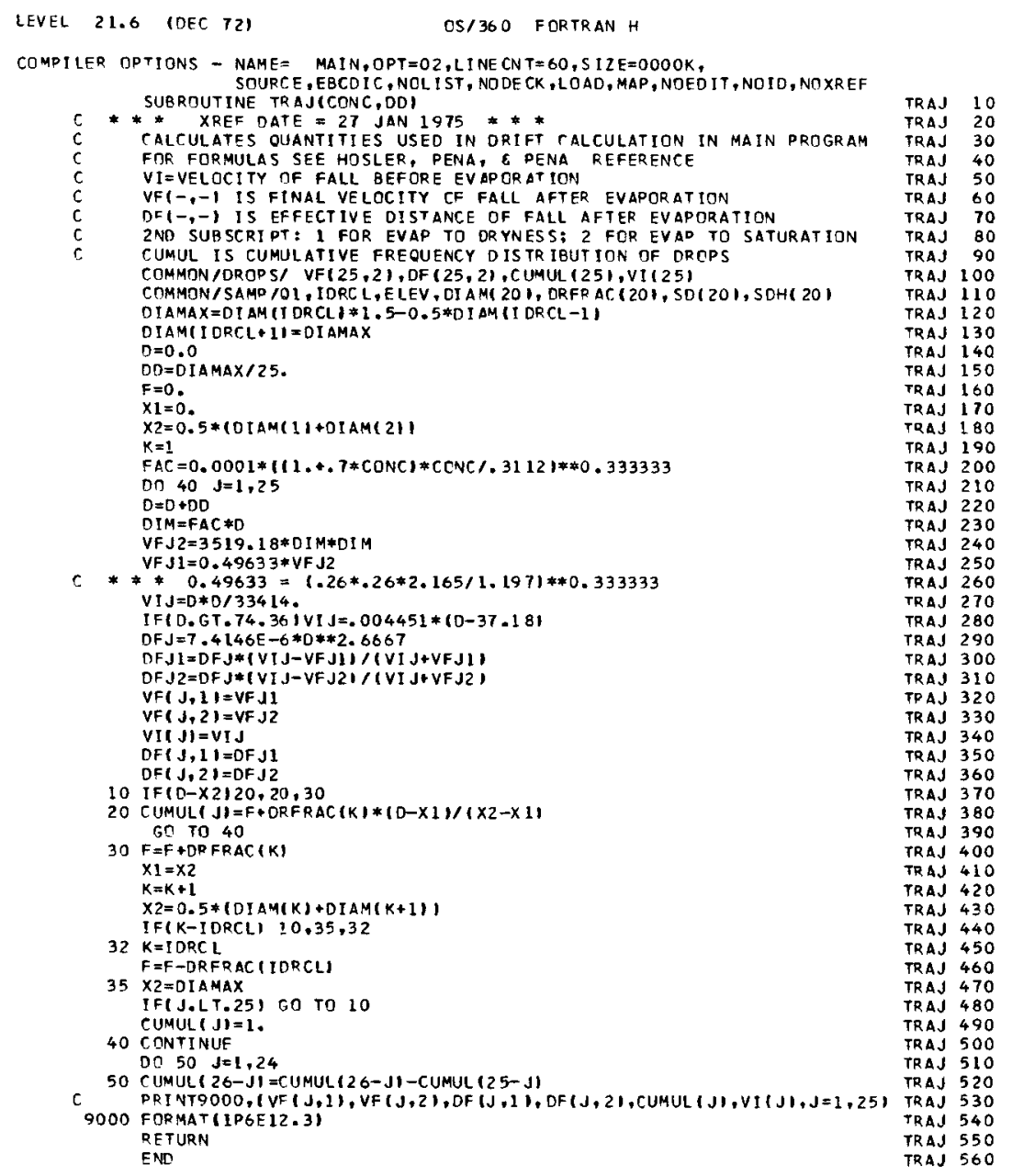
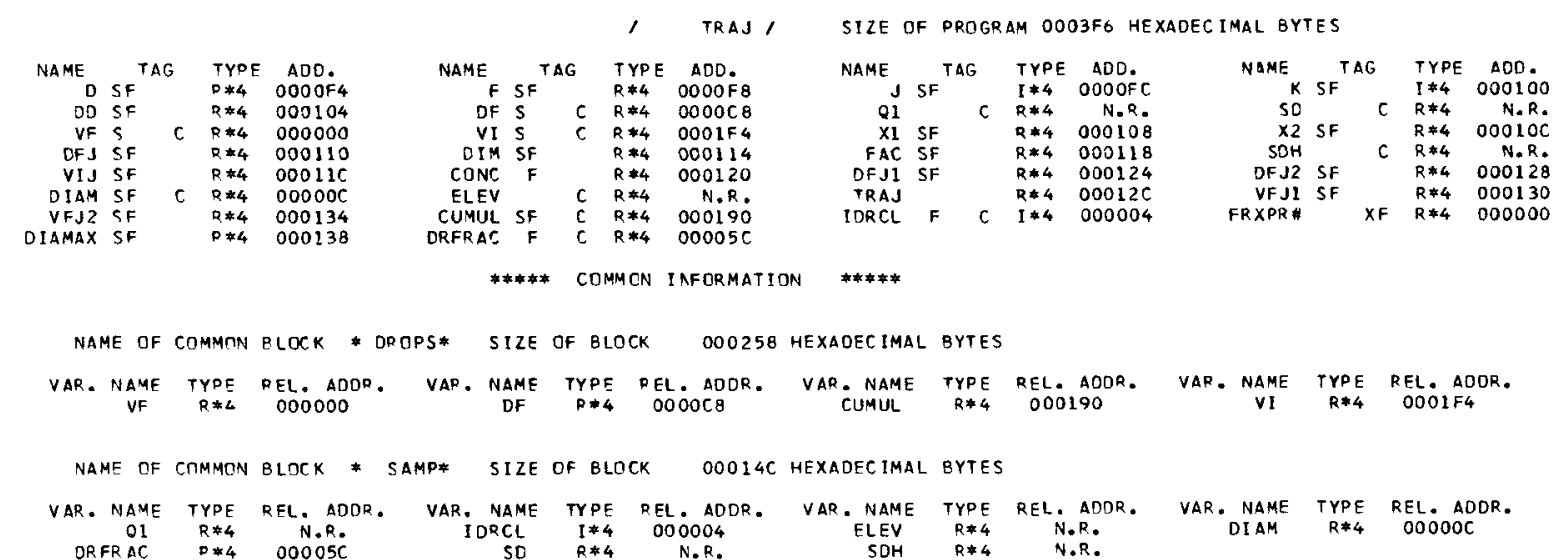


\begin{tabular}{|c|c|c|c|c|c|c|c|}
\hline$\angle A B E L$ & ADDR & LABEL & $A D O R$ & $\angle A B E L$ & $A D D R$ & LABEL & ADDR \\
\hline $\begin{array}{l}10 \\
35\end{array}$ & $\begin{array}{l}000204 \\
00034 E\end{array}$ & $\begin{array}{l}20 \\
40\end{array}$ & $\begin{array}{l}0002 \mathrm{EE} \\
00036 \mathrm{C}\end{array}$ & $\begin{array}{l}30 \\
50\end{array}$ & $\begin{array}{l}000318 \\
00038 E\end{array}$ & 32 & 000348 \\
\hline
\end{tabular}

*OPTIONS IN EFFECT* NAME $=$ MAIN, OPT $=02, L I N E C N T=0,512 E=0000 \mathrm{~K}$,

*OPTIONS IN EFFECT* SOURCE, EBCOIC, NOL IST, NOOECK, LOAO, MAP, NOEOIT, NOIO, NOXREF

*STATISTICS* SOURCE STATEMENTS = 48, PROGRAM SIZE = 1014

*STATISTICS* NO DIAGNOSTICS GENERATED

LEVEL 21.6 (OEC 72 )

OS/360 FORTRAN H

COMPILER OPTIONS - NAME $=$ MAIN, OPT $=02, L I N E C N T=60, S 1 Z E=0000 \mathrm{~K}$,

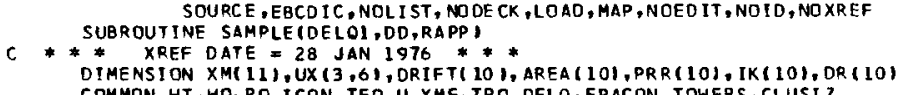

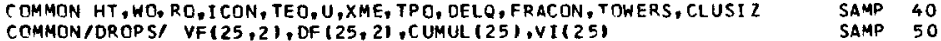
COMMON/SAMP /O1, IDRCL, ELEV, DI AML 20$)$, DRFRAC (20), SD(20), SOH(20) SAMP 60

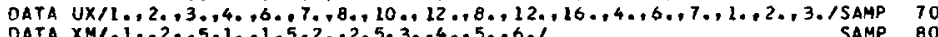
DATA XM/.1,.2, $, 5,1 ., 1.5,2,12.5,3 ., 4 \ldots 5 ., 6.1$ SAMP 80 $A B(X)=255.37+55555 * X \quad$ SAMP 90 $X M(11)=2 ; * X M(10)-X M(9)$
$R A D !=X M(1)$

OAREA $=0$

DO $I=I=1,10$
RAD $2 \approx X M(I+1)$

RAD $2 \approx X M(1+1)$
AREA $1=0.25 *(R A D 1+R A D 2) * * 2$

AREAI I I = ARE AI -OAREA

$P A D 1=R A D 2$

I CONTINUE

INCR $=1$

I $N C R=1$
I $E R=0$

IER $\approx 0 \quad$ OO $80 \quad I D B T=1,3$

$D B T=20 .+20 . * 1 D B T$

TED $=A B$ IDBT)

WB T $=0 B T \div 1,1-1$.

PRINT 8060, (XM(IG), IG=1,10)

PRINT 8010

WBT $=$ WB T -0.1 *DBT

RH=PVIOBT, WBT, ELEVI $\angle P V S C O B T$

RHFAC $=(1.0-$ RH $) * * 1.079$

$\mathrm{IRH}=2$

IF (RH.LT.0.5) IRH=1

CALCULATE TOWER EFFLUENT TEMPERATURE

IF (HBT.LT.80.) ENTHAL $=(H B T+4.30501 / 13.917-0.024846 * W B T)$

IF (KBT.GE. BO.) ENT HAL $=(W B T-13.8501 / 12.766-0.015652 * W 8 T)$

ENTHAL =ENTHAL+RAPP

FIENTHAL.GT. 43.6971T S= 12.766 *ENTHAL+13.851/11 .+.015652*ENTHAL) IFIENTHAL. LE. 43.697) T $S=13.917$ *ENT HAL $-4.3051 / 11 .+.024846 * E N T H A L$, $T P O=A B$ (TS)

$O E L O=D E L Q 1 * T P O$

DO 80 ICON $=1.6$

Do 80 IU $U=1,3$

$\mathrm{U}=\mathrm{V} * .51444$

$U=V *$
$K=25$
$O R=0$

$O R=0$.

$\triangle P R=0$.

$X X E=0 ; X=1,10$

$X M E=X M(I X) \neq 1609,344$

CALL PRISEIPR

DRIFT IIXI $=0$.

$P R P(I X)=P R$

$X M E=X M E-D X M$

$O P R=P R$
$O P R=X E$

$O X M E=X M E$

IFIRH.LT.0.76) GOTO 10

NO EVAPORATION
VFALL $=(H T+D R)$ *U/XME

$D I A=37.18+V F A L L / .00445$

IF IVFALL.LT.0.16548) DIA=SQRT( 33414 **VFALL

IDI $1 A=D I A / D O+1$.

I $K(I X)=101 A$

IFCIOIA.GT.251GO TO 50

DVR= (VFALL-U ODPR/OXME) $/ X M E$

DODR $=$ D VOR 0.004451

DF IVFALL.LT.0.16548I DDDR=0.5*DIA*DVDR/VFALL

DCOD=CUMULI

GO TO 40
CONTINUE 


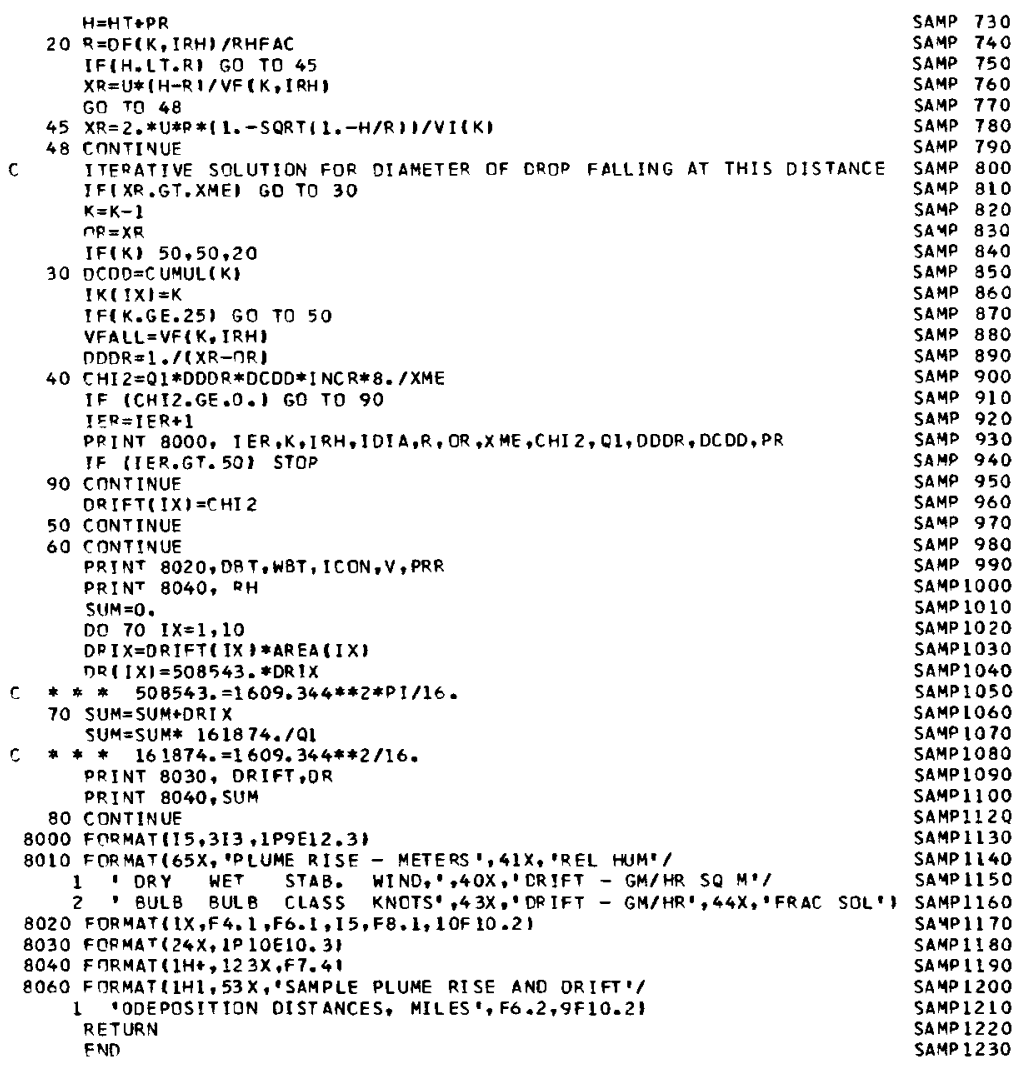

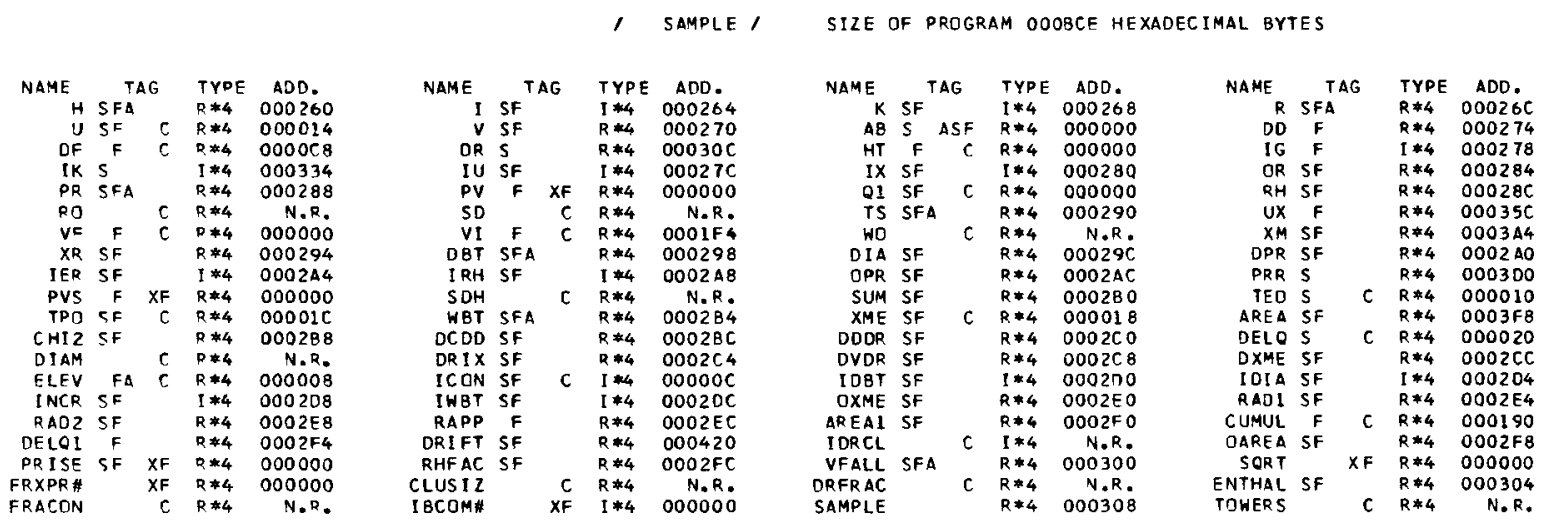

NAME JF COMMON BLOCK * * SIZE OF BLOCK 000030 HEXADEC IMAL bYTES
VAF. NAME TYPE REL. AOOR. $\begin{array}{rrrr}\text { HT } & R * 4 & 000000 \\ \text { TEO } & R * 4 & 000010\end{array}$ var. name type rel. ador.
var. Name type rel. ador.

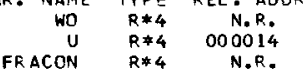
VAR. NAME TYPE REL. ADDR. $\begin{array}{rrr}\text { ICON } & I * 4 & 00000 \mathrm{C} \\ \text { TPO } & R * 4 & 00001 \mathrm{C} \\ \text { CLUSIZ } & R * 4 & \text { N.R. }\end{array}$

NAME IF COMMCN BLECK * DROPS* SIZE OF BLOCK 000258 HEXADECIMAL bYTES

VAP. Name tyPe PEl. 


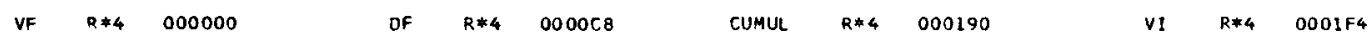

name of common block * Samp* Size of block o0014C hexadecimal bytes

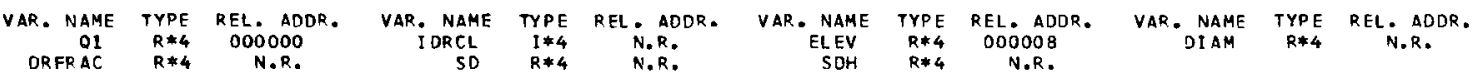

\begin{tabular}{|c|c|c|c|c|c|c|c|}
\hline LABEL & $A D D R$ & LABEL & $\triangle D O R$ & LABEL & $\triangle D D R$ & LABEL & ADDR \\
\hline $\begin{array}{r}1 \\
48 \\
50\end{array}$ & $\begin{array}{l}000506 \\
00090 E \\
000446\end{array}$ & $\begin{array}{l}10 \\
30 \\
60\end{array}$ & $\begin{array}{l}000870 \\
000942 \\
000446\end{array}$ & $\begin{array}{l}20 \\
40 \\
70\end{array}$ & $\begin{array}{l}000846 \\
000982 \\
000 A D 8\end{array}$ & $\begin{array}{l}45 \\
90 \\
80\end{array}$ & $\begin{array}{l}000800 \\
000 A 3 E \\
000840\end{array}$ \\
\hline
\end{tabular}

*OP TIONS IN EFFECT* NAME $=$ MAIN, OPT $=02, L$ INECNT $=60$, SI ZE $=0000 \mathrm{~K}$,

*OPTIONS IN EFFECT* SOURCE,EBCDIC,NDLIST, NOOECK, LO DD, MAP, NOEDIT, NOID, NE

*STATISTICS* SOURCE STATEMENTS $=127$, PROGRAM SIZE = 3022

*STATISTICS* No oiagnostics generated

\#\#*** END OF COMPILATION ******

109K BYTES OF CORE NOT USEO

LEVEL 21.6 IDEC 721 OS 360 FORTRAN H

COMPILER OPTIONS - NAME $=$ MAIN, OPT $=02, L$ INECNT $=60,5$ I ZE $=0000 \mathrm{~K}$,

SDURC E, EBCD IC, NOL IST, NODE CK, LOAO, MAP, NOEDIT, NO ID, NOXREF FUNCTION PVIOBT, WET, ELEVI
YAPOR PRESSURE INCHES OF MERCURY$$
\text { C }
$$

PV=PVS (WBT)- $(0.000367 * B P(E L E V) *$ (DET-WBT $) * 11 .+(W B T-32.1 / 1571.1)$ 100 RETURN
END

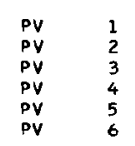

I PV 1 SIZE OF PRQGRAM 000156 HEXADEC IMAL BYTES

\begin{tabular}{|c|c|c|c|c|c|c|c|c|c|c|c|c|c|c|}
\hline $\begin{array}{r}\text { NAME } \\
\text { BP } \\
\text { WBT }\end{array}$ & $F_{F A}^{T A G} X F$ & $\begin{array}{l}\text { TYPE } \\
R * 4 \\
R * 4\end{array}$ & $\begin{array}{l}\text { ADD. } \\
000000 \\
000098\end{array}$ & $\begin{array}{c}\text { NAME } \\
\text { PV } \\
\text { ELEV }\end{array}$ & $S_{F A}^{T A G}$ & $\begin{array}{l}T Y P E \\
R * 4 \\
R * 4\end{array}$ & $\begin{array}{c}\triangle 00 . \\
000090 \\
00009 C\end{array}$ & $\begin{array}{l}\text { NAME } \\
\text { DBT }\end{array}$ & $F^{T A G}$ & $\begin{array}{l}T Y P E \\
R * 4\end{array}$ & $\begin{array}{c}\text { ADD. } \\
000094\end{array}$ & $\begin{array}{l}\text { NAME } \\
\text { PVS }\end{array}$ & $F^{T A G}$ & $\begin{array}{l}\text { TYPE AOD. } \\
R * 4 \quad 000000\end{array}$ \\
\hline
\end{tabular}

LABEL ADOR LABEL ADDR LABEL ADOR LABEL ADDR

100 OOOOFA NR

*OPTIONS IN EFFECT* NAME $=$ MAIN,OPT $=02, \mathrm{LINECNT}=60$, SI ZE $=0000 \mathrm{~K}$,

*OPTIONS IN EFFECT* SOURCE, EBCDIC,NOLIST, NODECK, LO AD, MAP, NOEDIT, NOIO, NDXREF

* STATISTICS* SOURCE STATEMENTS = 4 ,PROGRAM SIZE = 342

*statistics* no oiragnostics genfrateo

****** END OF COMPILATION *******

133K BYTES OF CORE NOT USED 


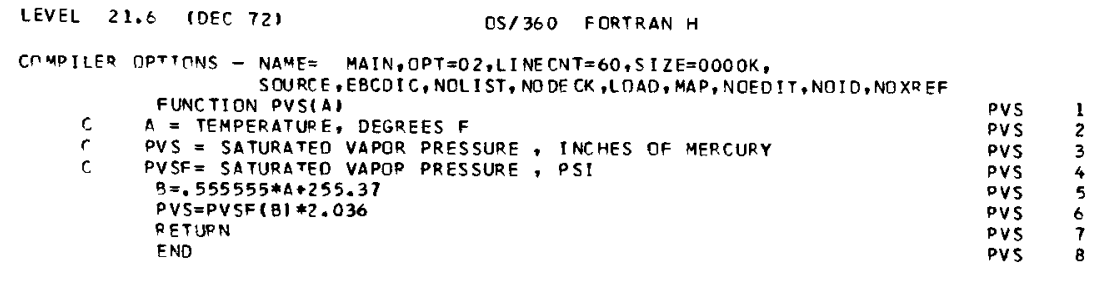$$
\text { (2) }
$$ 


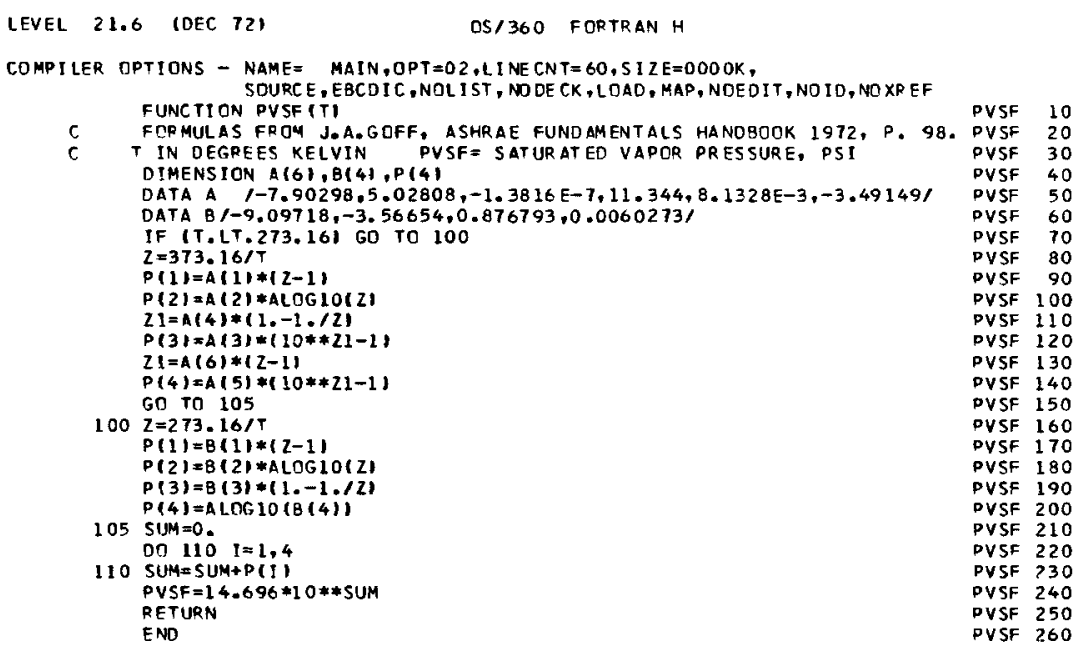

1 PVSF, SIZE OF PROGRAM O002C4 HEXADEC IMAL BYTES
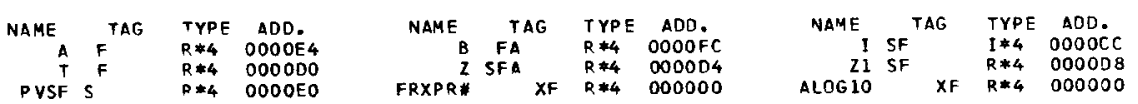
NAME TAG TYPE ADD.
SUM SF $R * 4$ DOO1OC

\begin{tabular}{|c|c|c|c|c|c|c|}
\hline LABEL & $A D D R$ & LABEL & ADDR & $\angle A B E L$ & $\triangle D D R$ & LABEL \\
\hline 100 & $0001 F 4$ & 105 & $00025 \mathrm{C}$ & 110 & $00026 \mathrm{~A}$ & \\
\hline
\end{tabular}

*OPTIONS IN EFFECT* NAME $=$ MAIN, OPT $=02$, LINECNT $=60$, SI ZE $=0000 \mathrm{~K}$.

\#OPTIONS IN EFFECT* SOURCE, EBCDIC, NOLIST, NODECK, LOAD, MAP, NDEDIT, NOIO, NOXREF

* STATISTICS* SOUPCE STATEMENTS $=\quad 25$, PROGRAM SIZE = 708

*STATISTICS* NO DIAGNOSTICS gENERATED

****** END OF COMPILATION ******

133K BYTES OF CORE NOT USEO

LEVEL 21.6 IOEC 721

OS 360 FORTRAN H

COMPILER OPTIONS - NAME $=$ MAIN, OPT $=02, L I$ INE CNT $=60, S$ I ZE $=0000 \mathrm{~K}$

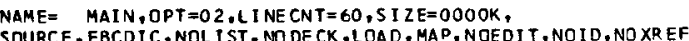
SUBROUT INE SOLARIIDAY, KGO, EDABC THIS SUBROUTINE SIMPLY INTERPCL ATES IN TABLES EOABC (I)= = QUATION OF TIME, MIN GRESI TOLAR RADIATION INTENSITIES AND ARE NOT USED IN OREAD

DTMENSION TABLE $(6,13)$, EDABCI5 DATA TABLE/21.0,-11.3,-20,00,390.0,0.142,0.058,

$52.0,-13.5,-10.80,385.0,0.144,0.058$

$\begin{aligned} & 80.0,-7.3 ; 0.00,376,0,0.156,0.071, \\ & 3\end{aligned} \quad 111.0,0.1,11.60,360.0,0.180,0.097$,

SOLA 1

SOLA

SOLA

SOLA

SOLA

SOLA 9

SOLA 10

SOLA 12

SOLA I3 


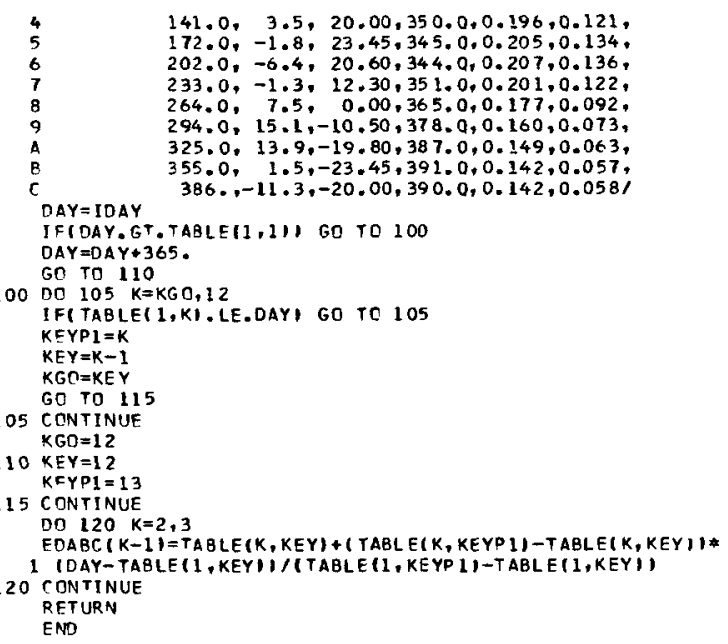

1 SOLAR , SIZE OF PRDGRAM 0003A4 HEXADECIMAL BYTES

\begin{tabular}{|c|c|c|c|c|c|c|c|c|c|c|c|c|c|c|c|}
\hline $\begin{array}{l}\text { NAME } \\
\text { K } \\
\text { I OAY }\end{array}$ & $\mathrm{SF}^{\text {TAG }}$ & $\begin{array}{l}\text { TYP } \\
I \neq 4 \\
I \neq 4\end{array}$ & $\begin{array}{c}A 0 D . \\
0000 A 4 \\
000084\end{array}$ & $\begin{array}{l}\text { NAME } \\
\text { OAY }\end{array}$ & $S_{S F}^{T A G}$ & $\begin{array}{l}T Y P E \\
R * 4 \\
P \neq 4\end{array}$ & ADO. & $\begin{array}{l}\text { NAME } \\
\text { KEY } \\
\text { XFYP }\end{array}$ & $S_{S F}^{T A G}$ & $\begin{array}{l}\text { TYPE } \\
I * 4\end{array}$ & AOD. & NAME & SF $^{T A G}$ & $\begin{array}{l}\text { TYPE } \\
I * 4\end{array}$ & $\begin{array}{c}A 00 . \\
0000 B 0\end{array}$ \\
\hline
\end{tabular}

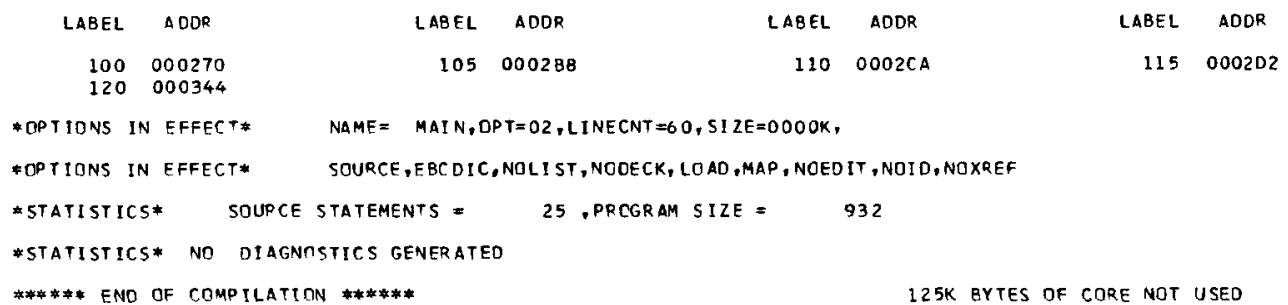

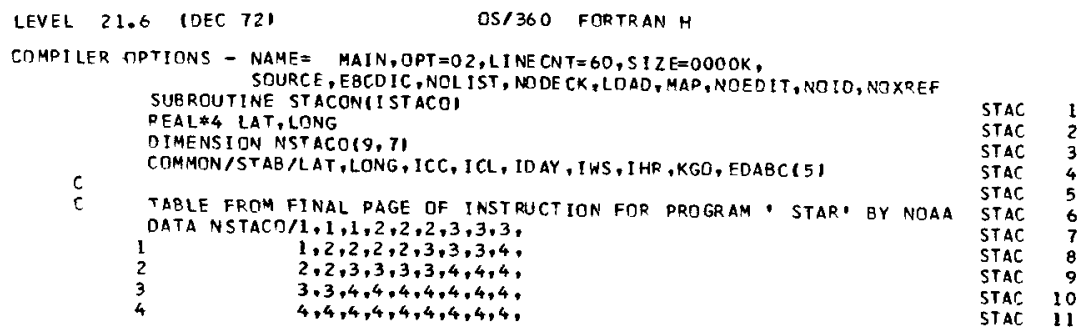




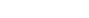

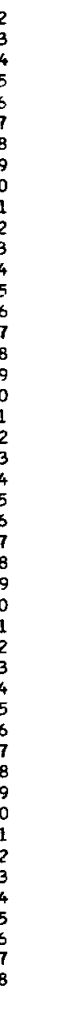


LEVEL 21.6 (DEC 721

DS/360 FORTRAN $H$

COMPILER APTIONS - NAME = MAIN, OPT $=02$, LINECNT $=60,5$ IZE $=0000 \mathrm{~K}$,

SOURCE, EBCDIC, NOLIST, NODECK, LOAD, MAP, NOEDIT, NOID, NOXREF SUERDUTINE PRISEIPR)

PRIS 10

C * * * * * * * * * * * * * ********* PRIS 30 11 "METEOROLOGICAL EFFECTS OF COOLING TOWER PLUMES", $\quad$ PRIS 40 $\begin{array}{lll}\text { S. R. HANNA, 1971, ATDL CONTRIBUTIUN } 48 \text {. } & \text { PRIS } 60 \\ \text { 3. } & \end{array}$ 2) "PLIIME RISE". G. A. BRIGGS, 1969, ATDL CONTRIBUTION 26. PRIS 70 C * 3) "PLUME RISE FROM MULTIPLE SOURCES", G. A. BRIGGS, *** PRIS 80

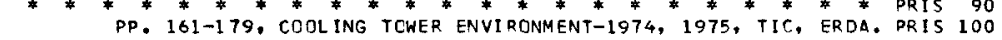
COMMON HT,WO,RO,ICON,TEO, U,XME,TPO. CELQ, FRACON,TOWERS, CLUSIZ PRIS 110 DATA G,CURT $/ 9.8066,0.333333333 /$ DATA TGI $/-0.0263,-0.0173,-0.01457,-0.01,0.00455,0.0263 / \quad$ PRIS 150 (CONI

PRIS 190

* * BUnYANCY FLUX, FBO. EQU. 3, REF. $1 . \quad$ PRIS 210 FBO*G*WO*RO*RO*11.-TEHT/TPO+DELQ*1.61+2454.*FR ACON/TPOII PR IS 220 IFIFBO.GE. O.I GO TO 110 PRINT 8000, TPO, TEHT

8000 FORMATI ONEGATIVE BUOYANCY FLUX, TPO= , F12.5, TEHT = 'F12.51 TEHT $=$ TPO

Gn to 100

110 CONTINUE

IFIU.LE.0.I GO TO 130

IF (ICON.GT.4) GO TO 160

$\mathrm{FBO4}=\mathrm{FBO} * 0.4$

$H=A M I N I I H T+304.81$

$X S=2.16 * F B \cap 4 * H * 0.6$

$X=A M I N I$ (XME, 3,0*XS)

120 CONTINUE

$C * \# \#$ EQU. $4.32 \prime$, REF. 2 。

$C * * * P R=$ PLUMF RISE, METERS.

Gก TO 140

130 CONTINUE 4.25 , REF. 1.

$*$ EQU. 4.25 , REF. 1 .
$P R=5.0 * S Q R T I S Q R T$ (FBO $/$ IS $\$ S Q R T(S) 111$

140 CONTINUE

IF IPR.GT.0.1 GO TO 150

8010 FORMATI'DNEGATIVE OR ZERO PLUME RISE: PR =',1PE12.41

150 CONTINUE

PATIO=CLUSI $2 / P R$

* * EQU. 12, PEF. 3.

* FAC T=6. \#RATIO* SORT(RATIO/TOWERS)

* * * EQU. 13 PEF 3

$P R=P R *($ IFACT+TOWERS I / (FACT+1.01)**CURT

PETURN

PRIS 230

PRIS 240

PRIS 260

PRIS 270

PRIS 280

PRIS 280

PRIS 300

DRIS 310

PRIS 320

PRIS 330

PRIS 340

PRIS 350

PR IS 360

PRIS 370

PRIS 380

PRIS 390

PRIS 400

DR IS 420

PRIS 420

PRIS 430

PRIS 440

PRIS 450

PRIS 460

PRIS 480

PRIS 490

PRIS 500

PR IS 510

PRIS 520

$\begin{array}{ll}\text { PRIS } & 520 \\ \text { PRIS } 530\end{array}$

PRIS 540

PRIS 550

PR IS 560

PRIS 570

$160 X=A M I N \geq(X M E, 2 \cdot 4 * U / S Q R T I S)$

ENO

1 PRISE $/$ SIZE OF PROGRAM O0045C HEXADECIMAL BYTES
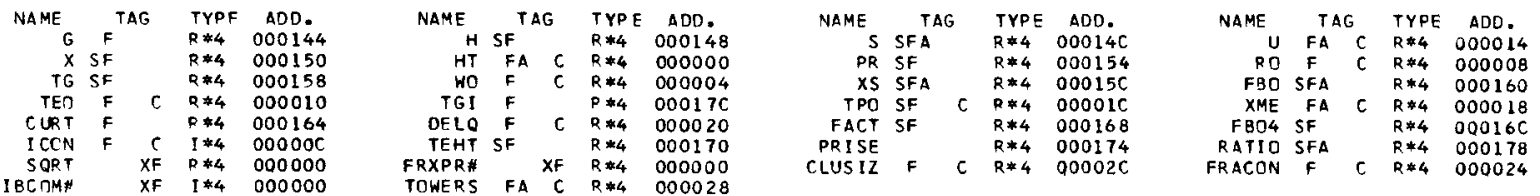

**** COMMCN I NFORMATION

$f \quad R=4,00178$

NAME OF COMMON BLOCK *

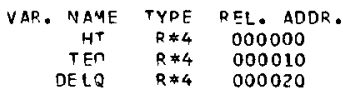

* SIZE OF BLOCK 000030 HEXADECIMAL BYTES

VAR. NAME TYPE REL. ADOR.

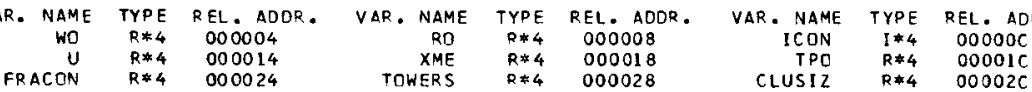

VAR. NAME TYPE REL. ADDR. 


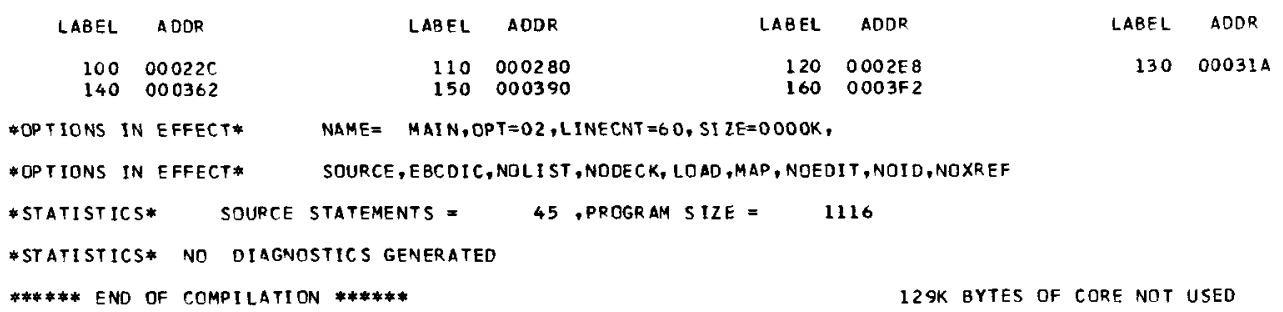

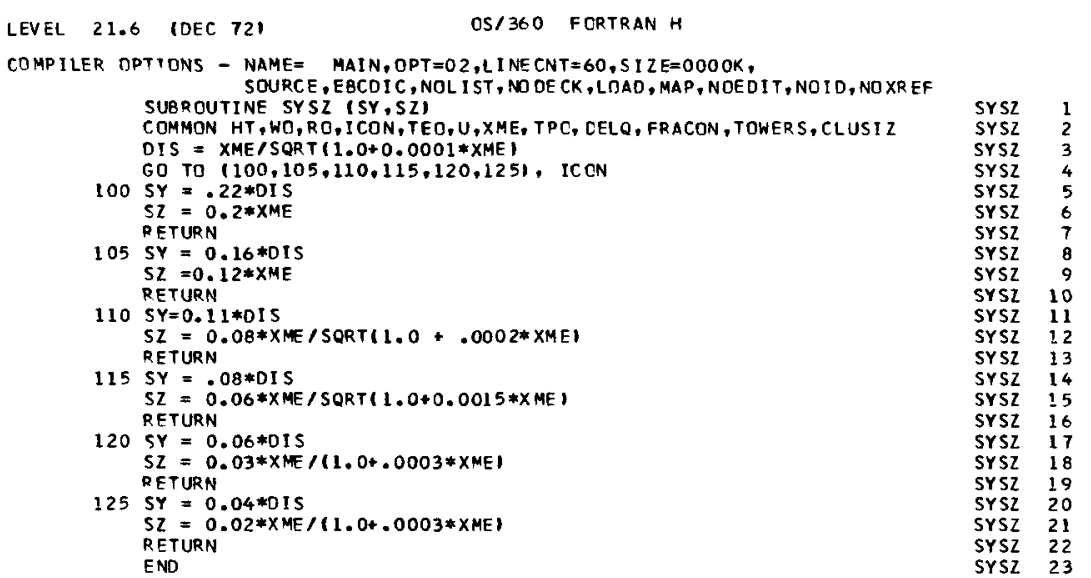

, SYSZ, SIZE OF PROGRAM O00200 HEXADEC JMAL BYTES

\begin{tabular}{|c|c|c|c|c|c|c|c|c|c|c|c|c|c|c|c|c|c|}
\hline $\begin{array}{c}\text { NAME } \\
\text { U } \\
\text { SZ S } \\
\text { TPO } \\
\text { SYSZ } \\
\text { TOWERS }\end{array}$ & ${ }_{\mathrm{C}}^{T A G}$ & $\begin{array}{l}\text { TYPE } \\
R * 4 \\
R * 4 \\
R * 4 \\
R * 4 \\
R * 4\end{array}$ & $\begin{array}{c}\text { ADD. } \\
\text { N.R. } \\
\text { OOOOEO } \\
\text { N.R. } \\
\text { OOOOEB } \\
\text { N.R. }\end{array}$ & $\begin{array}{r}\text { NAME } \\
\text { HT } \\
\text { HO } \\
\text { XME } \\
\text { SQRT }\end{array}$ & $\begin{array}{rl} & T A G \\
& C \\
& C \\
C A & C \\
X F & C \\
& C\end{array}$ & $\begin{array}{l}\text { TYPE } \\
R * 4 \\
R * 4 \\
R * 4 \\
R * 4\end{array}$ & 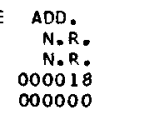 & $\begin{array}{r}\text { NAME } \\
\text { RO } \\
\text { DIS } \\
\text { DELO } \\
\text { CLUSIZ }\end{array}$ & & $\begin{array}{l}c \\
c \\
c \\
c\end{array}$ & $\begin{array}{l}\text { TYPE } \\
R * 4 \\
R * 4 \\
R * 4 \\
R * 4\end{array}$ & $\begin{array}{l}\text { ADO. } \\
\text { N.R. } \\
\text { OOOOE } \\
\text { N.R. } \\
\text { N.R. }\end{array}$ & $\begin{array}{r}\text { NAME } \\
\text { SY } \\
\text { TEO } \\
\text { ICON } \\
\text { FRACON }\end{array}$ & $F$ & $\Gamma A G$ & & 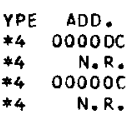 \\
\hline & & & & & & & SRMATT & $* * * * *$ & & & & & & & & & \\
\hline
\end{tabular}

name of common block * * Size of block 000030 hexadec imal bytes

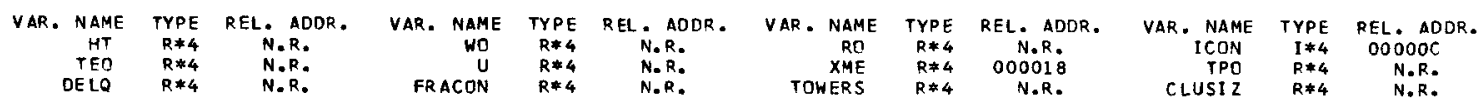

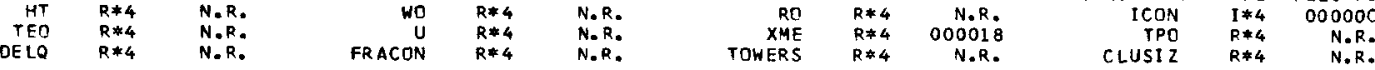

$\begin{array}{rrrrrrrr}\text { LABEL } & \text { ADOR } & \text { LABEL } & \text { ADDR } & \text { LABEL } & \text { ADDR } & \text { LABEL } & \text { ADOR } \\ 100 & 000158 & 105 & 000178 & 110 & 000198 & 115 & 0001 E 2 \\ 120 & 00022 C & 125 & 00025 A & 110 & & \end{array}$

*OPTIONS IN EFFECT* NAME $=$ MAIN, OPT $=02, L$ LNECNT $=60$, SI ZEE=0000K,

- OPTIONS IN EFFECT* SOURCE, EBCDIC, NOLIST, NODECK, LOAD, MAP, NCEDIT, NOID, NOXREF 


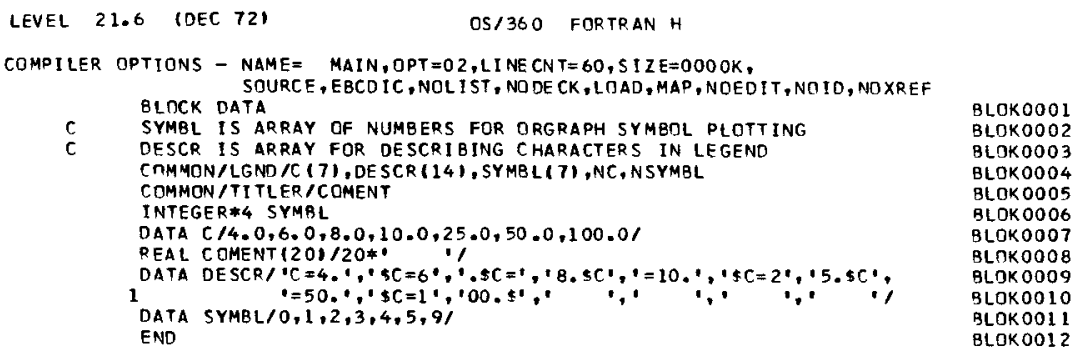

COMPILER OPTIONS - NAME = MAIN, OPT $=02, L I N E C N T=60,5 \pm Z E=0000 \mathrm{~K}$, SOURCE, EBCDIC, NOL IST, NO DE CK, LDAD, MAP, NOEDIT, NOIO, NOXREF BLDCK DATA

SYMBL IS ARRAY OF NUMBERS FOR ORGRAPH SYMBOL PLOTTING DESCR IS ARRAY FOR DESCRIBING CHARACTERS IN LEGENO C IMMON/LGND/C (7), DESCR $(14)$, SYMBLI 7$)$,NC, NSYMBL COMMON/TI TLER/COMENT INTEGER *4 SYMBL DATA C $/ 4.0,6.0,8.0,10.0,25.0,50.0,100.01 \quad$ BLOK0007

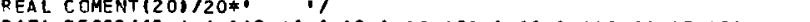

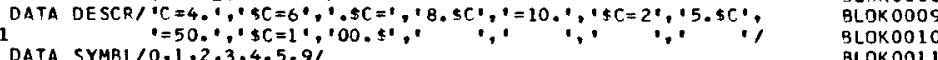
DATA SYMBL/ $0,1,2,3,4,5,91$

BLOK0012

, MAIN / SIZE OF PROGRAM O00008 HEXADECIMAL BYTES

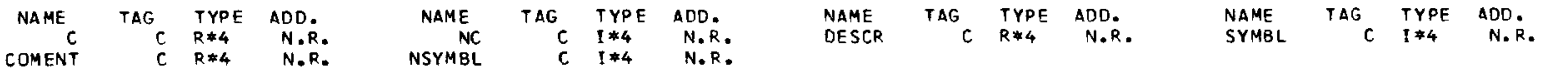
\#**** COMMON INFORMATION \#\#\#**

NAME OF COMMON BLOCK * LGND* SIZE OF BLOCK O00078 heXAdECIMAL bytes

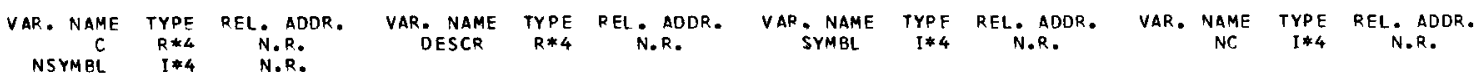

NAME OF COMMON BLOCK FTTLER SIZE CF BLOCK DOOOSO HEXADECIMAL BYTES

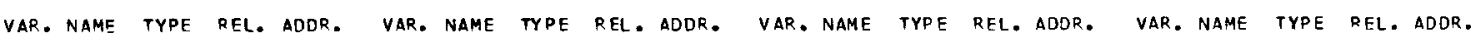

COMENT R*4 N.R.

*OPTIONS IN EFFECT* NAME $=$ MAIN,OPT $=02, L I N E C N T=60, S I Z E=0000 \mathrm{~K}$,

*DPTIONS IN EFFECT* SOURCE, EBCDIC,NOLIST, NODECK, LOAD, MAP, NOEDIT, NOID, NOXREF

* STATISTICS* SOURCE statements =

9 , PRCGRAM SIZE =

8

*STATISTICS* NO DIAGNOSTICS GENERATED

133K BYTES OF CORE NOT USED

LEVEL 21.6 (DEC 721

OS/360 FORTRAN H

COMPILER OPTIONS - NAME $=$ MAIN, OPT $=02$, L INECN T $=60,5$ I Z E $=0000 \mathrm{~K}$,

SOURCE, EBCDIC, NOLIST, NODECK, LDAD, MAP, NOEDIT, NOID, NOXREF

SUBROUTINE PREPIXNUM, IMAX,FF, F, ORIFT, TOPSI DE TERMINES CONTOUR LEVELS TO BE UEED AND SUPPLIES DATA FOR NORTH PREP

C AS DIRECTION 17

DTMENS ION FF( 1$), F(20,17)$, DRIFT $(17,19)$ NUMBER $=X N U M$ $\operatorname{TAP} S=0$.

SUM $=0$.

DO $100 \quad I=1,16$

100 SUM $=S U M+D R I F T(I, 1)$

SUM $=$ SUM 16 .

DO 110 IDIR $=1,16$

$F(1, I D I R)=S U$

$I D D X=I D I R+B$

IFIIDIR.GT: BI TDOX

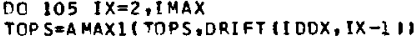

$105 \mathrm{~F}(1 \mathrm{X}, \mathrm{IDTR})=\mathrm{DR} I F T(I D D X,(X-1)$

110 CONTINUF

CONTINUF

DO 1 is I $X=1$, I MAX

$115 F(1 X, 17)=F(1 X, 1)$

$K=I F I X$ (ALOS, 1OITOPS),

IF(K.

$X T O P S=10 . * \# K$

$K=I F I X(T 0 P S / X T O P S)$

TOP $S=K * X T O P S$ 


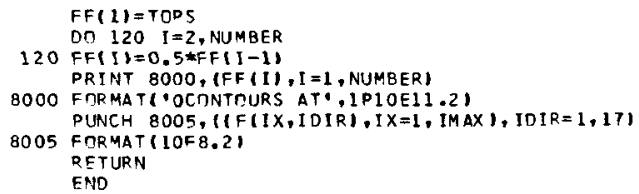

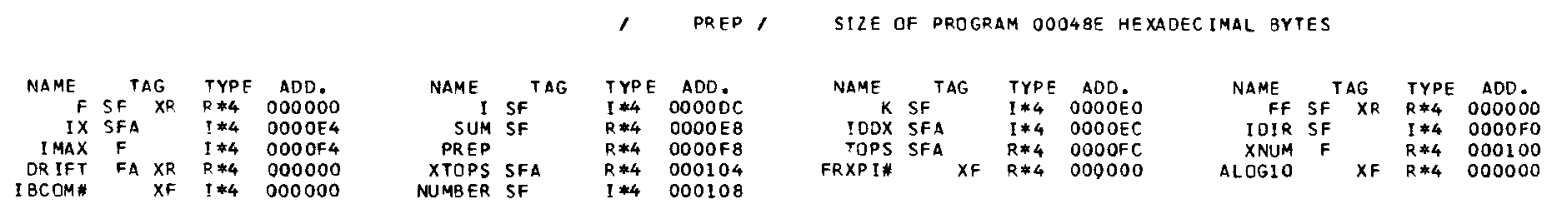

\begin{tabular}{|c|c|c|c|c|c|c|c|}
\hline LABEL & $A D O R$ & $\angle A B E L$ & $\triangle D O R$ & LABEL & $A D D R$ & LABEL & $A D D R$ \\
\hline $\begin{array}{l}100 \\
120\end{array}$ & $\begin{array}{l}0001 C 0 \\
00036 A\end{array}$ & 105 & $00025 E$ & 110 & 000268 & 115 & $00029 \mathrm{E}$ \\
\hline
\end{tabular}

*OPTICNS IN EFFECT* NAME $=$ MAIN, OPT $=02, L I N E C N T=60$, SI ZE $=0000 \mathrm{~K}$.

*OPTIONS IN EFFECT* SOURCE, EBCDIC,NDLIST, NODECK, LOAD,MAP, NOEDIT, NOID, NOXREF

*STATISTICS* SIURCE STATEMENTS = 36 , PROGRAM SIZE = 1166

* Statistics* no diagnostics generateo

****** END OF COMPILATION ******

125K GYTES OF CORE NOT USEO

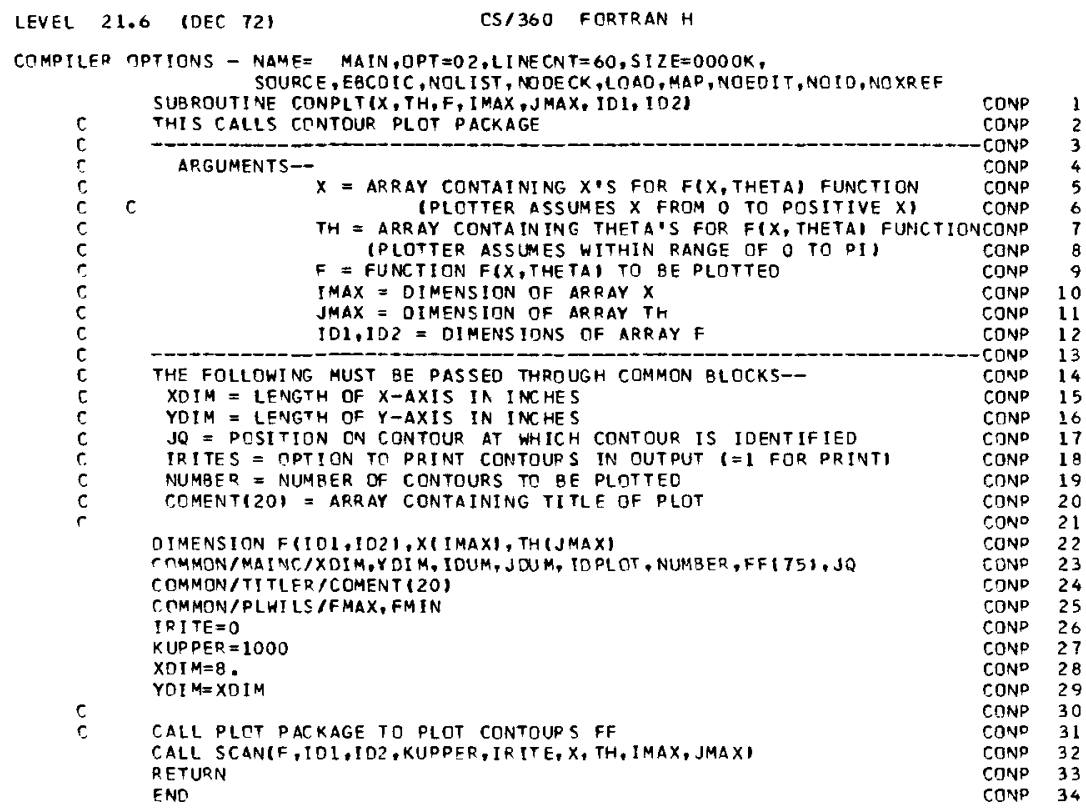


, CONPLT, SIZE OF PROGRAM OOOLF2 HEXADECIMAL BYTES
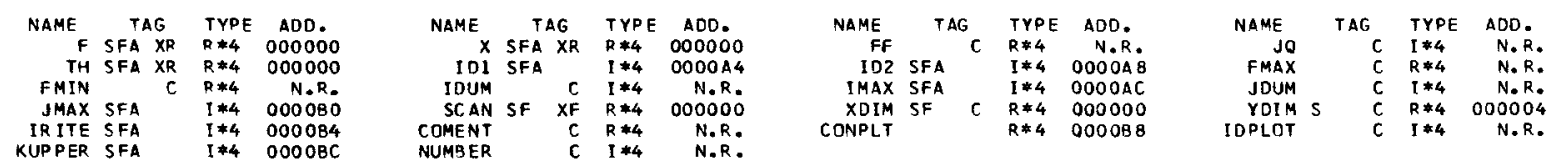

\section{***** COMMON INFORMATION \#****}

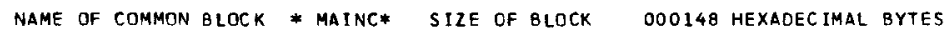

\begin{tabular}{|c|c|c|c|c|c|c|c|c|c|c|}
\hline $\begin{array}{l}\text { VAR. NAME } \\
\text { XDIM } \\
\text { IDPLOT }\end{array}$ & $\begin{array}{r}\text { TYPE } \\
R * 4 \\
I \$ 4\end{array}$ & $\begin{array}{c}\text { REL. ADDR . } \\
O 00000 \\
\text { N.R. }\end{array}$ & $\begin{array}{c}\text { VAR. NAME } \\
\text { YDIM } \\
\text { NUMBER }\end{array}$ & $\begin{array}{r}\text { TYPE } \\
R * 4 \\
1 * 4\end{array}$ & $\begin{array}{c}\text { REL. } A D D R \\
000004 \\
\text { N. R. }\end{array}$ & $\begin{array}{c}\text { VAR . NAME } \\
\text { IDUM } \\
\text { FF }\end{array}$ & $\begin{array}{r}T Y P E \\
I * 4 \\
R * 4\end{array}$ & $\begin{array}{c}\text { REL. } A D D R \text {. } \\
\text { N.R. } \\
\text { N.R. }\end{array}$ & VAR. $\underset{\substack{\text { JDUM } \\
\text { JO }}}{\text { NAME }}$ & $\begin{array}{l}\text { REL. } A D O R \text {. } \\
\text { N.R. } \\
\text { N.R. }\end{array}$ \\
\hline
\end{tabular}

NAME OF COMMON BLOCK *TITLER SIZE OF BLOCK O0OO50 hEXAOECIMAL BYTES

VAR. NAME TYPE REL. ADDR. VAR. NAME tYPE REL. ADDR, VAR. NAME TYPE REL. ADDR. VAR. NAME TYPE REL. ADDR. COMENT R*4 N.R.

NAME OF COMMON BLOCK *PLHILS* SIZE OF BLOCK O0000B HEXADECIMAL BYTES

VAR. NAME TYPE
FMAX
R*4

*OPTIONS IN EFFECT* NAME $=$ MAIN, OPT $=02, L I N E C N T=60$, SI ZE $=0000 \mathrm{~K}$,

* OPTIONS IN EFFECT* SOURCE, EBCDIC, NOLIST, NODECK, LCAD, MAP, NOEDIT, NOIO, NOXREF

*STATISTICS* SOURCE STATEMENTS = 12 ,PRCGRAM SIZE = 498

* Statistics* no diagnostics generateo

****** END OF COMPILATION ******

133K BYTES OF CORE NOT USED

LEVEL $21.6 \quad$ COEC 721

OS/360 FORTRAN

COMPILER DPTIONS - NAME $=$ MAIN, OPT $=02, L I N E C N T=60, S I Z E=0000 \mathrm{~K}$,

SOURCE, EBCDIC, NOLIST, NODECK, LOAD, MAP, NOEDIT, NOID, NOXREF

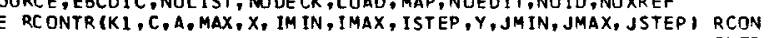

THE CONTOUR PLOTTING ROUTINE USES THE "ORGRAPH" PLOTTING PACKAGE CNTR

ORNL-4596
EACH CALL TO "RCONTR" MUST BE PRECEEDED BY A CALL TO "FIXPLT"

SEE "ORGR APH" MANUAL FOR USE OF "FIXPLT"

ARRAYS:

$X(N X) \& Y(N Y)$ DEFINE THE GRID POINTS FROM WHICH

XYINX,NY) DATA POINTS MILL HAVE A CONTOUR PLOT GENERATED

CINC) CINTAINS THE CONTOUR LINE VALUES WHICH WILL BE PLOTTEO

IN THE CALL TO MRCONTR";

CALL RCONTR (NC, C, XY, NX, X, NXF, NX, NOLTX,Y, NYF, NY, NDLTYI

VALUES OF $X(I X)$, YIIY),E XY (IX, IY) WHICH HILL BE USEO ARE

DE TERMI NED BY DO LOOPS

DO - I X $=$ NXF, NX, NDLTX

VALUES OF C(NC) ARE SET UP IN THE BLOCK. DATA ROUTINE

IF A LEGEND IS DESIREO SYMBL (NC) \& CESCR (--) MUST ALSO BE SET UP IN THE BLOCK DATA ROUT INE ISEE INCLUDEO EXAMPLE "ORGRAPH" MANUAL

OESCR IS ARRAY FOR DEFINING SYMBOLS IN THE LEGEND DE SCR MUST BE DIMENSIONED L AR GE ENOUGH TO HOLO

NC TITLES IEACH FOLLOWED OY "S") FOR THE LEGEND

SYMBL IS ARRAY OF NUMBERS FOR ORGRAPH SYMBOL PLOTTING

SYMBL MUST BE OIMENSIONED AT LEAST NC

CALL TO "T ITLE" MAY BE REMOVED

SEE "ORGPAPH" MANUAL FOR USE DF "TTTLE"

A LEGEND IS PRODUCED IF "NSYMBL," IS GREATER OR EQUAL TO 0

"PLID" IDENTIFIES PLOT WITH DATE, HASP LOG NUMBER, $\varepsilon$ THE

TIME AT WHICH JOB WAS EXECUTED

LANGUAGE ROUTINE

EXAMPLE OF DATA AS SET UP IN BLOCK DATA

OATA C/20,0,40,0,80,0,160,0,320,0,640,0,1280,0

OATA OESCR/ $C=20.05 C=40.0$
DATA SYMBL $10,1,2,3,4,5,91$

ADAPTED FROM LAHRENCE RADIATICN LAB REPORT CIC-NC.3-003

ASSUMES THAT A(I, J) $=F C N(X\{1), Y(J))$

DIMENSION A(MAX,1), C(11), X (1), Y(1)

COMMON JOTOUAD/XC(2),YC(2),ZC $(4), 2 M I N, Z M A X, K K 1$ 


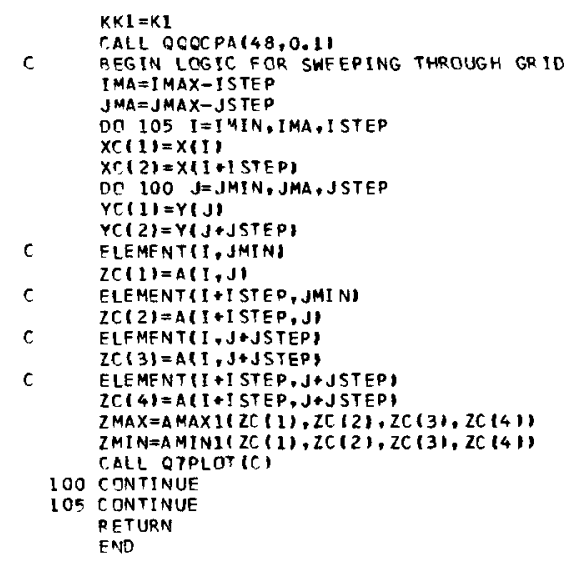

NAME DF COMMON BLOCK *Q70UAD* SIZE OF BLOCK 00002C HEXADECIMAL BYTES

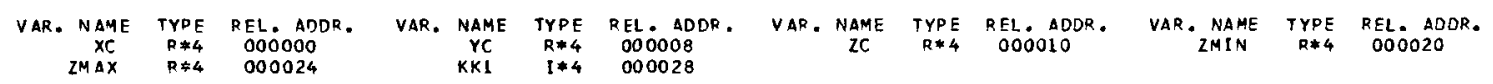
$\begin{array}{rrr}X C & R * 4 & 000000 \\ Z M A X & R \div 4 & 000024\end{array}$

COMPILER OPTIONS - NAME = MAIN,OPT $=02, L I N E C N T=60,51 Z E=0000 \mathrm{~K}$,

\begin{tabular}{|c|c|}
\hline & LTR I \\
\hline $\begin{array}{l}\text { COMMON/CONT II, I SAVE, JSAVE,KSAVE, X(2,50),Y(2,50),CL } \\
\text { DIMENS ION Z(KM,KN), C(KNCL) }\end{array}$ & LTR I \\
\hline$k=K$ SAVE & LTR1 \\
\hline$I=I$ SAVE & LTRI \\
\hline$J=J S A V E$ & LTRI \\
\hline
\end{tabular}




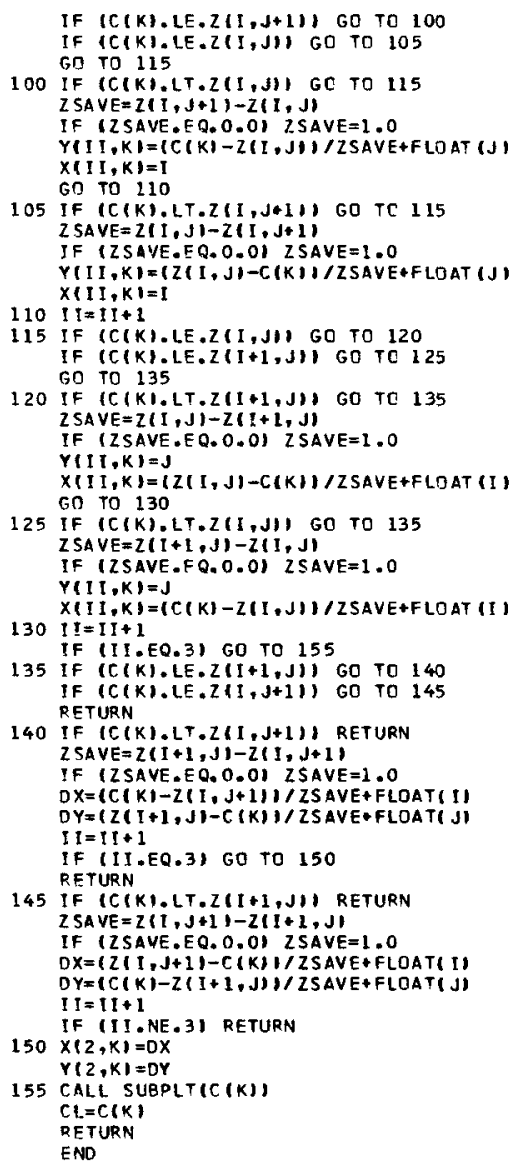

NAME TAG TYPE ADD. $\begin{array}{ccccc}\text { JSAVE } & F & C & 1 * 4 & 000008 \\ \text { SUBPLT } & \text { SF } & X F & R * 4 & 000000\end{array}$

***** COMMON INFORMATION
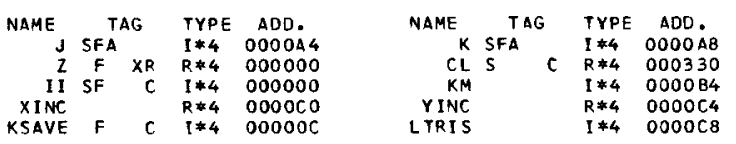

******

NAME OF COMMON BLOCK * CONT* SIZE OF BLOCK 000334 HEXADEC IMAL BYTES

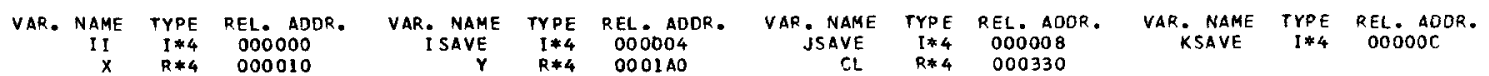

$\begin{array}{rcrcrrrr}\text { LABEL } & \text { ADDR } & \text { LAREL } & \text { ADOR } & \text { LABEL } & \text { ADOR } & \text { LABEL } & \text { ADDR } \\ 100 & 000144 & 105 & 000248 & 110 & 00020 C & 115 & 0002 E 8 \\ 120 & 00032 E & 125 & 00030 A & 130 & 00046 E & 000482 \\ 140 & 0004 B 8 & 145 & 00056 C & 150 & 000620 & 135 & 000638\end{array}$

\#OPTIONS IN EFFECT* NAME $=$ MAIN, OPT $=02, L I N E C N T=60$, SI $2 E=0000 \mathrm{~K}$, 
*OPTIONS IN EFFECT* SOURCE, EBCDIC,NOLIST, NODECK, LOAD,MAP, NOEOIT, NOID, NOXREF
*STATISTICS*
STURCE STATEMENTS =
82 , PROGRAM SIZE =
1768

* Statistics* nO Diagnostics generated

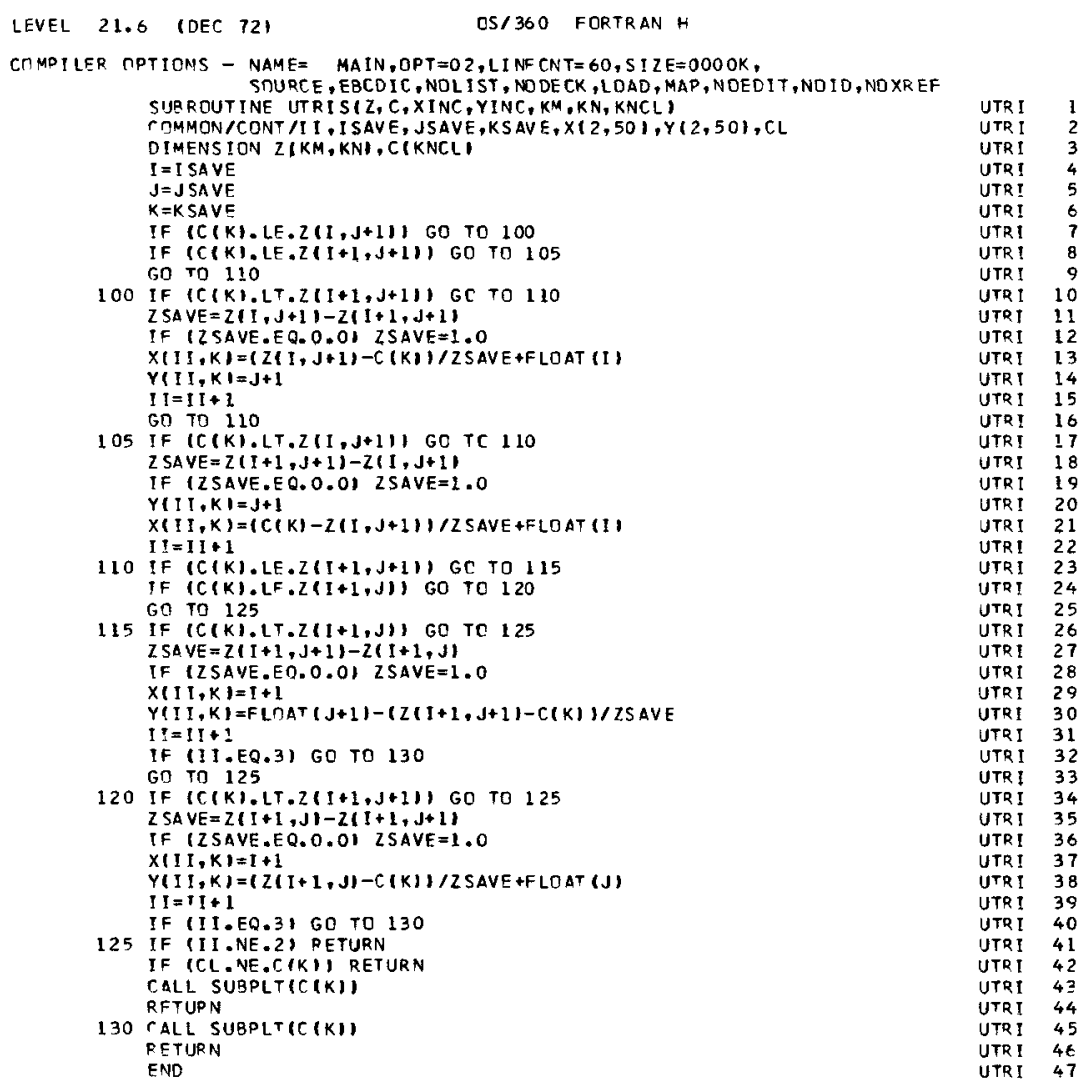

, UTRIS, SIZE OF PROGRAM OOOS9A HEXADECIMAL BYTES

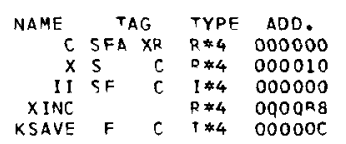

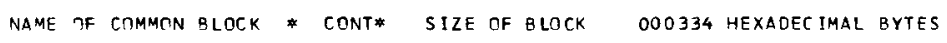

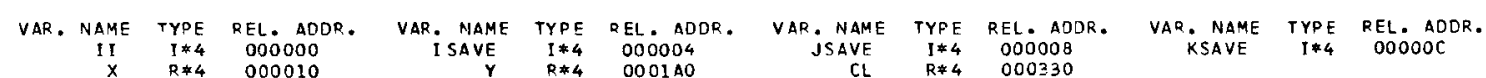




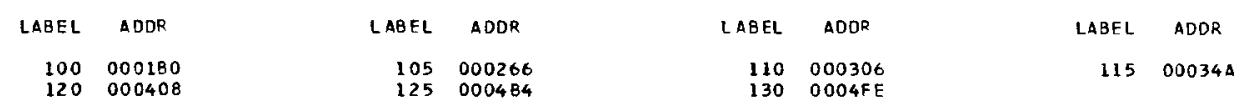

*OPTIONS IN EFFECT* NAME $=$ MAIN,OPT $=02, L$ LINECNT $=60, S 1 Z E=0000 \mathrm{~K}$,

\#OP TIONS IN EFFEC T* SOURCE, EBCDIC, NOLIST, NODECK, LDAD, MAP, NOEDIT, NOID, NOXREF

*STATISTICS* SOURCE STATEMENTS $=\quad 63$, PRCgram SIZE = 1434

* statistics* no oingnostics generated

****** END DF COMPILATION *******

I21K BYTES OF CORE NOT USED

LEVEL 21.6 IDEC $721 \quad$ CS/360 FORTRAN H

COMDILER OPTIONS - NAME $=$ MAIN, OPT $=02, L I N E C N T=60$, S1ZEE=0000K,

SOURCE, EBCDIC, NOL IST, NODE CK, LOAD, MAP, NOEOI T, NOID, NO XREF SUBROUTI NE OTPLOTICNI

DIMENSION CN(1), C(50)
COMMON $/ Q 7$ QUAD $X(2), Y(2), Z(2,2), Z M I N, Z M A X, K L$

IF (ZMAX.EQ.ZMIN) RETURN

IF ICNTII.GT. ZMAXI RETURN

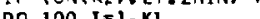

IF ICNIII,GE.ZMIN) GO TO 105

100 CONTINUE

DO 00 CONTINUE $110 \mathrm{~J}=1, \mathrm{KL}$.

110 CONTINUE

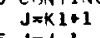

$115 \mathrm{~J}=\mathrm{J}-1$

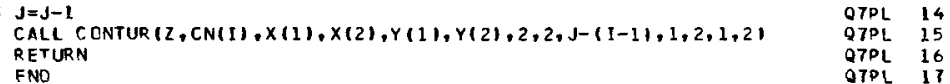

, OTPLOT , SIZE OF PROGRAM 000250 HEXADECIMAL BYTES

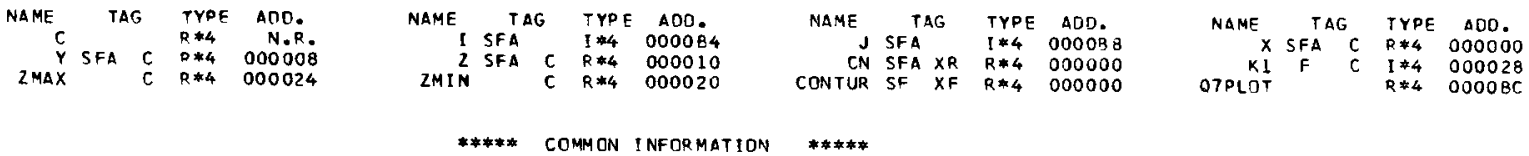

NAME OF COMMON BLOCK \#QTQUAD* SIZE OF BLOCK O0002C HEXADECIMAL BYTES

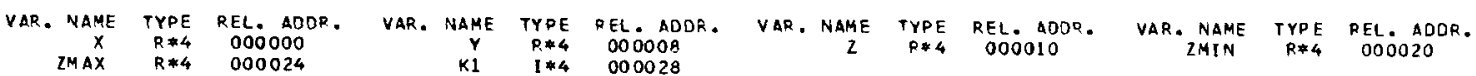


LeVEL 21.6 IOEC 721

OS/360 FORTRAN H

COMPI LER OPTIONS - NAME $=$ MAIN, OPT $=02, \angle I N E C N T=60,5$ S ZZE=0OOOK,

SOURCE, EBCDIC, NOL IST, NODECK, LOAD, MAP, NOEDIT, NO IO, NOXREF SUBROUTINE CONTUR IZ, C, PIMIN, PIMAX, P ZMIN, P ZMAX, M, N, NCL, MMIN,

1 MMAX, NMIN, NMAXI

COMMONCONT I ISAVE, JSAVE, KSAVE, X $(2,50), Y(2,50), C L$ COMMON/SUBT XINC, YINC, PMINI, PMIN

$K M=M$
$K N=N$

KNCL=NCL

XINC= (PIMAX-PIMINI/FLOATIMMAX-MMINI

YINC= (P2MAX-PZMINI/FLOAT IMAXX -NMINI

PMINI $=$ PIMIN

PMINZ $\approx$ P $2 M I N$

MMA MMA X-1

NN $=$ NMAX $X-1$

DO 190 J J NMT N, NN

185 I $=M M I N, M M$

$k=1$

100 IF $(Z(I, J), G E . Z(1+1, J))$ GO TO 110

AMAX $=2(I+1, J)$

105 IF (AMAX.LT.Z(I,J+1) AMAX $=211, \mathrm{~J}+11$ Go in 115

110 AMAX $=2(1, J)$

IF $(2(1, J) \cdot L E \cdot 2(I+1, J))$ GC TO 125

AMI $N=Z(I+1, J)$

20 iF (AMIN.GT.Z1T, J+1) AMIN=Z(I, J+1) $G 0$ TO 130

125 AMINEZ $(1, \mathrm{~J})$
GO TO 120

130 IF (CCK).GT.AMAX) GO TO 135

If (CIKI.LT.AMIN) GO TO 135

JSAVE $=\sqrt{ }$

I SAVE $=$ I

KSAVE $=K$

135 IF $(211, \mathrm{~J}+1), G E . z(1+1, \mathrm{~J}+1) 1$ GO TO 145 AMAX $=2(1+1, j+11$

140 IF (AMAX.LT.ZCI+1, J1) AMAX $=Z(I+1, J)$ GO TO 150

145 AMAX $=2(1, J+1)$

150 IF $(Z 1$ I J J II).LE.ZII+1,J+1I) GO TO 160

AMI $N=2(1+1, j+1)$

155 IF (AMIN.GT.ZII+1,J) AMIN=Z(I+1, J)

GO TO 165

160 AMI $N=2(I, J+1)$

GO TO 155

165 IF (CIKI.LT.AMIN) GO TO 170

JSAVE $=J$

ISAVE
KSAVE

GO TO 180

$170 k=k+1$

IF (K.LE.NRL) GO TO 100

GO TO 185

175 CALL LTRISIZ, C, XINC, YINC, KM, KN, KNCLI $I I=1$

180 CALL UTRIS(Z,C,XINC, YINC, KM, KN, KNCL, $I=1$

$$
\text { TOO TO } 170
$$

185 CONTINUE

CONTINUE
RETURN

END
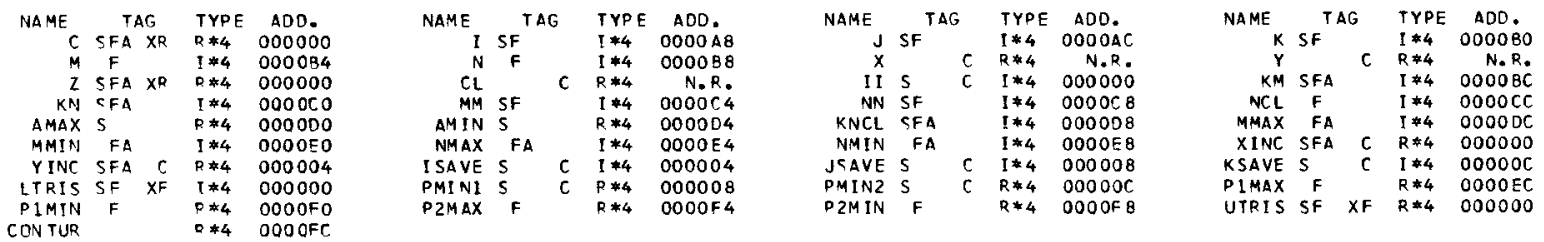

***** COMMON INFRR,MATION

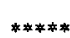

NAME DF CIMMTN BLOCK * CONT* SIZE OF BLOCK 000334 HEXADECTMAL BYTES 


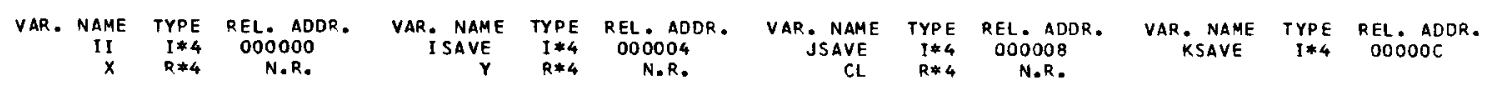

NAME OF COMMON BLOCK * SUB* SIZE OF BLOCK OOOOI0 HEXADECIMAL BYTES

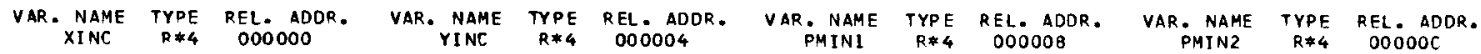

$\begin{array}{rcrcrrrr}\text { LABEL } & \text { ADDR } & \text { LABEL } & \text { ADDR } & \text { LABEL } & \text { AODR } & \text { LABEL } & \text { ADOR } \\ 100 & 0002 C 2 & 105 & 0002 E 4 & 110 & 0002 F C & 115 & 000308 \\ 120 & 00031 C & 125 & 000334 & 130 & 000340 & 1155 & 000368 \\ 140 & 006386 & 145 & 00039 E & 150 & 0003 A 4 & 155 & 00038 E \\ 160 & 000306 & 165 & 0003 E 2 & 170 & 0003 F E & 175 & 000414 \\ 180 & 000426 & 185 & 000438 & 190 & 000448 & & \end{array}$

*OPTIONS IN EFFECT* NAME $=$ MAIN,OPT $=02, L I N E C N T=60$, SI ZE $=0000 \mathrm{~K}$,

*OPTIONS IN EFFECT* SOURCE, EBCDIC,NOLIST, NODECK, LOAD, MAP, NOEDIT, NDID, NOXREF

* STATISTICS* SOURCE STATEMENTS $=77$, PRCGRAM SIZE = 1368

* STATISTICS* No Diagnostics generateo

LEVEL 21.6 (OEC 72$)$

OS/360 FORTRAN H

COMPILER OPTIONS - NAME $=$ MAIN, OPT $=02, L I N E C N T=60, S I Z E=0000 \mathrm{~K}$, SOURCE, EBCDIC, NOL IST, NODECK, LOAD, MAP, NOEDIT, NOID, NOXREF
SONS - NAME SUBROUTINE SUBPLT (CC)

COMMON COMMON/LGNO /C 171 , DE SCR 141, , SYMEL 171 , NC, NSYMBL

$S Y M B=-1.0$

IF (NSYMBL. LT. O) GO TO 110

OD 100 ISYMEI, NC

IF ICC.EO.CIISYMII GO TO 105

100 CONTINUE

105 CONTINUE

110 K=KSAVE

$J j=2$

IFIII E EO.2) J J $=$

DO $115 \mathrm{I}=1, \mathrm{JJ}$

$X(I, K)=(X(I, K)-1.0) * X I N C+P M I N 1$

$Y(I, K)=(Y(I, K)-1,0) * Y I N C+P M I N 2$

$V(I)=X(I, K)$

115 CONTINUE

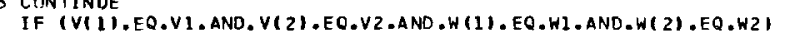

IF IVIII.EO

IF IVII).EO.VI21.AND.WIII.EQ.W(2I) $N=1$

$V 1=V(1)$

$V 2=V(2)$

$W 1=W(1)$

IF (YI2).GE.V(1)) GO TO 120

$V P(1)=V I 21)$

VP $(2)=V(1)$

$H O(1)=H(2)$

$W P(2)=H(1)$

CALL LINPLT (VP, WP, $N, S Y M B, 0)$

PRINT 8000 , VP, WP, SYMB

SUBP 35

8000 FORMAT (' $V(1)=9,1 P E 10.3, \cdot V(2)=1, E 10.3,+W(1)=1, E 10.3, \quad 3$

$1 \quad H(2)=+, E 10.3, \cdot$ SYMB=1,I5),

SUBP 39

$\begin{array}{ll}20 \text { CALL LINPLTIV, H,N,SYMB,OI } & \text { SUBP } 40 \\ \text { PRINT BOOO,V,W,SYMB } & \text { SUBP } 41\end{array}$

$\begin{array}{lrl}\text { RETURN } & \text { SUBP } & 42 \\ \text { ENO } & \text { SUGP } & 43\end{array}$ 


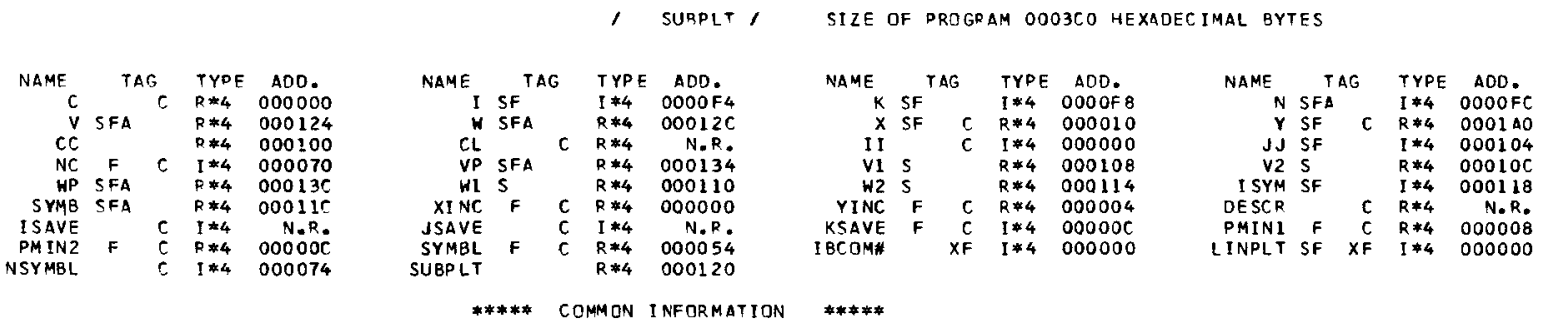

NAME DF COMMON BLOCK * SUB* SIZE CF BLOCK 000010 heXAdeC IMAL Bytes

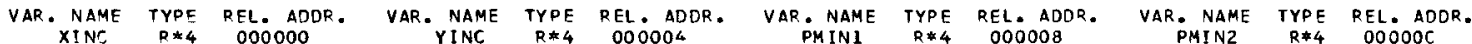

NAME OF COMMON BLOCK * CONT* SIZE OF BLOCK 000334 HEXADECIMAL BYTES

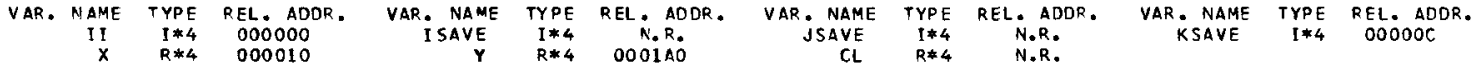

NAME OF COMMON BLOCK * LGND* SIZE OF BLOCK O00078 HEXADECIMAL BYTES

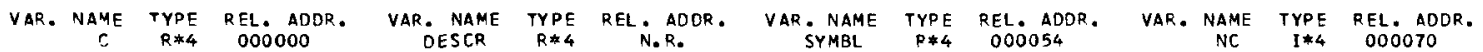
$\begin{array}{ccccccccccc}C & R * 4 & 000000 & \text { DESCR } & R * 4 & \text { N.R. } & \text { SYMBL } & P * 4 & 000054 & \text { NC } & \text { I*4 } \\ \text { NSYMBL } & I * 4 & 000074 & & & & & & & & \end{array}$

$\begin{array}{rlrlrrrr}\text { LABEL } & \text { ADOP } & \text { LABEL } & \text { ADOR } & \text { LABEL } & \text { ADOR } & \text { LABEL } & \text { ADOR } \\ 100 & 0001 C 8 & 105 & 000102 & 110 & 0001 E 2 & 115 & 000264 \\ 120 & 000350 & 105 & & \end{array}$

*OPTIONS IN EFFFCT* NAME $=$ MAIN,OPT=02, LINECNT $=60$, SIZE $=0000 \mathrm{~K}$,

* OPTIJNS IN EFFECT* SOURCE, EBCDIC, NOLIST, NODECK, LOAD, MAP, NOEOIT, NOI D, NOXREF

*STATISTICS* SNURCE STATEMENTS = 47 . PROGRAM SIZE = 960

* STATISTICS* No dIAgNDStics generateo

\#***** END OF COMPILATION ******

125K BYTES OF CORE NOT USEO

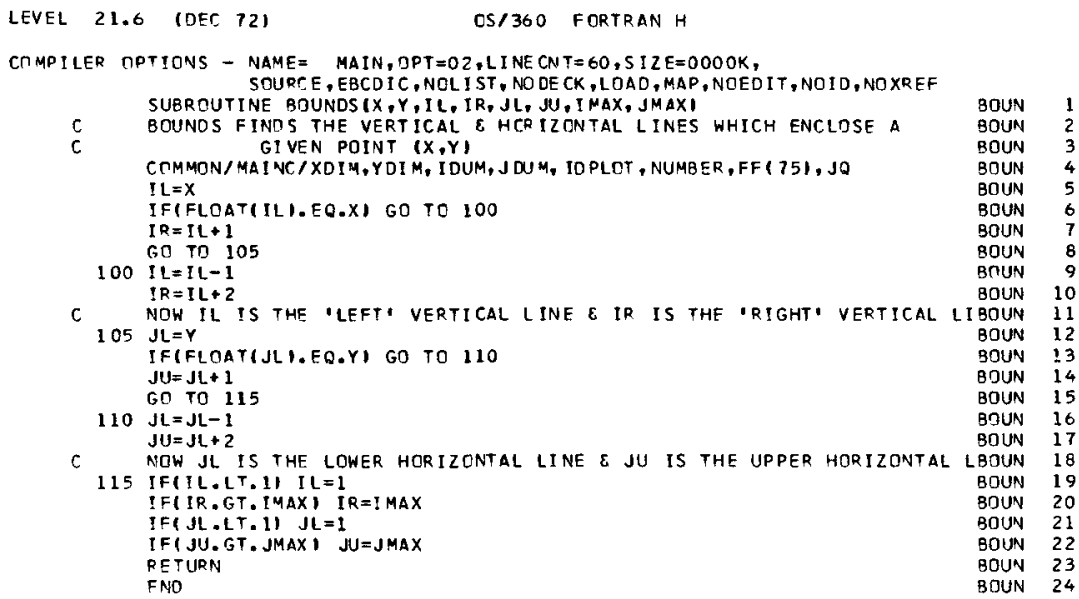


, BOUNOS, SIZE OF PROGRAM O00258 HEXADEC
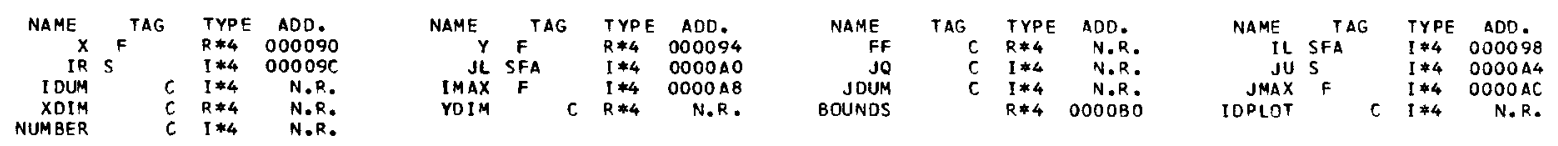

***** COMMON INFORMATION ******

name of common block * mainc* Stze of block 000148 hexagecimal bytes

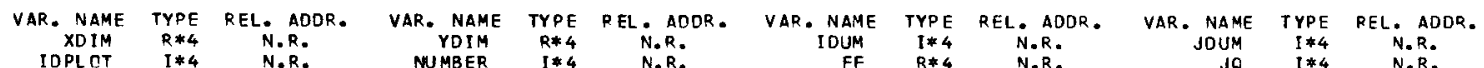

$\begin{array}{rlrcrrrr}\text { LABEL } & \text { ADDR } & \text { LABEL } & \text { ADOR } & \text { LABEL } & \text { ADDR } & \text { LABEL ADDR } \\ 100 & 00011 \mathrm{E} & 105 & 00012 \mathrm{E} & 110 & 000180 & 115 & 000190\end{array}$

*OPTIONS IN EFFECT* NAME $=$ MAIN,OPT $=02, L I N E C N T=60$, SI ZE $=0000 \mathrm{~K}$,

*OPTIONS IN EFFECT* SOURCE, EBCDIC, NOLIST, NODECK, LOAD, MAP, NOEDIT, NOID, NOXREF

* STATISTICS* SOURCE STATEMENTS = 26 .PRCgRaM SIZE = 600

* Statistics* no diagnostics generated 


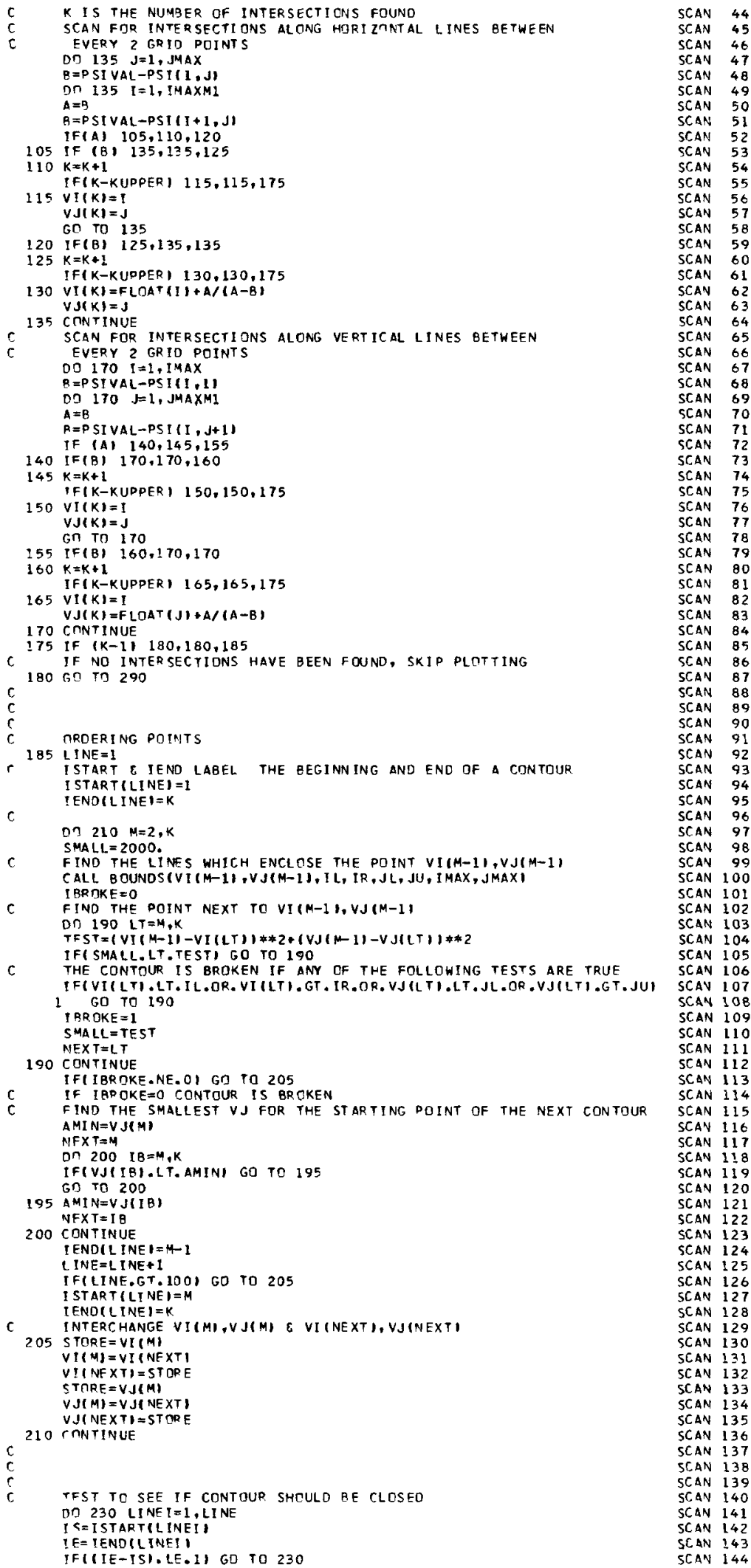




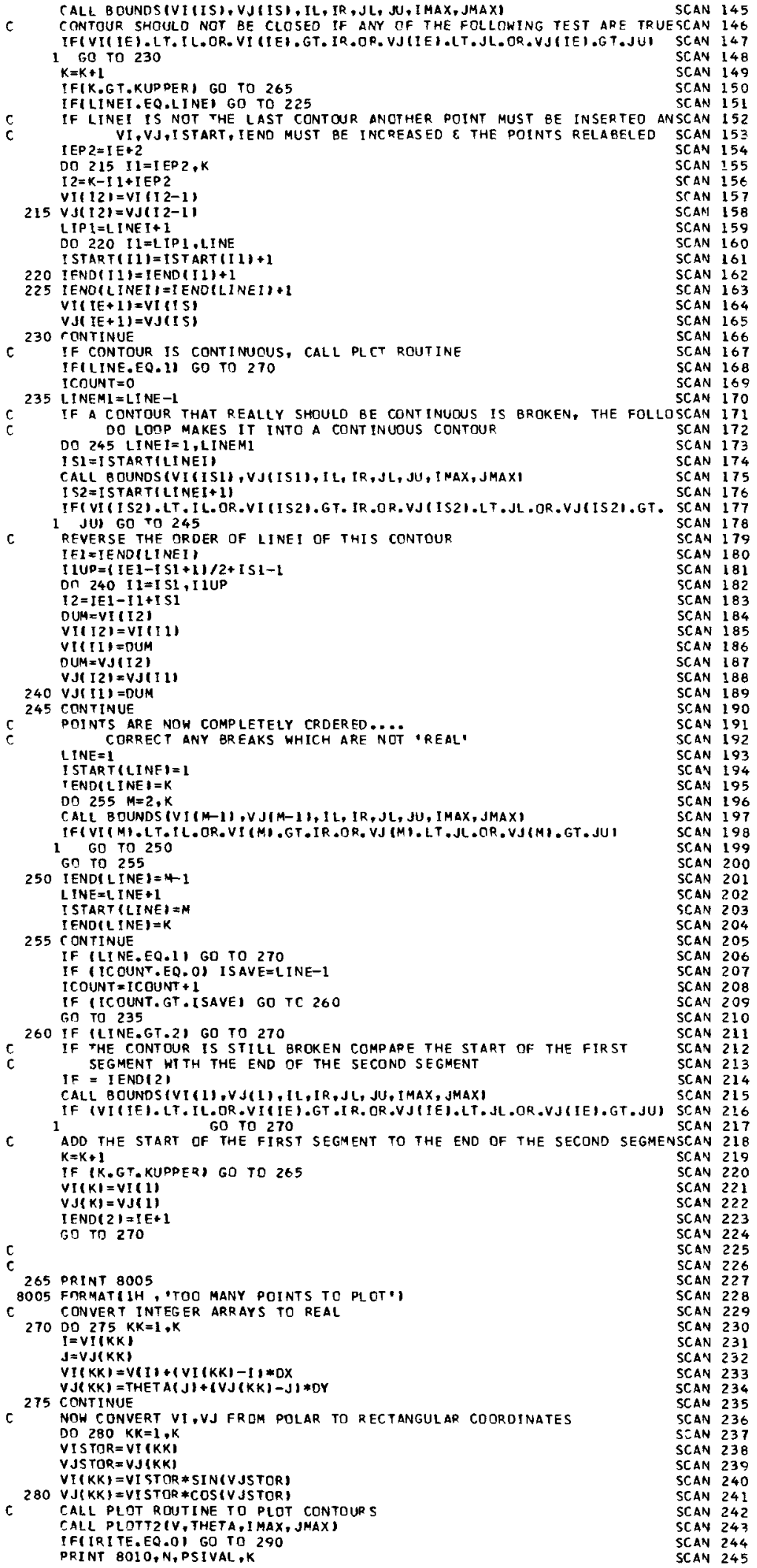



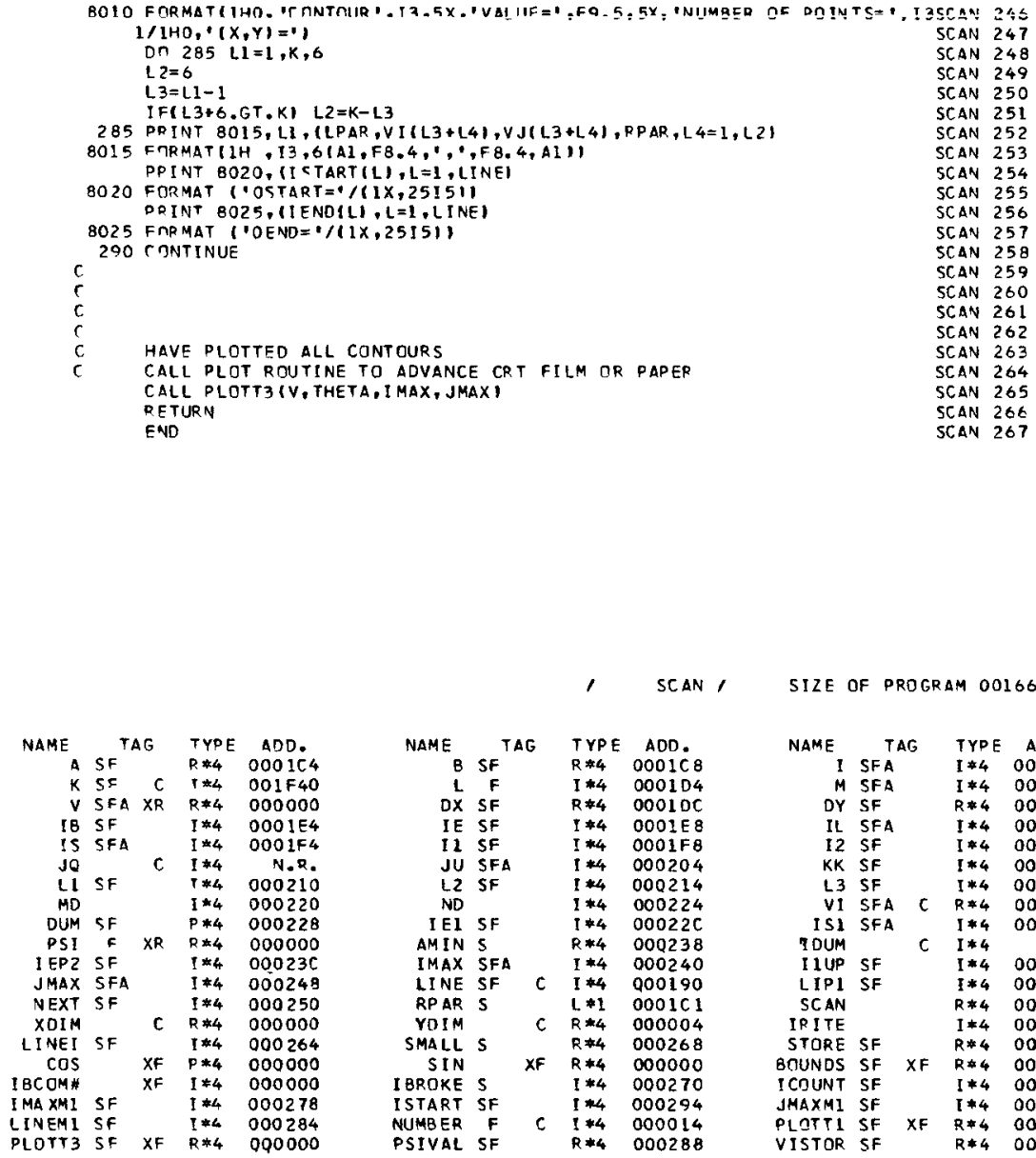

\begin{tabular}{|c|c|c|c|c|}
\hline & & & 1 & SCAN \\
\hline NAME & & G & TYPE & $A D D$. \\
\hline$B$ & SF & & $R * 4$ & $0001 C_{8}$ \\
\hline$i$ & $F$ & & $I * 4$ & 000104 \\
\hline$D \bar{x}$ & SF & & $R * 4$ & $00010 \mathrm{C}$ \\
\hline $\mathrm{IE}$ & SF & & $I \neq 4$ & $0002 E 8$ \\
\hline 12 & SF & & $I * 4$ & $0001 F B$ \\
\hline ju & SFA & & $I * 4$ & 000204 \\
\hline 12 & SF & & $I * 4$ & 000214 \\
\hline ND & & & $1 * 4$ & 000224 \\
\hline I EI & SF & & $I * 4$ & $00022 \mathrm{C}$ \\
\hline AMIN & S & & $R * 4$ & 000238 \\
\hline I MAX & SFA & & $I * 4$ & 000240 \\
\hline IINE & SF & c & $I \neq 4$ & 000190 \\
\hline RP AR & 5 & & $L * 1$ & $0001 C 1$ \\
\hline YDIM & & $c$ & $R * 4$ & 000004 \\
\hline SMALL & s & & $R \neq 4$ & 000268 \\
\hline SIN & & $\mathbf{x F}$ & $R * 4$ & 000000 \\
\hline I BROKE & s & & $I * 4$ & 000270 \\
\hline ISTART & SF & & $1 * 4$ & 000294 \\
\hline NUMB ER & $F$ & c & $1 * 4$ & 000014 \\
\hline VAL & SF & & $R * 4$ & 000288 \\
\hline
\end{tabular}

SIZE OF PROGRAM 001666 HEXADECIMAL BYTES PAGE OOG
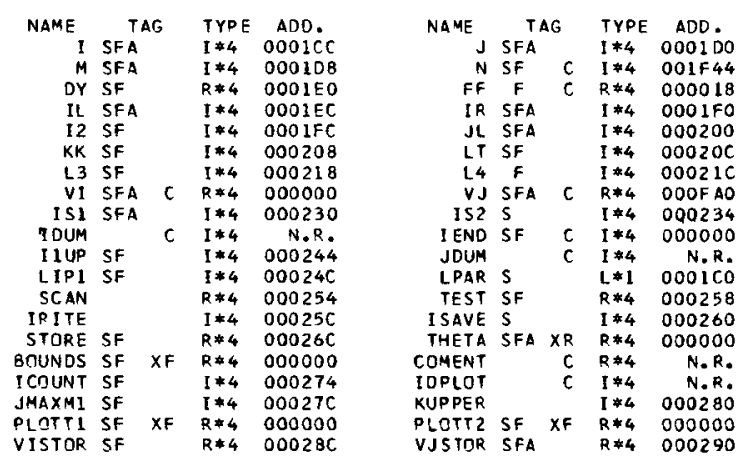

COMMEN I AFORMATION

VISTOR SF R R $00028 \mathrm{C}$

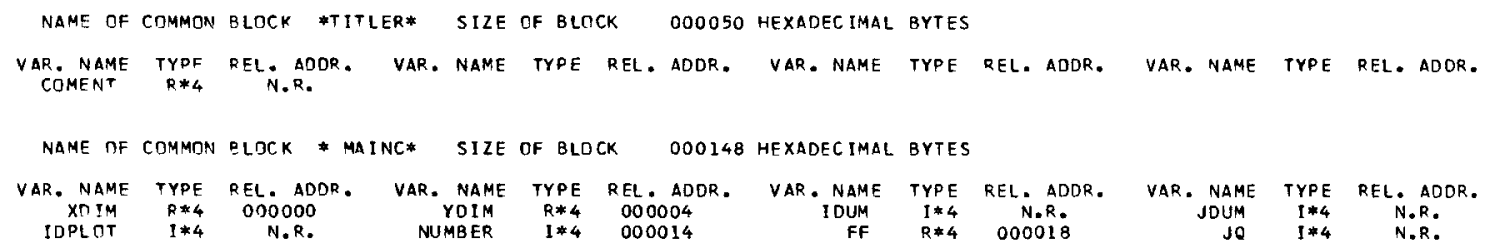

LABEL ADDR

$100 \quad 000528$

$120 \quad 000608$

$140 \quad 000826$

$\begin{array}{ll}160 & 000880 \\ 180 & 000936\end{array}$

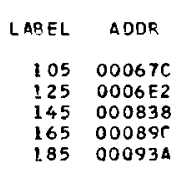

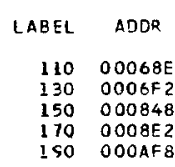

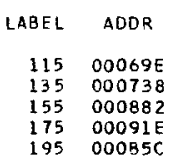




\begin{tabular}{|c|c|c|c|c|c|c|c|}
\hline $\begin{array}{l}200 \\
220 \\
240 \\
260\end{array}$ & $\begin{array}{l}000860 \\
\text { Q0ODC2 } \\
000 F 06 \\
001188\end{array}$ & $\begin{array}{l}205 \\
225 \\
245 \\
265\end{array}$ & $\begin{array}{l}\text { OOOBAE } \\
\text { OOODDO } \\
000 F \text { EO } \\
001204\end{array}$ & $\begin{array}{l}210 \\
230 \\
250 \\
270\end{array}$ & $\begin{array}{l}\text { OOOBDA } \\
000 E 06 \\
001112 \\
0012 F 0\end{array}$ & $\begin{array}{l}215 \\
235 \\
255 \\
275\end{array}$ & $\begin{array}{l}000078 \\
000 E 50 \\
00113 E \\
0013 C 0\end{array}$ \\
\hline
\end{tabular}

*OPTIONS IN EFFECT* NAME $=$ MAIN,OPT $=02$, LINECNT $=60$, SI ZE $=0000 \mathrm{~K}$,

*OPTIONS IN EFFECT* SOURCE, EBCDIC,NOLIST, NODECK, LOAD, MAP, NOEOIT, NOID, NOXREF

*STATISTICS* SOURCE STATEMENTS $=213$, PROGRAM SIZE $=5734$

*STATISTICS* NO DIAGNOSTICS genERATED

****** ENO OF COMPILATION ******

85K BYTES OF CORE NOT USED

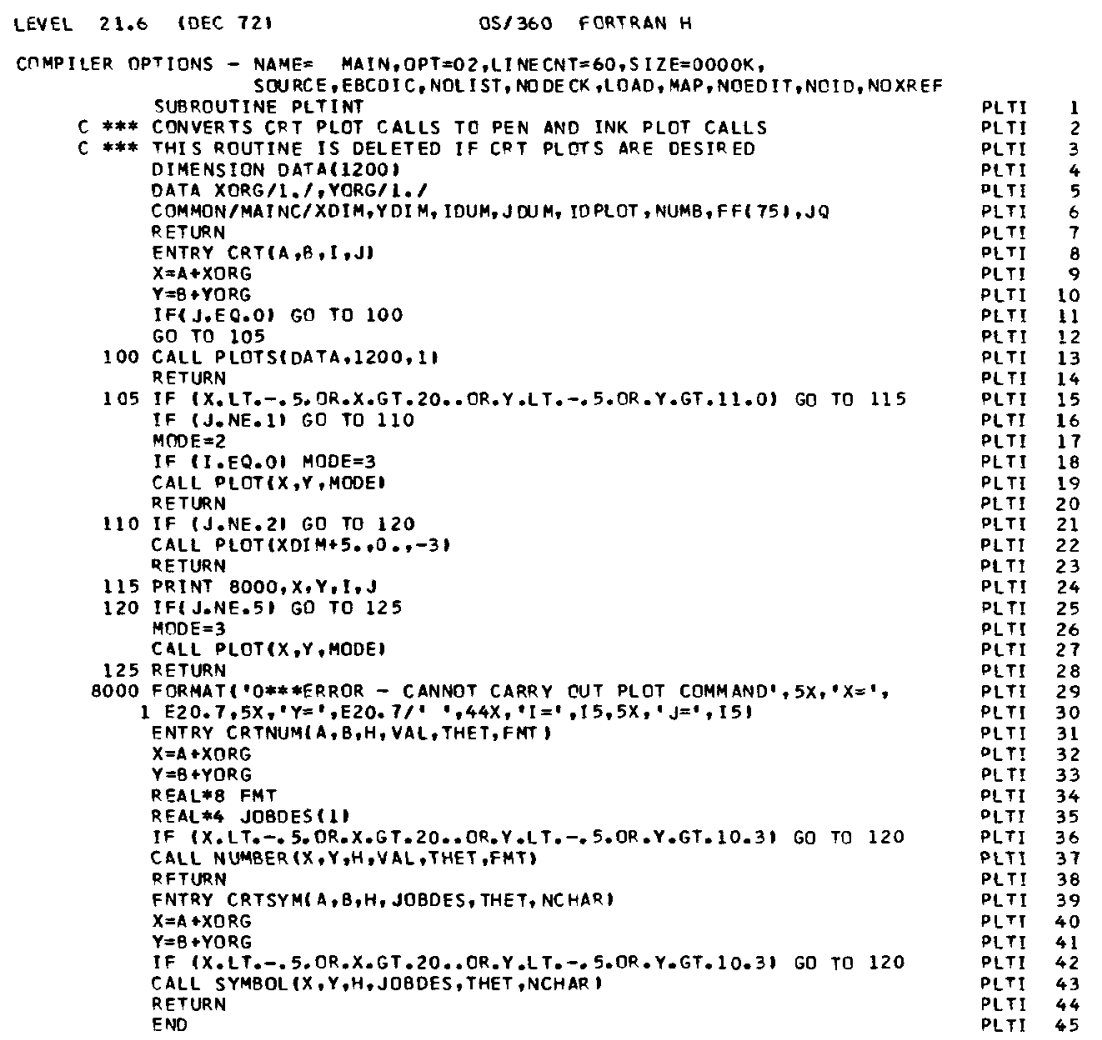

, PLTINT, SIZE OF program oOIBCa hexadec Imal bytes
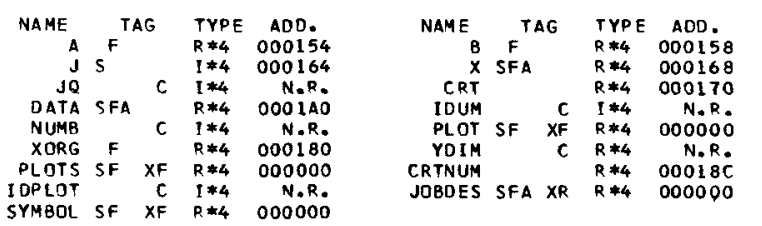
NAME TAG TYPE ADD.
$\begin{array}{llll}H & S F A & R * 4 & 00015 \mathrm{C}\end{array}$
$\begin{array}{rlll}Y & \text { SFA } & R * 4 & 00016 C \\ \text { FMT SFA } & R * 8 & 000198\end{array}$
FMT SFA $C \quad \begin{aligned} & R * 8 \\ & 1 * 4\end{aligned}$
$\begin{array}{llll}\text { THET SFA } & 1 * 4 & N * R \text {. } \\ \text { YHA } & 000 I 7 C\end{array}$
YORG $F \quad R * 400018$
CRTSYM R R*4 Q00190
NUMBER SF XF $1 * 4$ 000000
NAME TAG TYPE ADD.
$\begin{array}{clcc}1 & S \\ \text { FF } & & 1 * 4 & 000160 \\ R * 4 & N . R \text {. }\end{array}$
VAL SFA R*G 000174
MODE SFA $1 * 4 \quad 000178$
XOIM SFA C R $\$ 4$ O00000
NCHAR SFA I $\$ 4000188$
IBCOM\# XF I $* 4 \quad 000000$




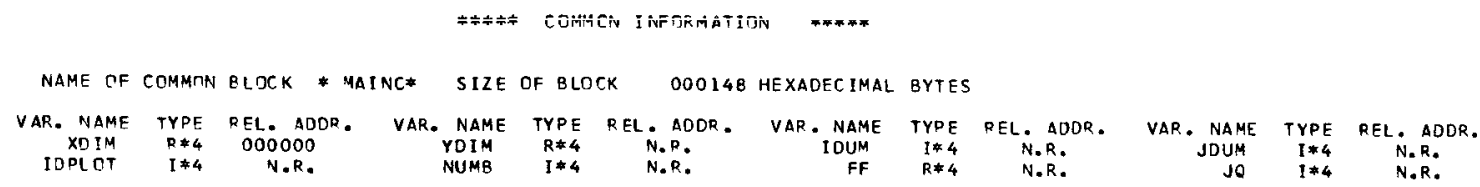

\begin{tabular}{|c|c|c|c|c|c|c|c|}
\hline LABEL & $A D D F$ & LABEL & ADOR & LABEL & ADOR & LABEL & $A D D R$ \\
\hline $\begin{array}{l}100 \\
120\end{array}$ & $\begin{array}{l}0014 \mathrm{~F} 2 \\
0015 \mathrm{C}\end{array}$ & 105 & 001504 & 110 & 001566 & 115 & 001592 \\
\hline
\end{tabular}

*OPTIONS IN FFFECT* NAME $=$ MAIN,OPT $=02, L I N E C N T=60,51 Z E=0000 \mathrm{~K}$,

*OPTIONS IN EFFECT* SOURCE, EBCDIC, NOLIST, NODECK, LOAD, MAP, NCEOIT, NOIO, NOXREF

* STATISTICS* STURCE STATEMENTS = 50 , PRCgRAM SIZE = 6346

*STATISTICS* No DIAGNOSTICS gENERATED

*\#**** END OE COMPILATION ******

125K BYTES OF CORE NOT USED

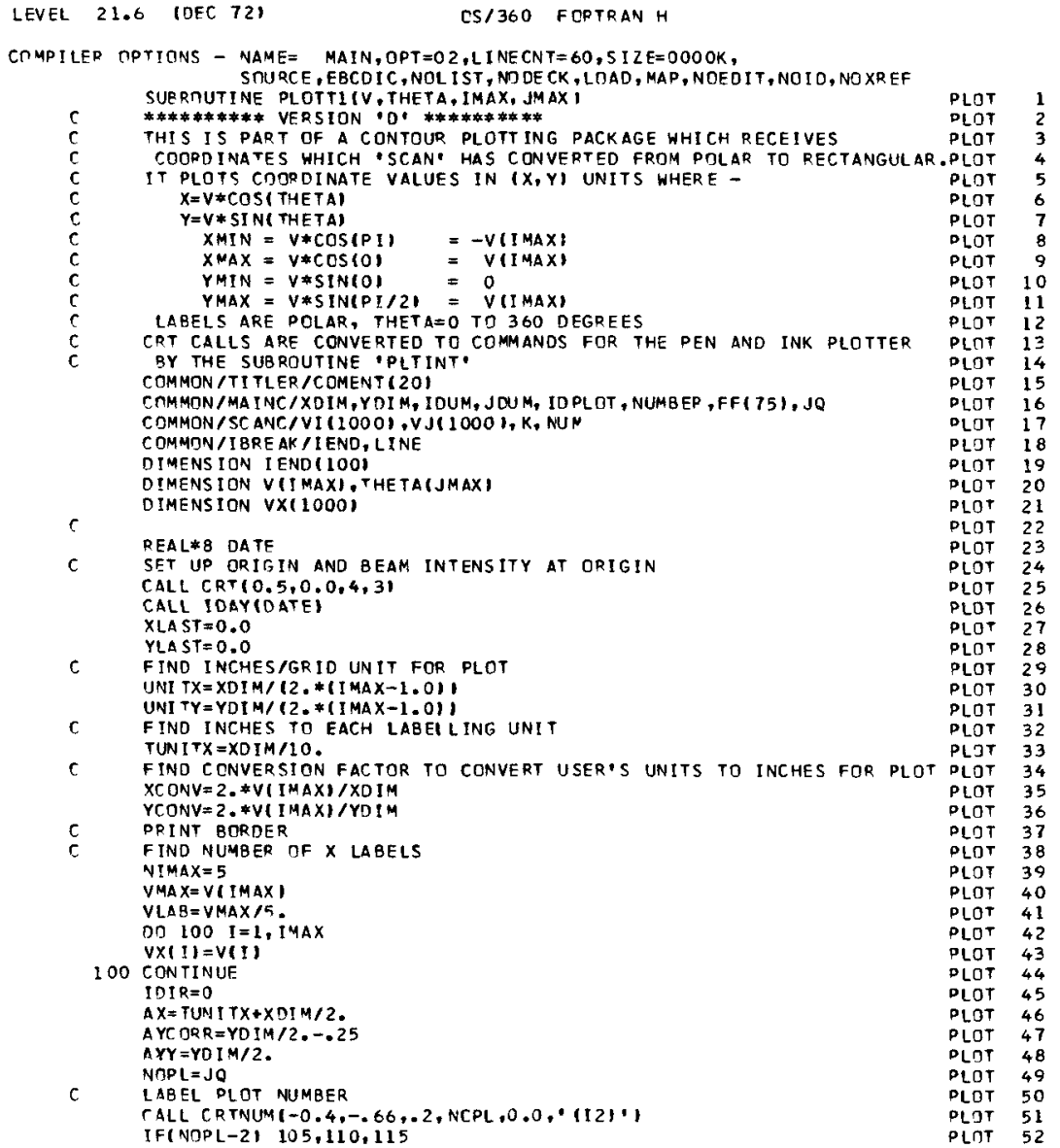


105 CALL CRTSYMC $0.4,-.66, .2, \cdot$ AMOUNT OF DRIFT',0.0, 15 ,

GO TO 125

10 CALL CRTSYM10,8,-066,2,0HOURS OF FOG $, 0,0,121$

GO TD 125

115 IFINOPL 31 GO TO 120

CALL CRTSYM10.8,-.66,.2, 'HCURS OF ICE', 0.0,121

GO TO 125

120 CALL CRTSYM10.8,-.66, 2, SALT IN AIR $1,0.0 .121$

125 NPLOT=O

FIND LaBel at ORIGIN IX LaBel, and PLot $A X P L=V \times(1)$

IF IIDIR.EQ.01 GO TO 135

$A X=-T U N I T X+X D I M / 2$

I $D I R=1$

135 GO TO 140

CALL CRTNUMIXX, AYCORR, $0.1, A X P L, 0,0,1 / F 5,21,1$

$140 \times X=X D I M / 2$.

MOVE BEAM TO $V=0$

CALL CRTIXX,AYY,0,1

DO $160 \mathrm{~N}=1$, NI MAX

C DRAH LINE TO NEXT LABEL

CALL CRTIAX,AYY,20,11

DRAW TICK MARK AT POINT TO BE LABELLLED

CALL CRTSYMIAX, AYY, 0.1,3,0.0,-21

$A X P L=N * V L A B$

IF IAXPL.GE.100.1 GO TO 145

C AXCORR=AX-.14257

PRINT LABEL UNDER TICK MARK
CALI CRTNUMIAXCORR, AYCORR, 0.1, AXPL, $0.0, \cdot(F 5.2) \cdot 1$ CALL CRTNUM

$145 A X C O R R=A X-.17107$

CALL CRTNUMIAXCORR, AYCORR, 0.1, AXPL, $0.0,1(F 6.2), 1$

C MDVE BEAM BACK TO $X$-AXIS

50 CALL CRTIAX,AYY,O,1)

IF (IDIR.EO.1) GO TO 155

$A X=A X+T U N I T$

60 TO 160

$155 \triangle X=A X-T U N I T X$

160 CONTINUE

$C$ FINISH DRAWING $X$-AXIS

IF IIOIR.EQ.1) GO TO 165

CALL CRTIXD IM, AYY, 20,10 GO TO 130

165 CALL CRT 0.0, AYY, 20,11

CALL CRTIXDIM, AYY

C LABEL 90 DEGREE LINE

I OGREE $=90$

$X X=X D I M+.1$

$Y Y=A Y Y-$.

CALL CRTNUMIXX,YY,0.1, IDGREE, $0.0, \cdot(12) \cdot)$ DRAW $0-180$ DEGREE LINE

$X X=.5 * X D I M$

CALL CR $Y Y=Y D I M$

CALL CRT $X X, Y Y, 20,1)$

LABEL 0-180 DEGREE LINE

$X X=.5 * X D I M-.11407$

$Y Y=Y D I M+.1$

CALL CRTNUM $(X X, Y Y, 0.1$, IDGREE, 0.0, 1121 ,

IDGREE $=180$

$X L=X X$

CALL CRTNUM $(X L, Y L, 0,1,1$ IDGREE, $0.0, \cdot(13) 1)$

C DRAW 45 AND 225 DEGREE LINES

$x X=, 5 * X O I M$

CALL CRTIXX,AYY, 0,1

XRAD $=V$ (IMAX) $/ X$ CONV

$S I D E=S Q R T(X R A O * * 212$.

$X X=S I D E+X D I M / 2$.

$Y Y=A Y Y+S I D E+$.

CALL CRTIXX,YY, 20,11

$X X 1=.5 * X 01 M$

CALL CRT (XX1, AYY,0,1)

$X X 1=X D I M / 2,-S I D$

$Y Y I=A Y Y-S I D E$

C CALL CRTIXX1,YY1,20,1I

$X L=X X+.15$

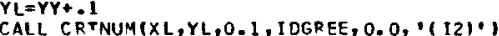

I DGREE $=225$

$X$ DEREE $=225$

$X \mathrm{~L}=X X 1-.2$

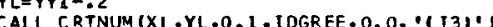

C DRAH 135 DEGREE AND 315 DEGREE LINE

$X X=.5 * X D I M$

CALL CRTIXX,AYY, 0,1

$X X=X D I M / 2,-S I O E$

$X X=X O T M / 2$.
$Y Y=A Y Y+S I D E$

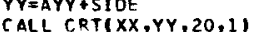

$X X 1=.5 * X D I M$

CALL CRT $X X 1, A Y Y, 0,11$

$X X 1=X D I M / 2 .+S 1 D$

$Y Y 1=A Y Y-S I D E$

C LALL CRT $(X X 1, Y Y 1,20,11$ 1

IDGREE $=315$

PLOT 53

PLOT 54
PLOT 55

PLOT 56

PLOT 57

PLOT 58

PLOT 59

PLOT 60

PLDT 61

PLOT 63

PLOT 64

PLOT 65

PLOT 66

PLOT 67

PLOT 68

PLOT 69
PLOT 70

PLOT 71

PLOT 72

PLOT 73

PLOT 74 .

PLOT 76

PLOT 77

PLOT 78

PLOT 79

PLOT 81

PLOT 82

PLOT 83

PLOT 84

PLOT 86

DLOT 87

PLOT 88

PLOT 89

PLIT 90
PLOT 91

PLOT 92

PLOT 93

PLOT 94

PLOT 95

PLOT 96

PLOT 97

PLOT 98

PLOT 99

PLOT 100

PLOT 102

PLOT 103

PLOT 104

PLOT 105

PLOT 106

PLOT 107

PLOT 108

PLOT 110

PLOT 111

PLOT 112

PLOT 113

PLOT 114

PLOT 115

PLOT 116

PLOT 117

PLOT 119

PLOT 120

PLOT 120

PLOT 122

PLOT 123

PLOT 124

PLOT 125

PLOT 126

PLOT 127

PLOT 12

PLOT 129

PLOT 130

PLOT 132

PLOT 133

PLOT 134

PLOT 135

PLOT 136

PLOT 137

PLOT 138

PLOT 140

PLOT 140

PLOT 142

PLOT 143

PLOT 144

PLOT 145

PLOT 146

PLOT 147

PLOT 148

PLOT 149

PLOT 150

PLOT 151

PLOT 152

PLOT 153 


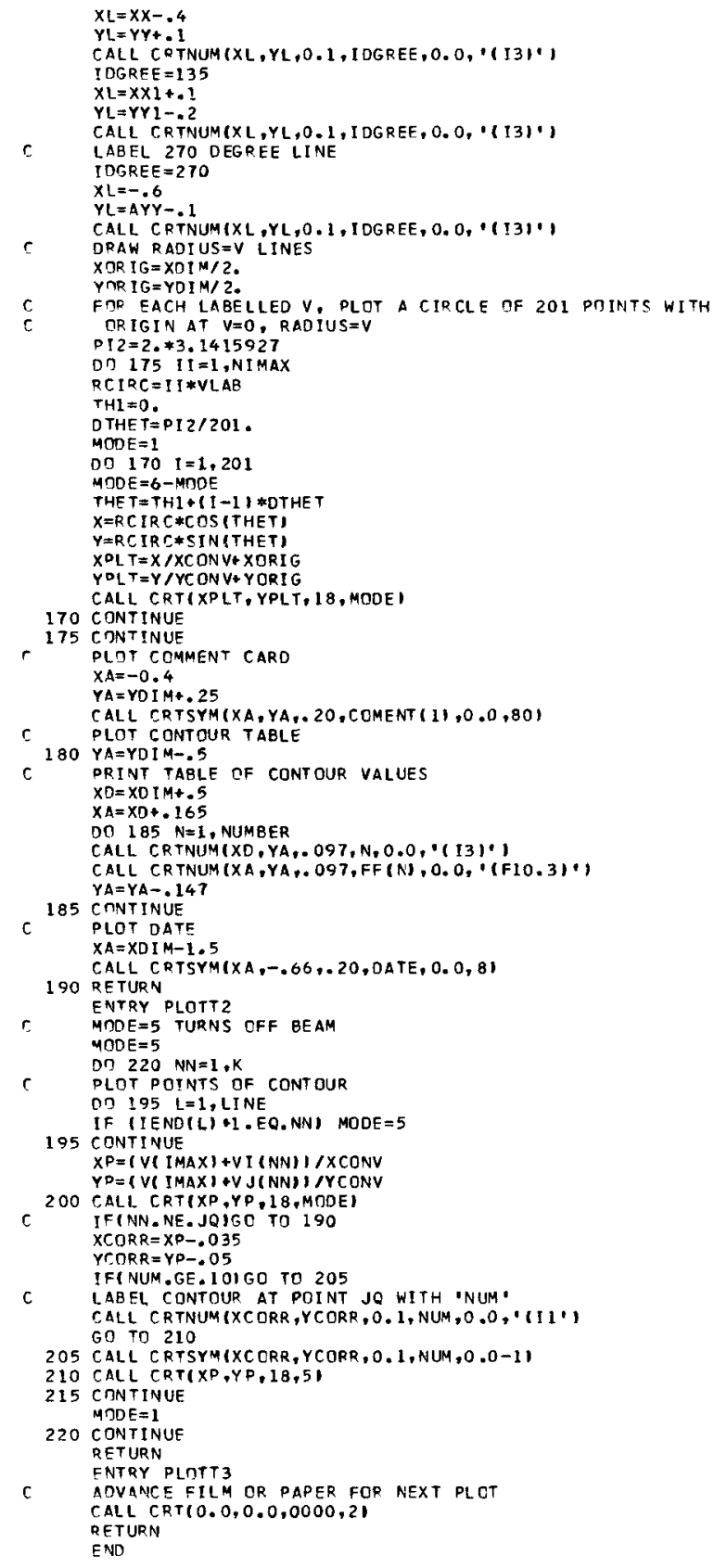

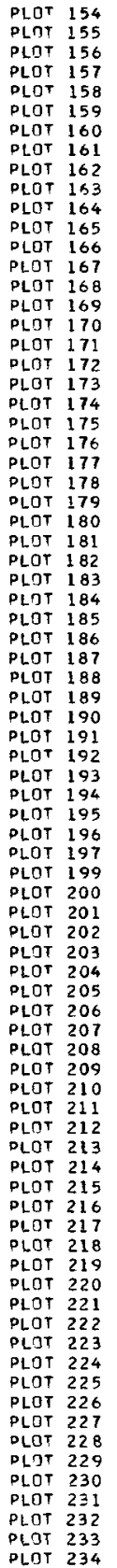

, Plottl, SIzE of program oolfoc hexadecimat bytes
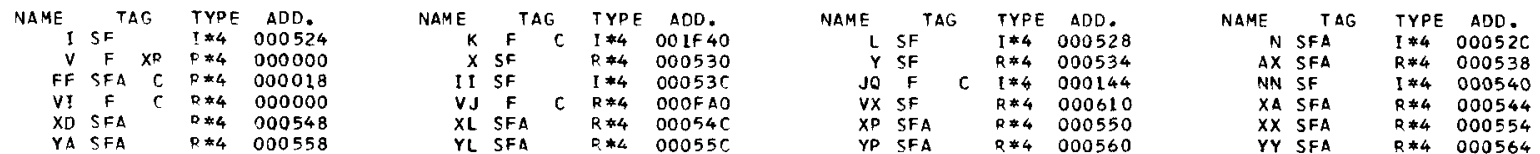


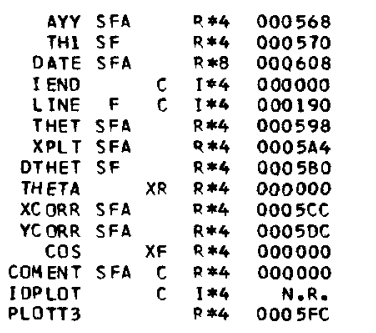
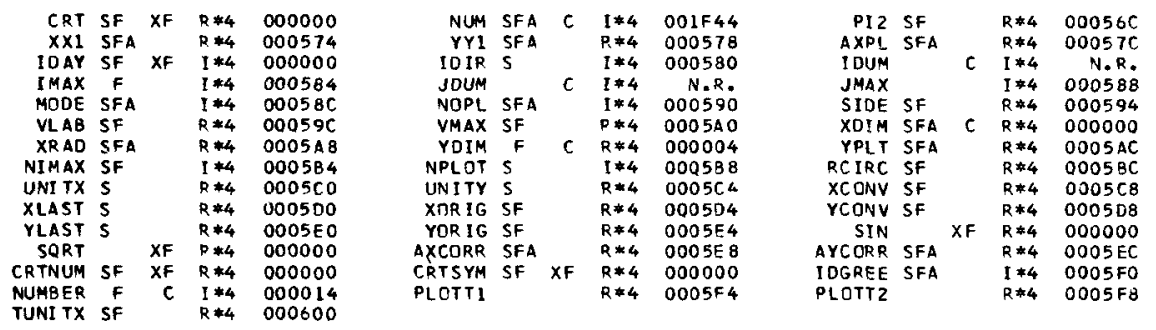

***** COMMCN INFORMATION

NAME OF COMMON BLOCK \#TITLER SIZE OF BLOCK OOOO50 HEXADECIMAL BYTES

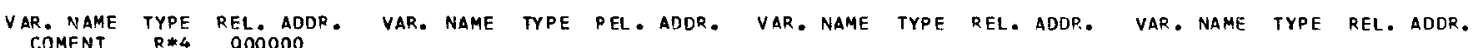

NAME OF COMMON BLOCK * MAINC* SIZE OF BLOCK O00148 HEXADECIMAL BYTES

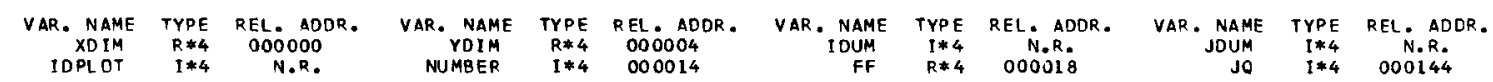

NAME OF COMMON BLOCK * SCANC* SIZE OF BLOCK DOIF 48 HEXADECIMAL BYTES

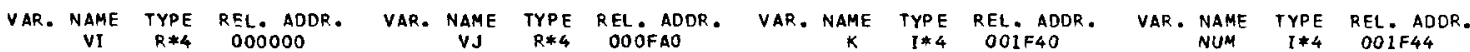

NAME OF COMMON BLOCK *IBREAK* SIZE OF BLOCK O00194 HEXADEC IMAL BYTES VAR. NAME TYPE
IEND
I*4
000000

\begin{tabular}{|c|c|c|c|c|c|c|c|}
\hline LABEL & $\triangle D D R$ & $\angle A B E L$ & $\triangle D D R$ & $\angle A B E L$ & $\triangle D O P$ & LABEL & $A D O R$ \\
\hline $\begin{array}{l}100 \\
120 \\
140 \\
160 \\
180 \\
200\end{array}$ & $\begin{array}{l}0016 F 8 \\
00179 A \\
0017 F 4 \\
0018 C 6 \\
001 C C 4 \text { NR }\end{array}$ & $\begin{array}{l}105 \\
125 \\
145 \\
165 \\
185\end{array}$ & $\begin{array}{l}001764 \\
0017 A 4 \\
001882 \\
0018 E A \\
001022\end{array}$ & $\begin{array}{l}110 \\
130 \\
150 \\
170 \\
190 \\
210\end{array}$ & $\begin{array}{l}001772 \\
0017 \mathrm{BE} \\
001898 \\
001 C 8 \mathrm{E} \\
00104 \mathrm{E} \text { NR }\end{array}$ & $\begin{array}{l}115 \\
135 \\
155 \\
175 \\
195 \\
215\end{array}$ & $\begin{array}{l}001780 \\
00170 A \\
0018 B A \\
001 C 92 \\
0010 B C\end{array}$ \\
\hline 200 & OOIOEC NR & 205 & $001 E 28$ & 210 & $001 E 32$ & 215 & DOIE3C NR \\
\hline
\end{tabular}

*OPTIONS IN EFFECT* NAME $=$ MAIN,OPT $=02$, LINECNT $=60$, SI ZE $=0000 \mathrm{~K}$,

* OPTIONS IN EFFECT* SOURCE, EBCDIC, NOLIST, NDOECK, LOAD, MAP, NOEDIT, NOT O, NOXREF

*STATISTICS* SOURCE STATEMENTS = 191 ,PROgRAM SIZE $=8044$

*STATISTICS* No DiAgnostics generated

***** END OF COMPILATION ******

97 BYTES OF CORE NOT USED

*statistics* no olagnostics this step

F128-LEVEL LINKAGE EOITOR OPTIONS SPECIFIED LIST,MAP
DEFAULT OPTIONISI USED SIZE= 1149504,286721
SYSPRINT DEFAULT BLOCKING USED $1-1$

MODULE MAP

CONTROL SECTION

NAME ORIGIN LENGTH

$\begin{array}{lrr}\text { MAIN } & 00 & 1249 C \\ \text { READIN } & 124 A 0 & 582\end{array}$
ENTRY

name location name location name location name location 


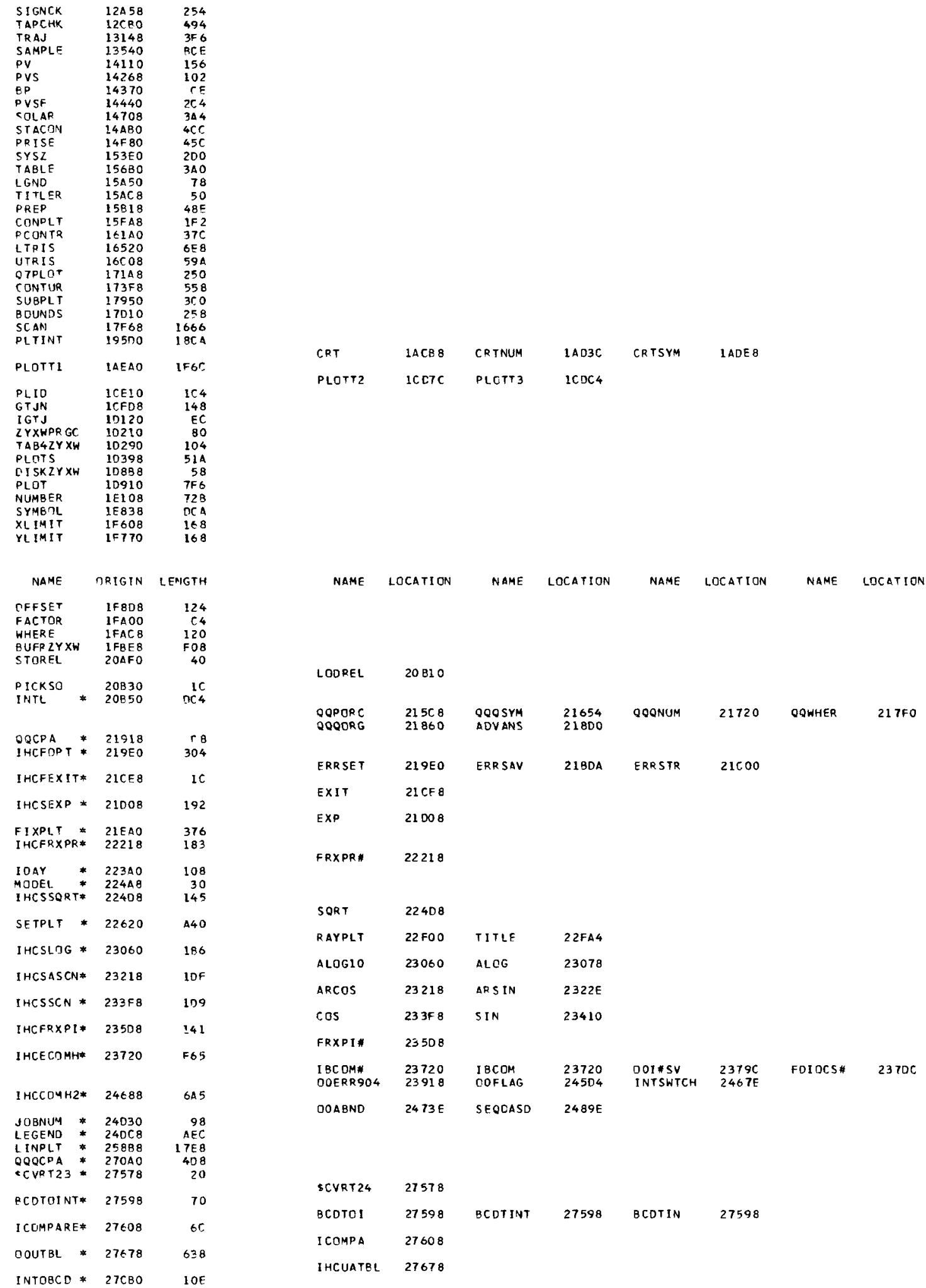




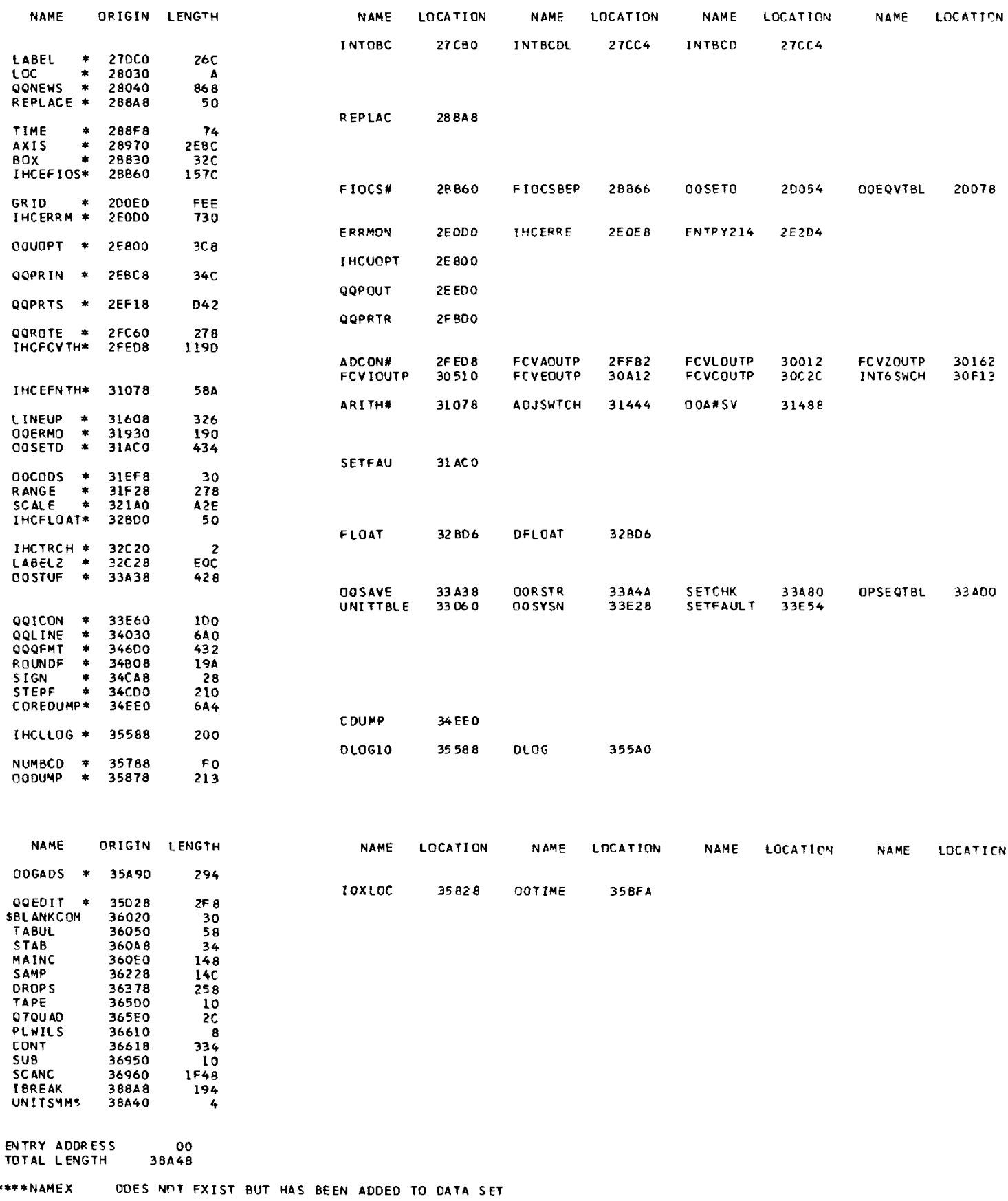


101

\section{Appendix F}

SAMPLE ORFAD OUTPUT 
PROGRAM ORFAD

Example conling tower calculation - natural dRAFt - CASE 1

DATE: 04-03-76 HASP NO.: 545 JEB NO.: MELF

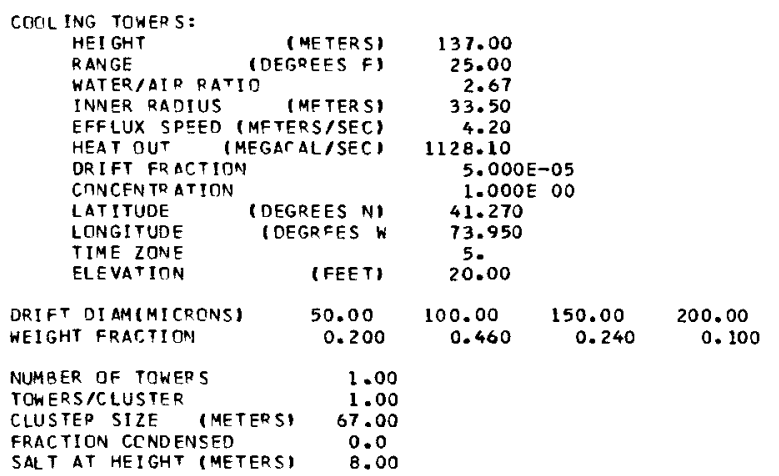

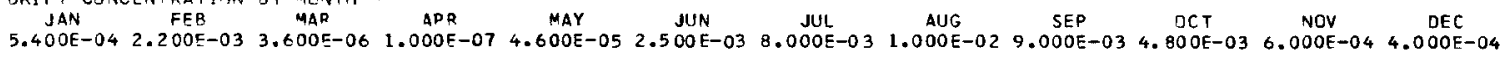
ANALYZES 10 YEARS STARTING 1959

ALL INPUT REAE

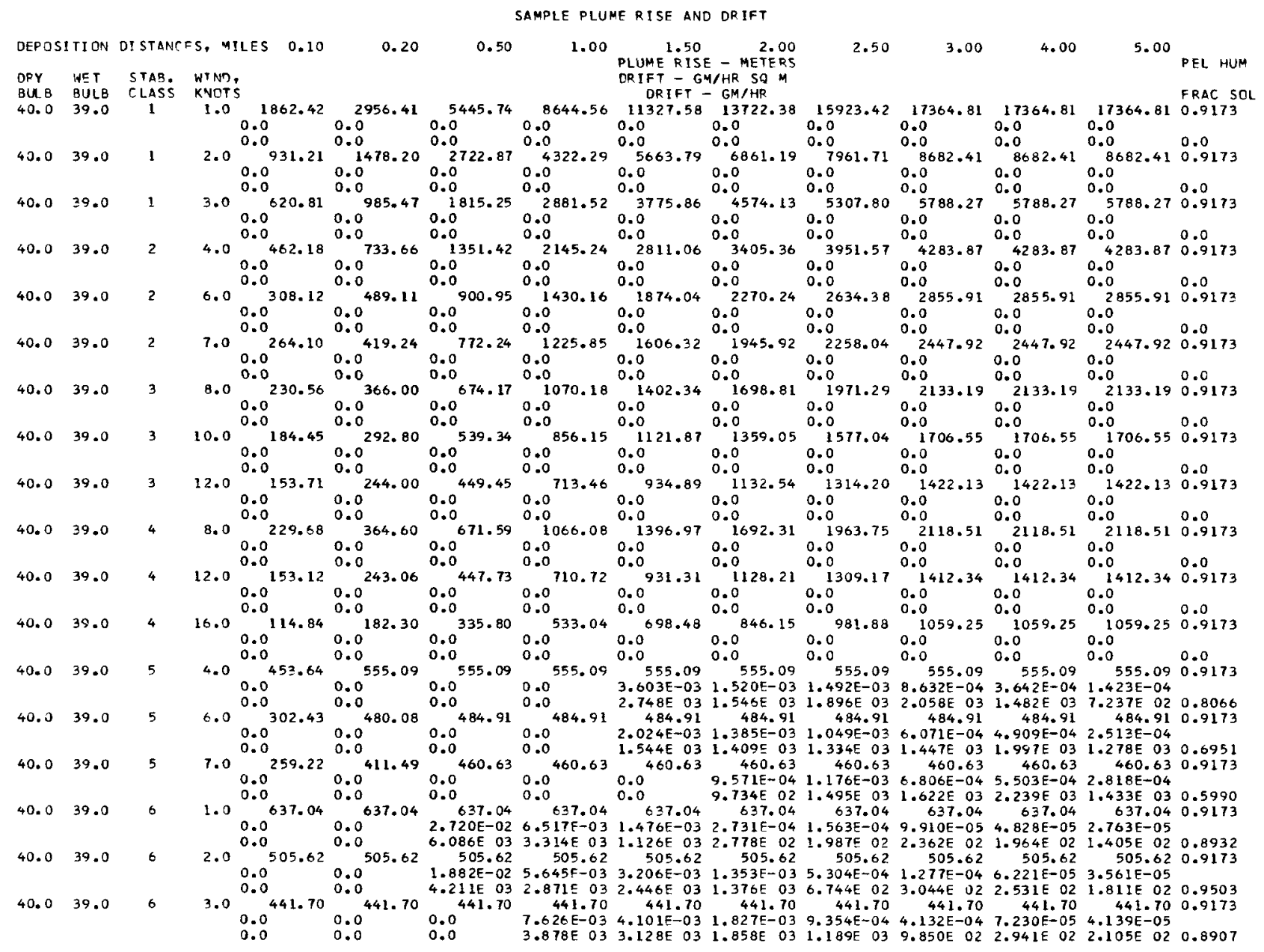


SAMPLE PLUME RISE AND DRIFT

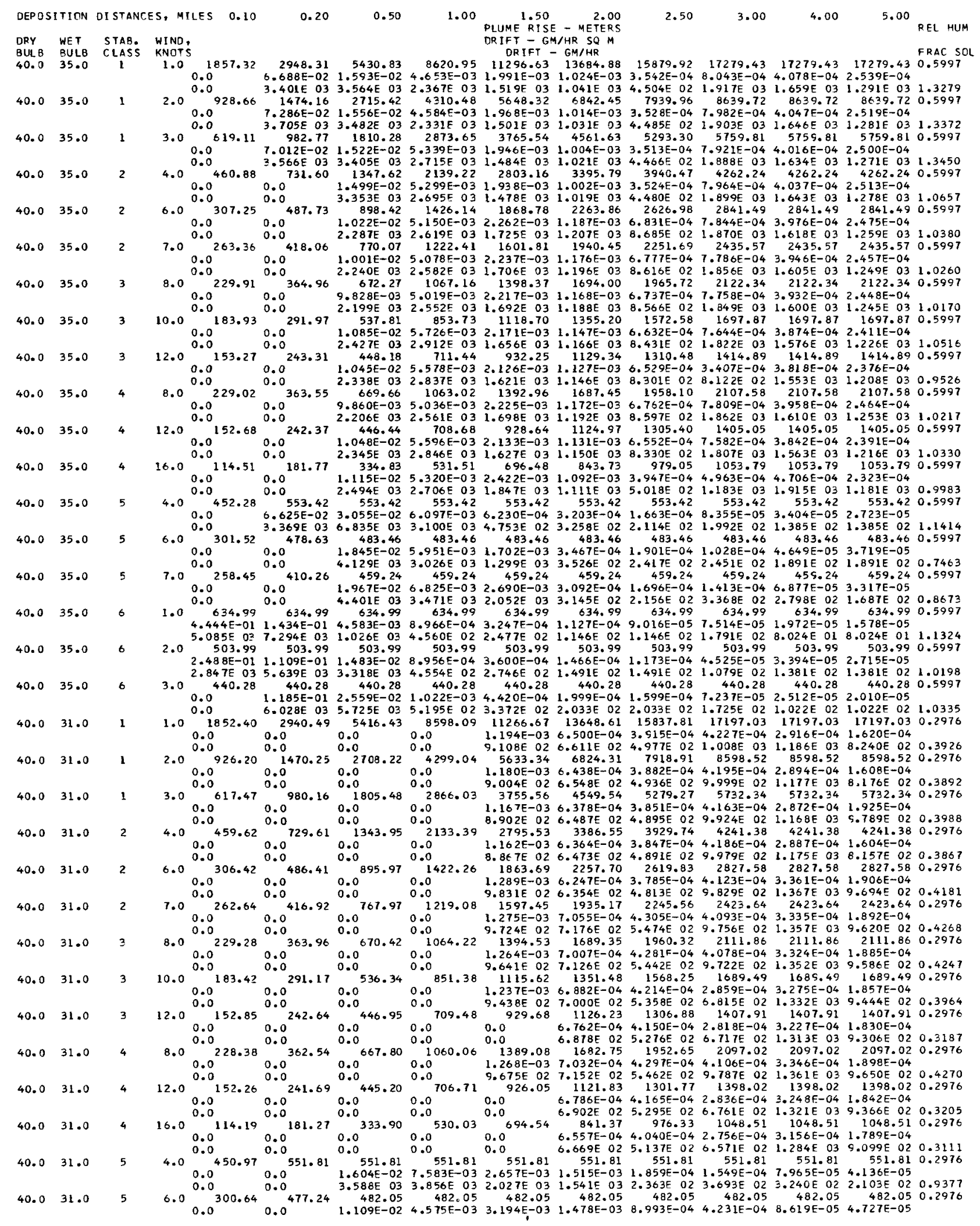


SAMPLE PLUME RISE ANO DRIFT

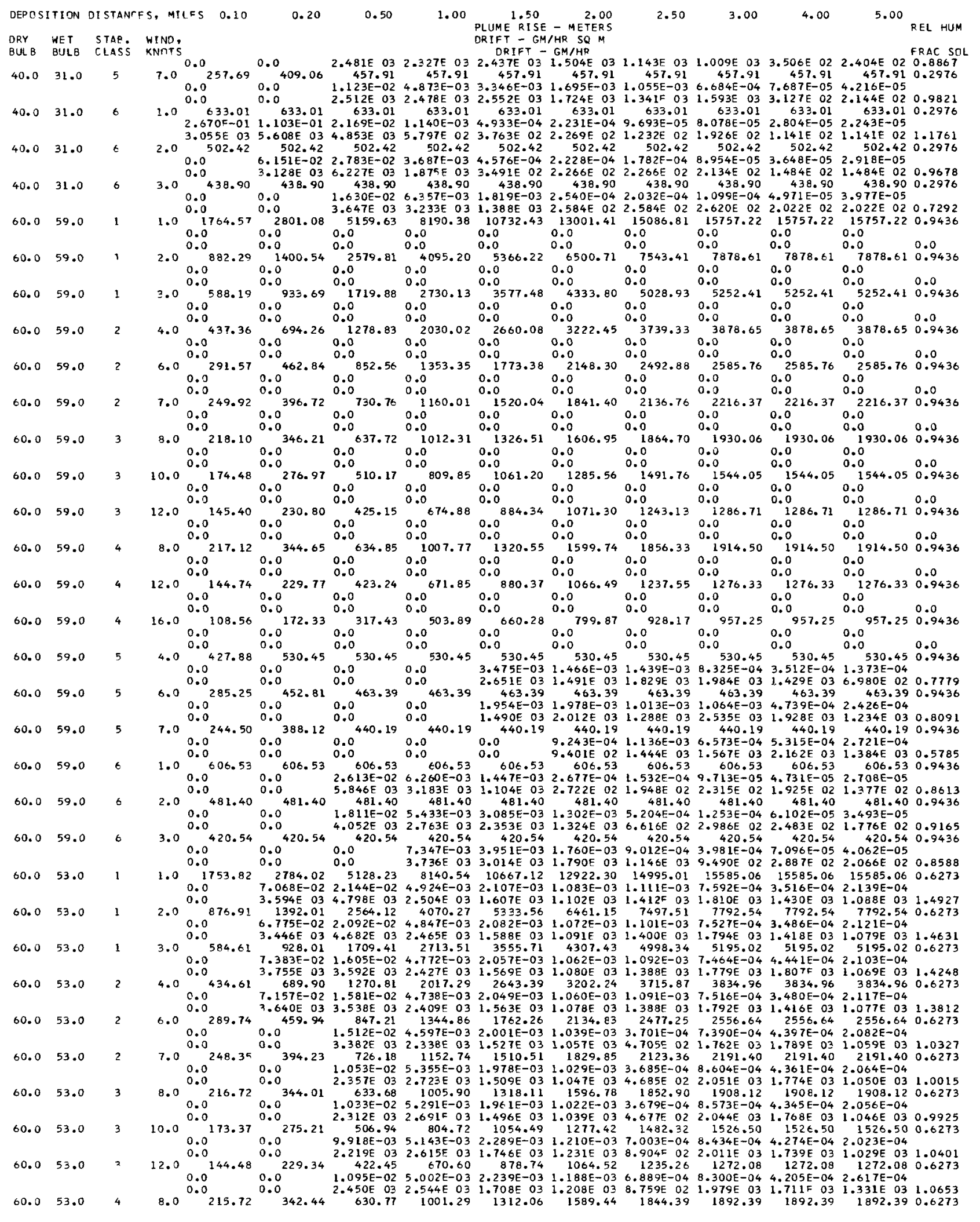


SAMPLE PLUME RISE AND DRIFT

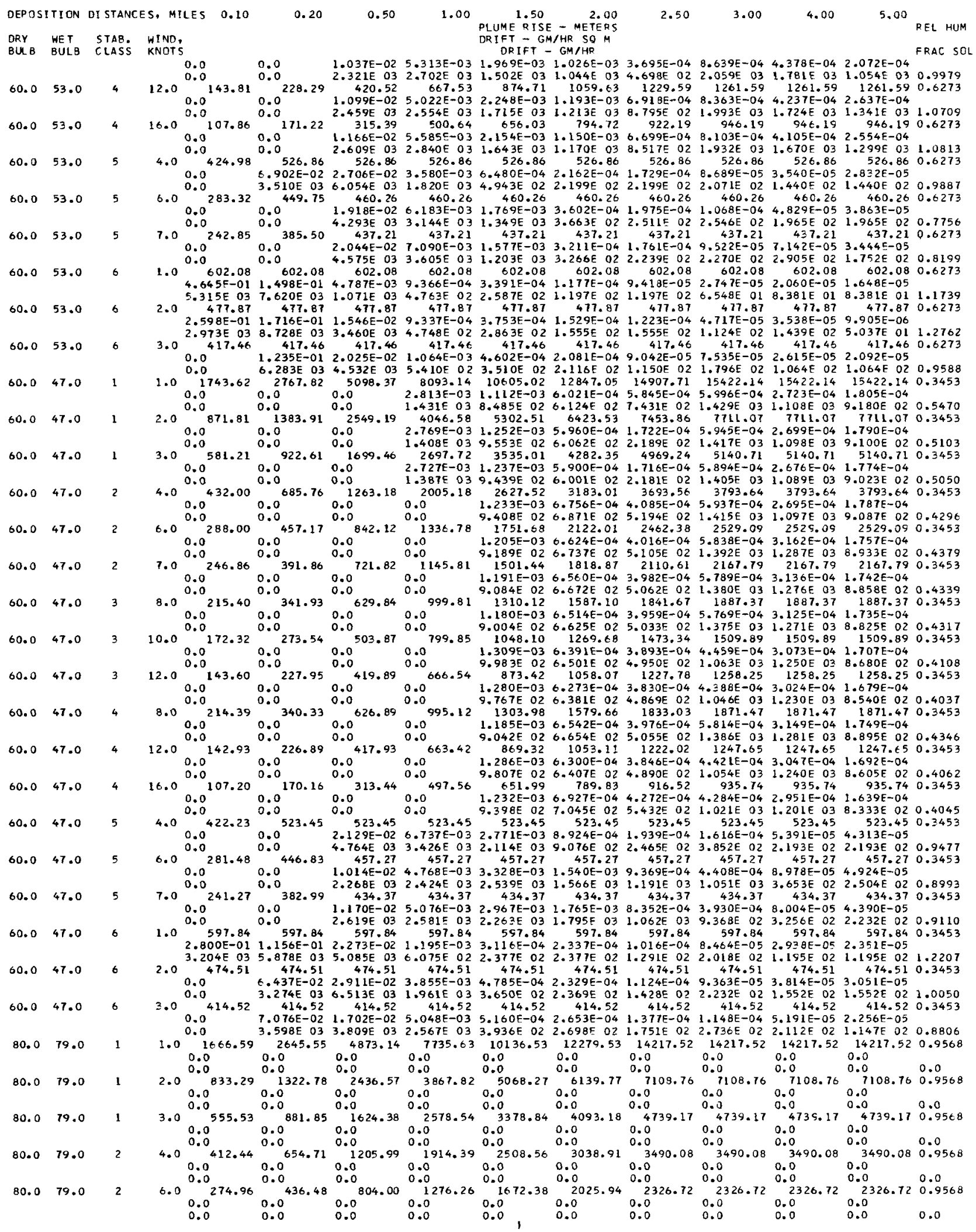




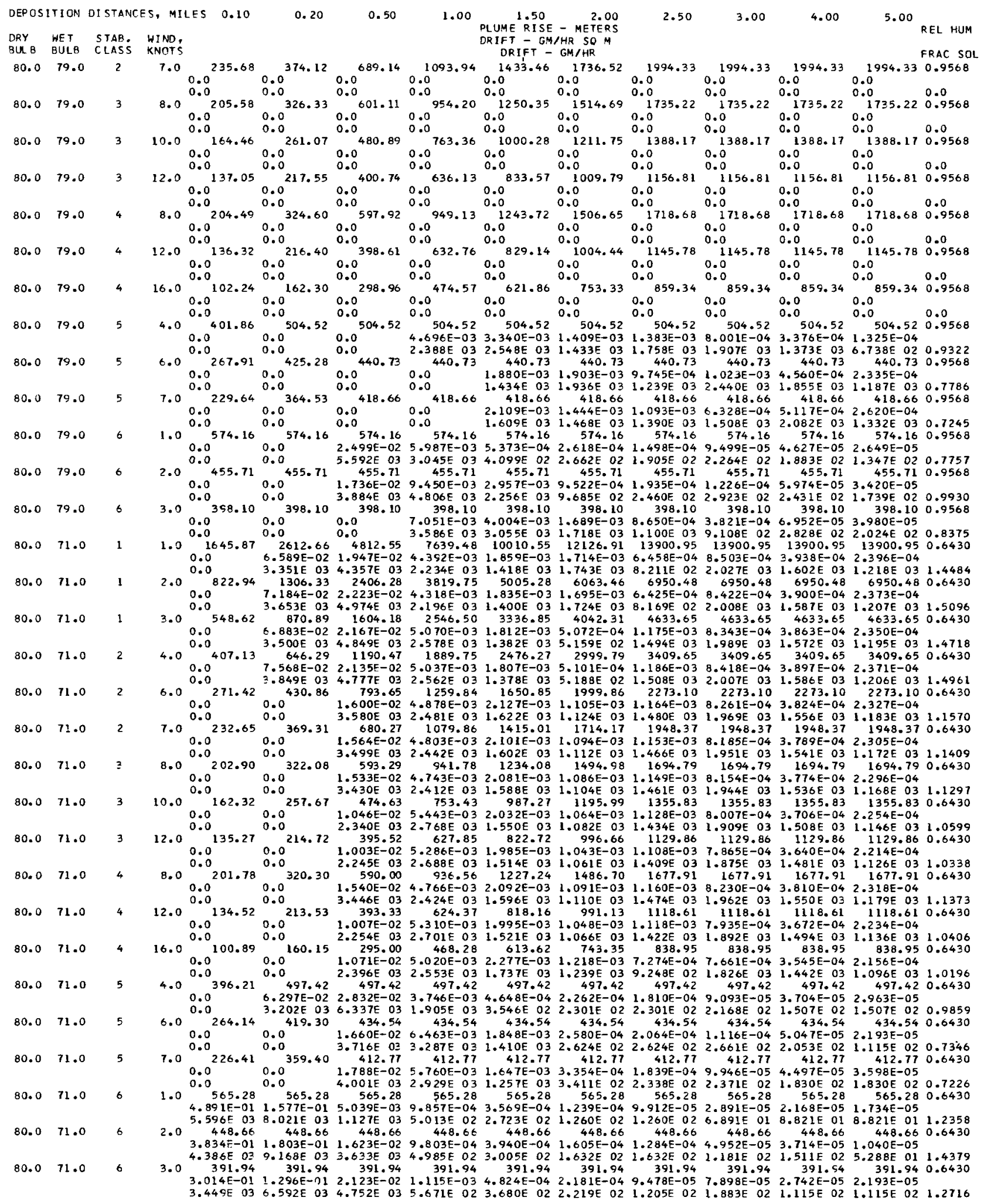




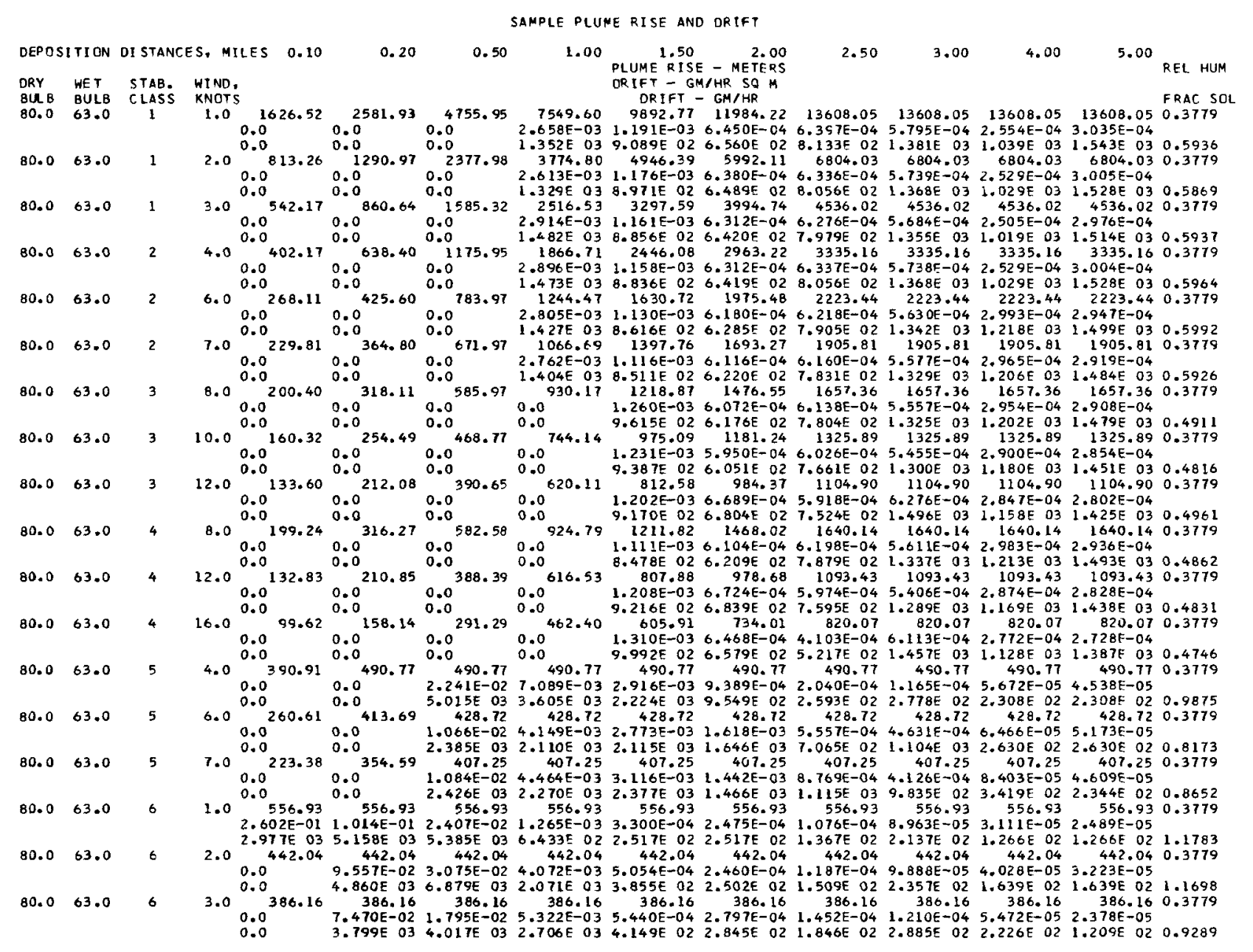

PROGRAM ORFAO

EXAMPLE CODLING TOWER CALCULATION - NATURAL DRAFT - CASE 1

852 HOURS DF FOG REPORTED

O HOURS OF ICE FOG REPORTED

283 HOURS OF GROUND FOG REPORTED

404 HOURS WHEN DRY BUL $B=W E T$ BULB

I4 HOURS INCOMPLETE DATA

10 YEAR AVERAGE

HOURS OF ADOIT IONAL FOG PER YEAR

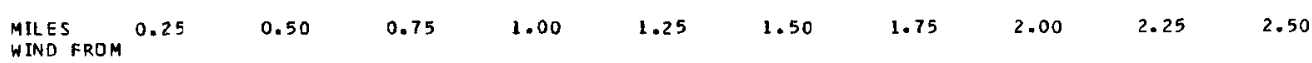

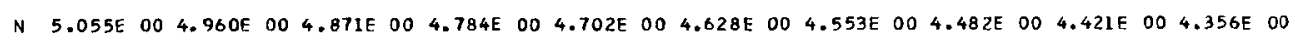
NNE 5.543E $005.436 E$ OO $5.339 E$ OO $5.242 E$ OO $5.154 E 00 \quad 5.070 E 00 \quad 4.991 E 004.913 E 004.843 E \quad 004.774 E \quad 00$

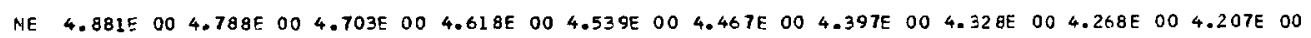

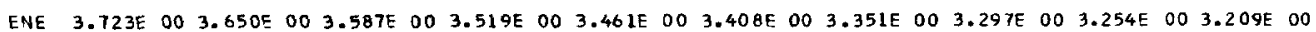

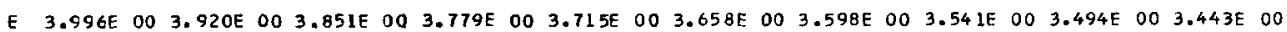
ESE 2.529E OO 2.480E OO 2.436E OO 2.391E OO 2.350E OQ 2.314E O0 2.276E O0 2.240E O0 2.210E OO 2.178E OO

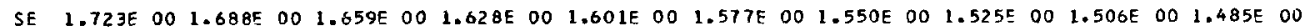


SSE $1.631 E$ QO $1.598 E$ OO $1.571 E$ OO $1.539 E$ OO $1.514 E 00 \quad 1.492 E \quad 00 \quad 1.467 E$ OO $1.442 E$ OO $1.425 E$ OO $1.405 E$ OO

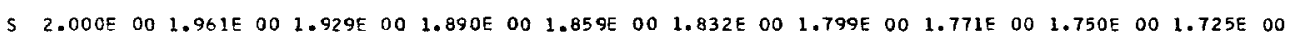

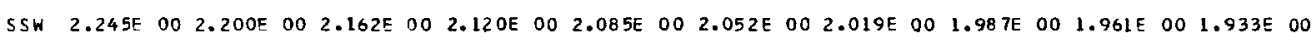

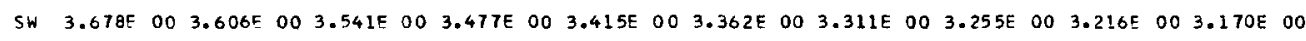
WSW 5.441E OO 5.337E $005.244 E$ OO 5.143E 00 5.054E $004.981 E$ OO 4.898E $004.815 E$ OO 4.758E $004.692 E$ OO

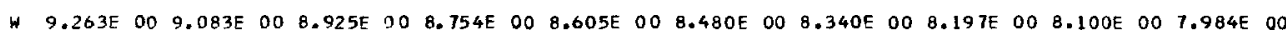
WNW 5.057E $004.959 E$ OO 4.872E $004.778 E$ OO 4.696E $004.629 E$ OO 4.552E $004.473 E$ OO 4.421E OO 4.360E OO

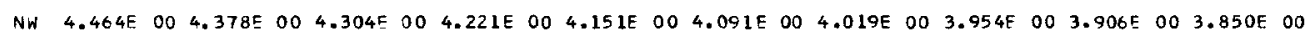

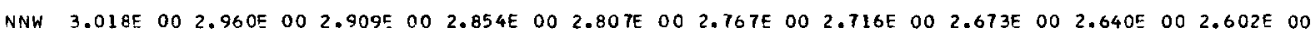

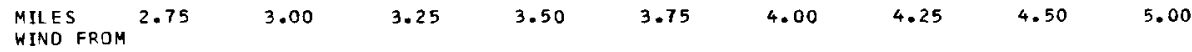

$N \quad 4.292 E$ E $004.224 E$ EO 4.171E $004.118 E$ O0 4.069E $004.014 E 003.971 E 003.925 E \quad 003.838 E \quad 00$

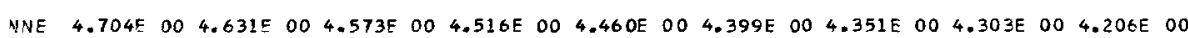

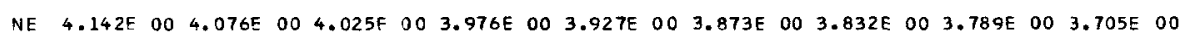

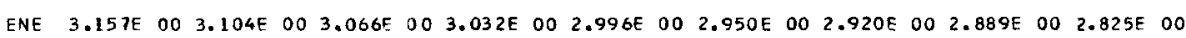

E 3.391F $00 \quad 3.334 \mathrm{E} 00 \quad 3.292 \mathrm{E} 00 \quad 3.254 \mathrm{E} 00 \quad 3.215 \mathrm{E} 00 \quad 3.168 \mathrm{E} 00 \quad 3.136 \mathrm{E} 00 \quad 3.101 \mathrm{E} 00 \quad 3.033 \mathrm{E} \quad 00$ ESE 2.146E DO 2.110E OO 2.083E OO 2.059E OO 2.034E $002.005 E 001.984 E 001.963 E 001.919 E \quad 00$

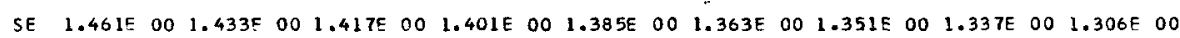

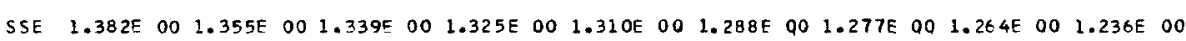

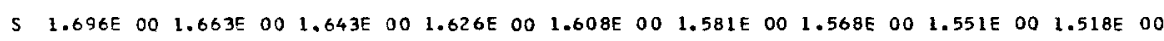

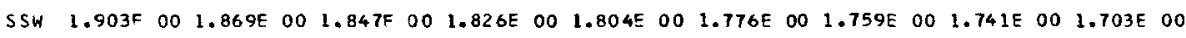

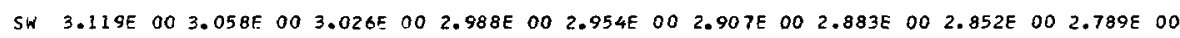
HSW 4.613E DO 4.529E OO 4.478E OO 4.425E OO 4.376E $00 \quad 4.303 E \quad 00 \quad 4.266 E$ OO 4.219E OO 4.130E DO

W 7.854E DO 7.713E OO 7.622E OO 7.532E 00 7.449E $007.328 E 007.266 E$ OO 7.181E OO 7.028E QO

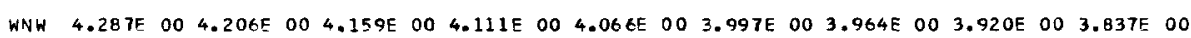
NW 3.786E O0 3.719E $00 \quad 3.674 E$ E $003.632 \mathrm{E}$ O0 3.592E $00 \quad 3.535 \mathrm{E} \quad 00 \quad 3.504 \mathrm{E} \quad 00 \quad 3.463 \mathrm{E} \quad 00 \quad 3.388 \mathrm{E} \quad 00$

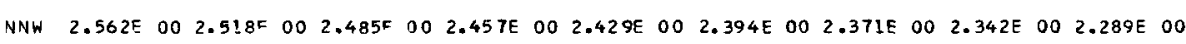
HOURS ANALYZED $=7618$
}

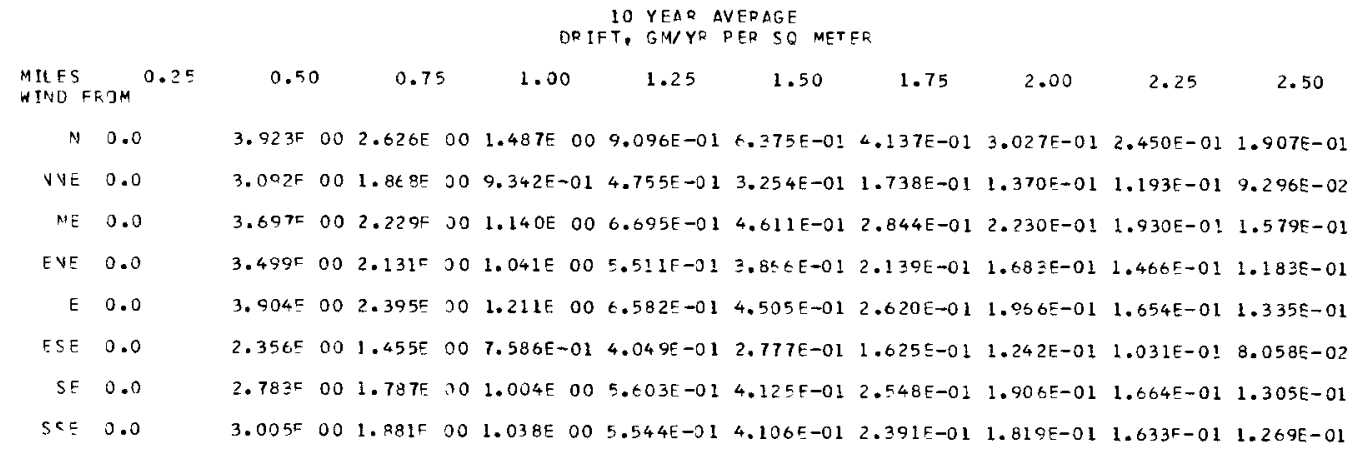




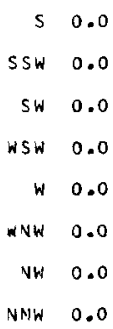

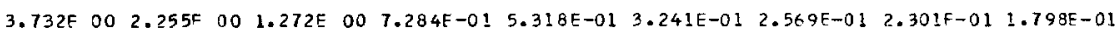
$3.274 \mathrm{E} 001.990 \mathrm{E}$ 00 1.136E $006.679 \mathrm{E}-01 \quad 5.021 \mathrm{E}-013.088 \mathrm{E}-01 \quad 2.61 \mathrm{EE}-012.257 \mathrm{E}-01 \quad 1.761 \mathrm{E}-01$ 6.777E $004.231 \mathrm{E} 002.369 \mathrm{E} 001.372 \mathrm{E} 001.000 \mathrm{E} 00 \quad 6.494 \mathrm{E}-01 \quad 4.977 E-01 \quad 4.334 E-01 \quad 3.426 E-01$ 8.876F 00 5.623E 00 3.271E 00 2.065E $001.596 \mathrm{E}$ OO 1.101E $00 \quad 8.706 E-01 \quad 7.473 E-01 \quad 6.201 E-01$ 1.594F $011.034 \mathrm{~F} \quad 01 \quad 6.012 \mathrm{E} \quad 00 \quad 3.803 \mathrm{E} 00 \quad 2.764 \mathrm{E}$ 00 $1.845 \mathrm{E} \quad 00 \quad 1.424 \mathrm{E}$ 00 $1.162 \mathrm{E} \quad 00 \quad 9.345 \mathrm{E}-01$ $9.637 F 006.176 E$ E $003.277 E$ E $1.980 E 00$ 1.362E $00 \quad 8.446 E-01 \quad 6.423 E-01 \quad 3.111 E-014.032 E-01$ $7.496 \mathrm{E} 00 \quad 4.8515002 .609 \mathrm{E}$ 00 1.545E $001.045 \mathrm{E} 00 \quad 6.446 \mathrm{E}-01 \quad 4.746 E-0 ! 3.652 E-012.937 E-01$ 4. $231 E \quad 002.897 E$ OO $1.720 E$ OO $1.128 E$ OO $7.829 E-01 \quad 5.127 E-01 \quad 3.727 E-01 \quad 2.930 E-01 \quad 2.265 E-01$

10 YEAR AVERAGE HOURS OF AODITIONAL ICE PER YEAR

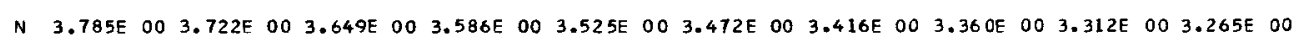 NNE 4.480E $00 \quad 4.400 E$ O0 4.319E $00 \quad 4.243 E$ O0 4.172E $00 \quad 4.106 E \quad 00 \quad 4.039 E \quad 00 \quad 3.976 E \quad 00 \quad 3.919 E \quad 003.862 E$ OO NE 4.266E DO 4.192E $004.112 E$ OO 4.040E OO 3.973E $003.912 E$ 00 3.848E $003.787 E \quad 003.733 E \quad 003.679 E \quad 00$ ENE 2.549E 00 2.506E OO 2.459E $00 \quad 2.416 E$ OO 2.374E $00 \quad 2.338 E$ OQ 2.299E OO 2.262E $00 \quad 2.232 E$ OO $2.200 E$ DO E 3.169E $003.115 E 003.056 E$ O0 3.002E 00 2.951E $00 \quad 2.906 E 002.859 E 002.813 E 002.772 E \quad 002.733 E \quad 00$ ESE 1.646E OO $1.619 E$ OO $1.588 E$ OO $1.560 E$ OO $1.533 E$ OO $1.510 E$ OO $1.485 E \quad 001.461 E \quad 001.441 E \quad 001.420 E$ OO SE 7.920E-01 7.822E-01 7.656E-01 7.530E-01 7.389E-01 $7.290 E-01 \quad 7.163 E-01 \quad 7.042 E-01 \quad 6.952 E-01 \quad 6.863 E-01$ SSE $8.405 E-01 \quad 8.284 E-018.122 E-01 \quad 7.977 E-01 \quad 7.834 E-02 \quad 7.729 E-01 \quad 7.592 E-01 \quad 7.463 E-01 \quad 7.370 E-01 \quad 7.270 E-01$ 
$5 \quad 9.292 E-019.179 F-01 \quad 8.980 E-01 \quad 8.813 E-01 \quad 8.664 E-018.567 E-018.408 E-018.262 E-018.154 E-018.046 E-01$

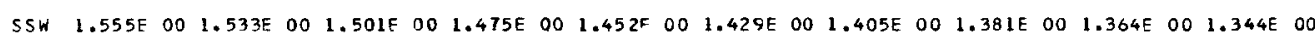

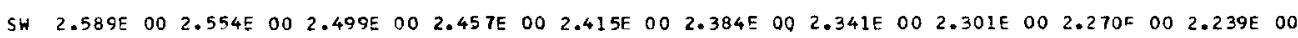
WSW 3.229E $003.184 E$ O0 3.115E $003.063 E 003.011 E 00 \quad 2.969 E \quad 002.918 E 002.866 E 002.828 E \quad 002.791 E \quad 00$

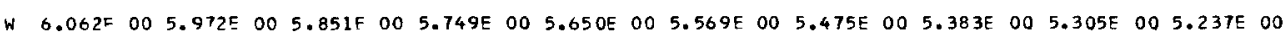

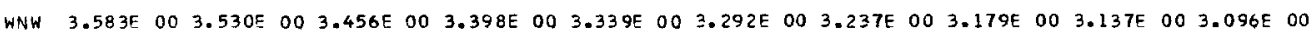
NW 3.011E 00 2.965E $002.906 E$ EO 2.855E 00 2.805E $002.76^{\circ} 6$ E 00 2.719E 00 2.675E 00 2.636E $00 \quad 2.602 E$ DO

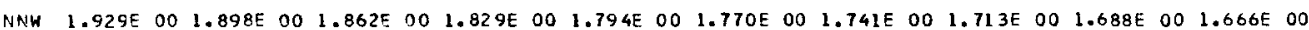

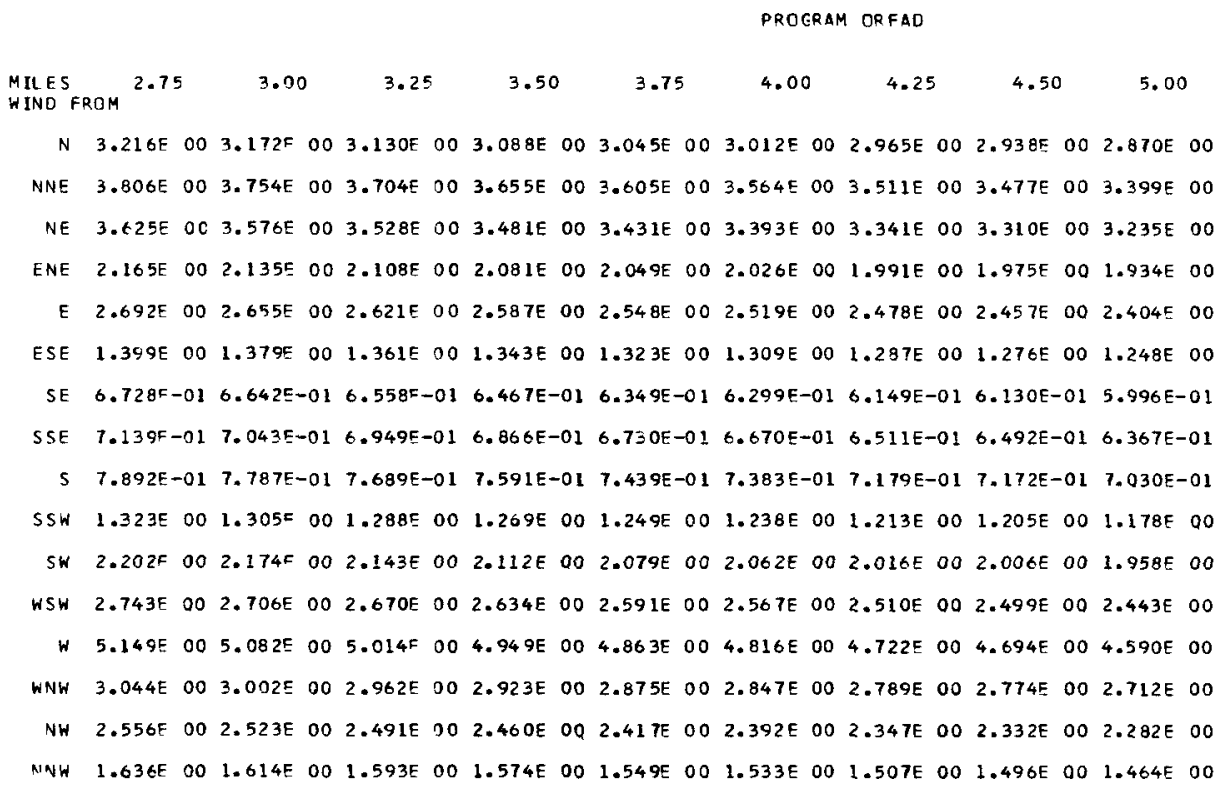

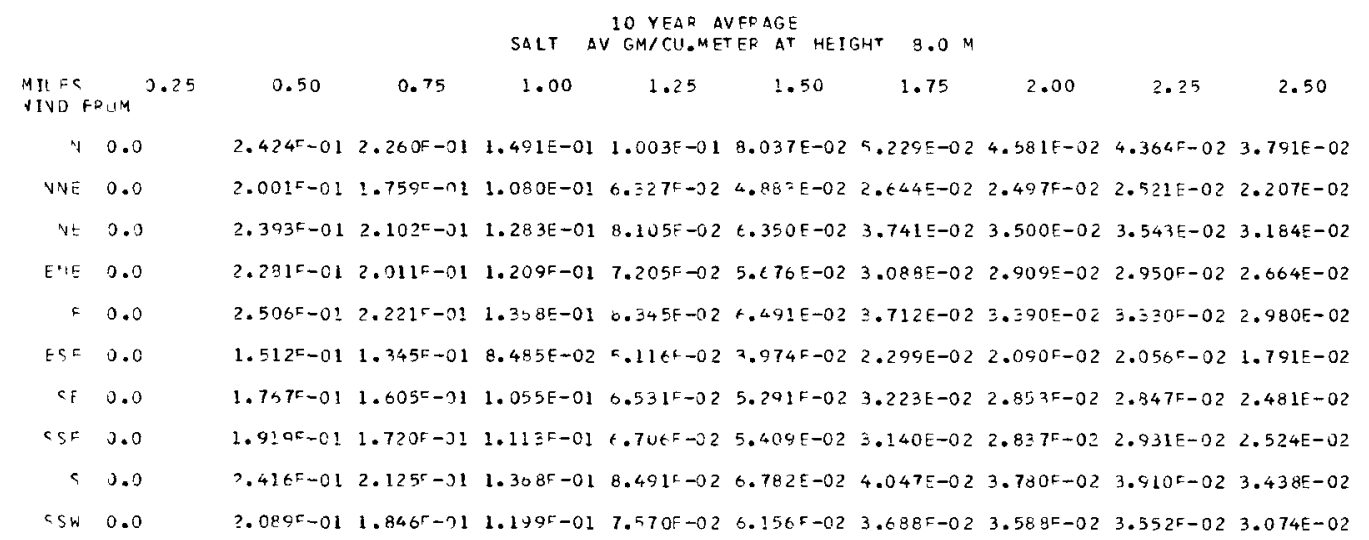




\begin{abstract}
SW 0.0
WSW 0.0

W 0.0

NAN 0.0

NW 0.0

NNW 0.0

$4.353 E-013.894 E-01 \quad 2.525 E-01 \quad 1.589 E-01 \quad 1.272 E-01 \quad 7.90 E 5-02 \quad 7.152 E-02 \quad 7.138 E-02 \quad 6.248 E-02$ 5.658E-01 5.103E-01 3.373E-01 2.205E-01 1.834E-01 1.187E-01 1.084E-01 1.057E-01 9.509E-0? 9.839F-01 $9.022 F-01 \quad 5.997 E-01 \quad 4.056 E-013.258 E-01 \quad 2.127 E-01 \quad 1.893 E-01 \quad 1.753 E-01 \quad 1.552 E-01$ $\begin{array}{lllllll}5.979 F-01 & 5.447 E-01 & 3.455 E-01 & 2.293 E-01 & 1.788 E-01 & 1.109 E-01 & 9.903 E-02 \quad 9.242 F-02 \quad 8.096 E-02\end{array}$

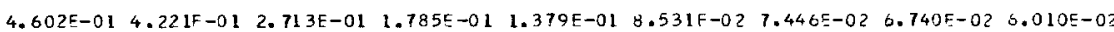
$2.476 E-012.358 C-01 \quad 1.614 E-01 \quad 1.164 E-019.154 E-02 \quad 6.185 E-02 \quad 5.233 E-02 \quad 4.754 E-02 \quad 4.132 E-02$
\end{abstract}

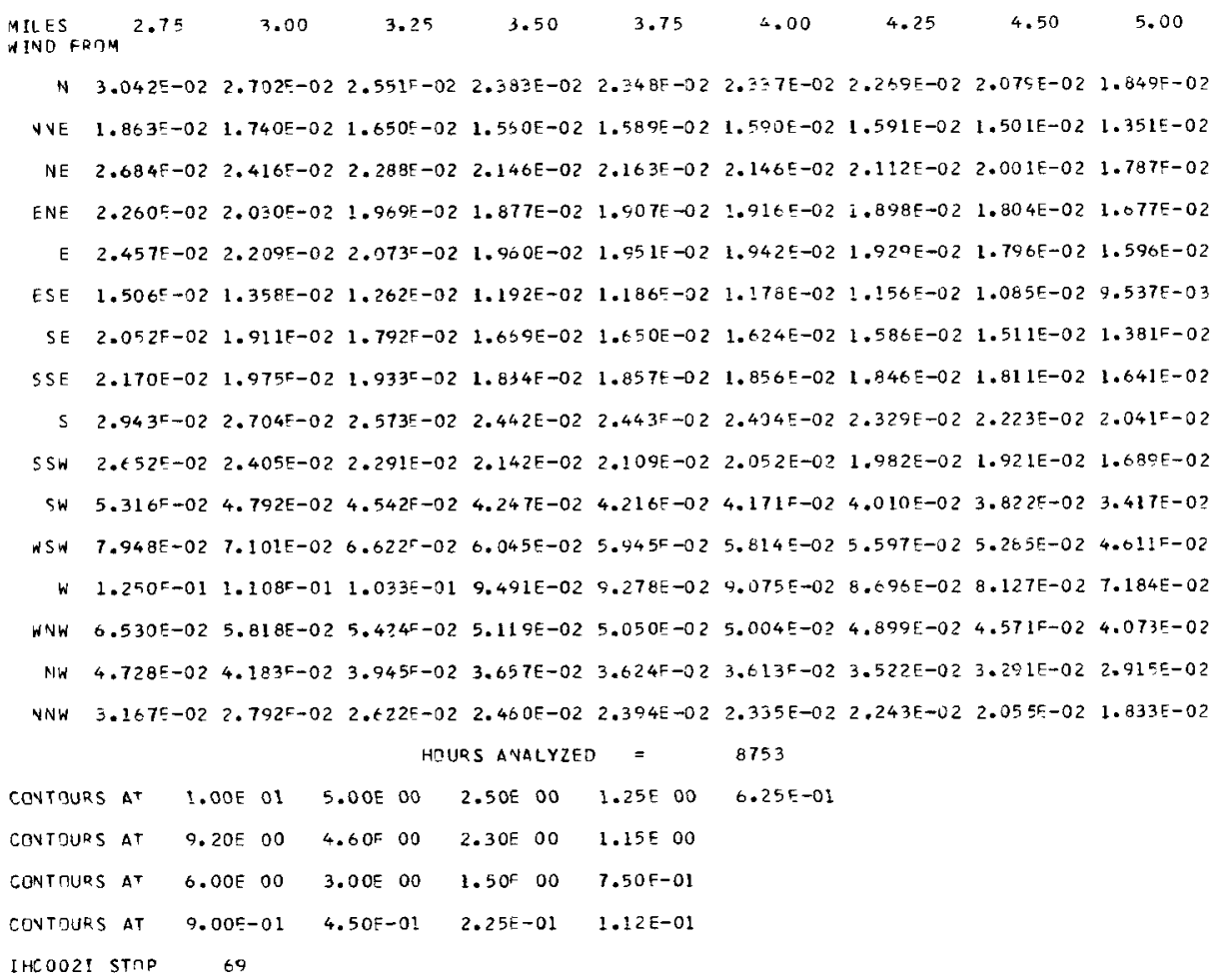




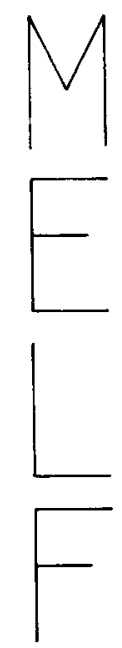

PLOT 19
01.48 .14
04-03-76
P-660 
EXAMPLE COOLING TOWER CALCULATION - NATURAL DRAFT - CASE 1

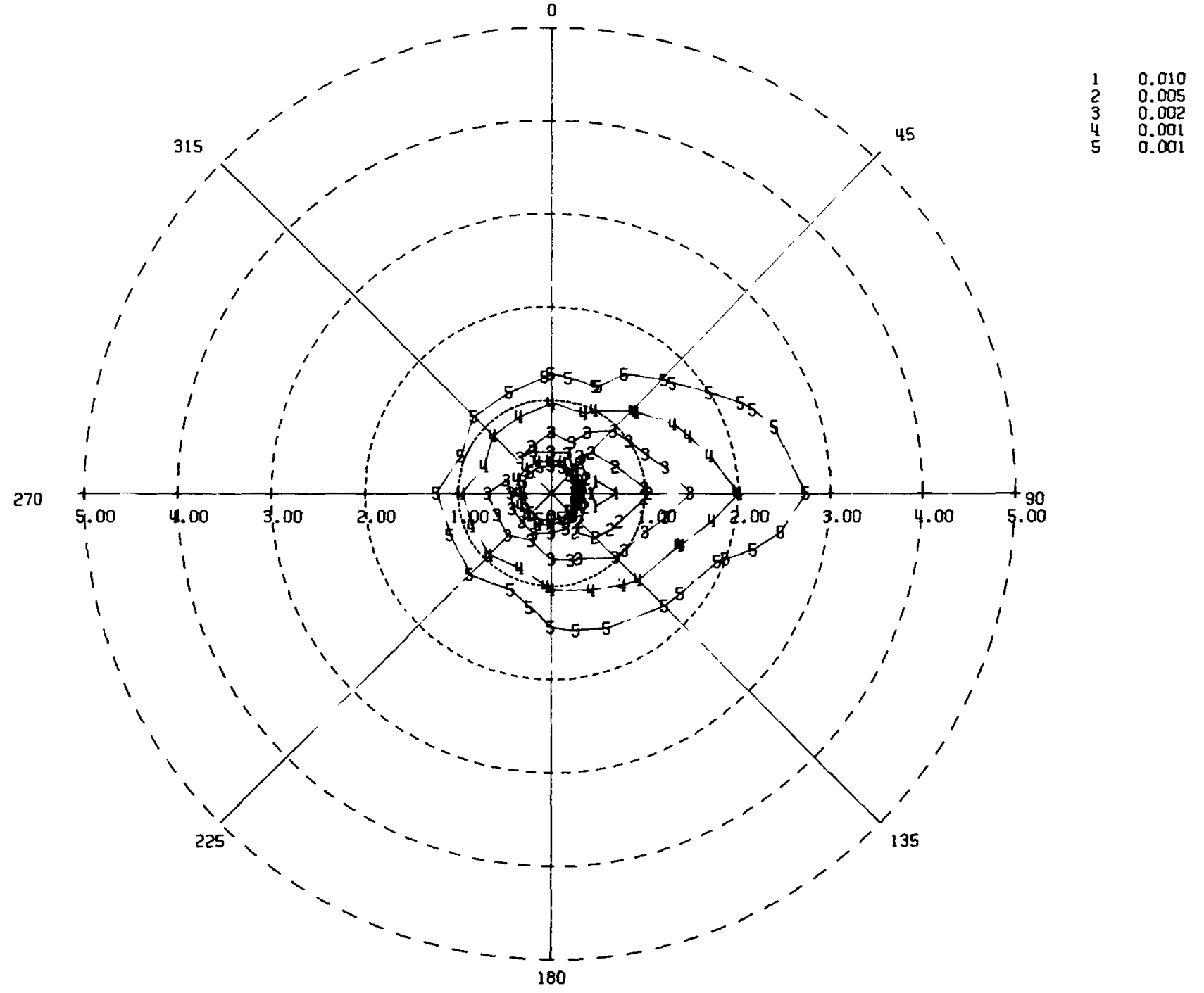

1 AMOUNT OF ORIFT

$04-03-76$ 


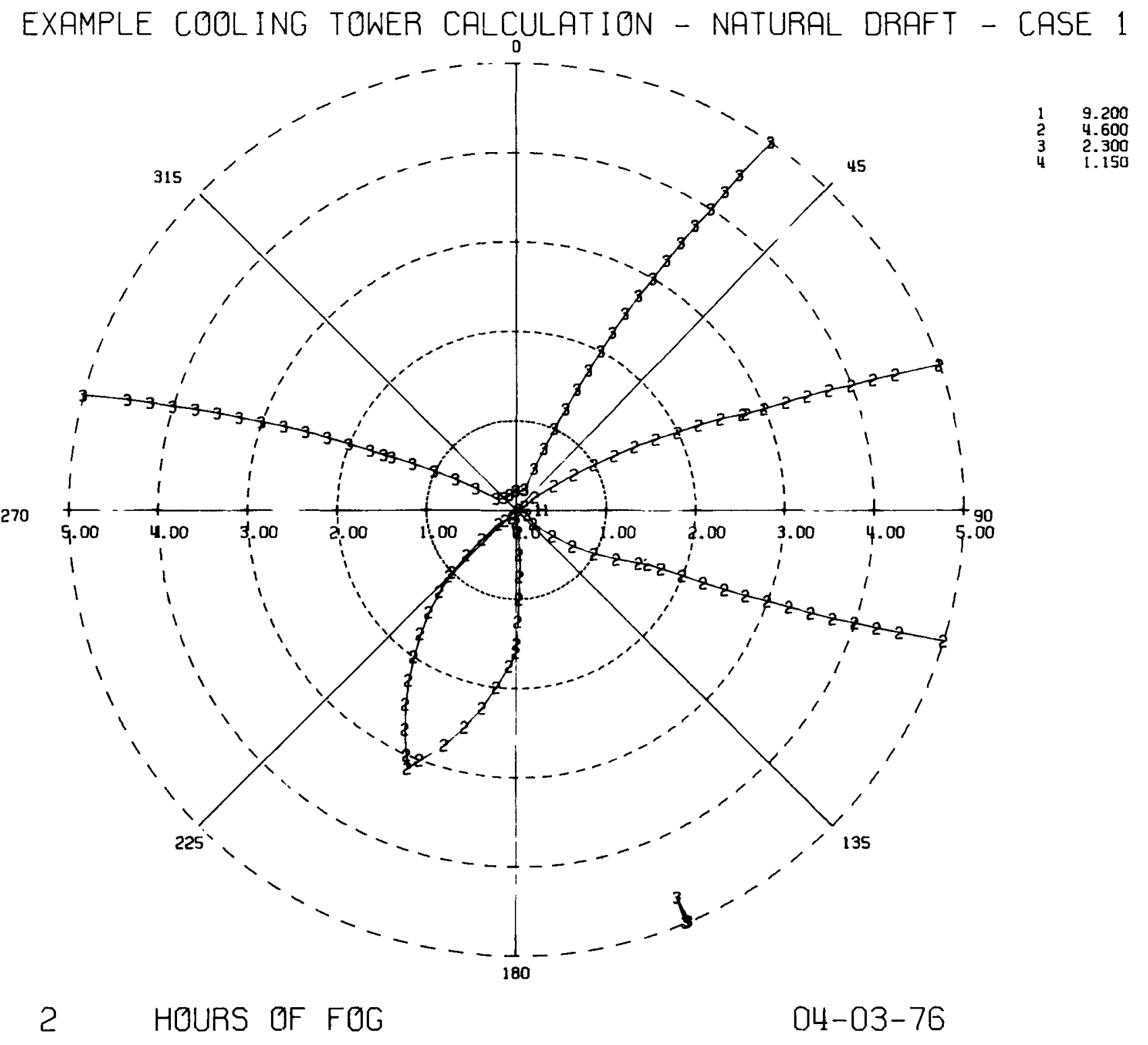


EXAMPLE COOLING TOWER CALCULATION - NATURAL DRAFT - CASE 1

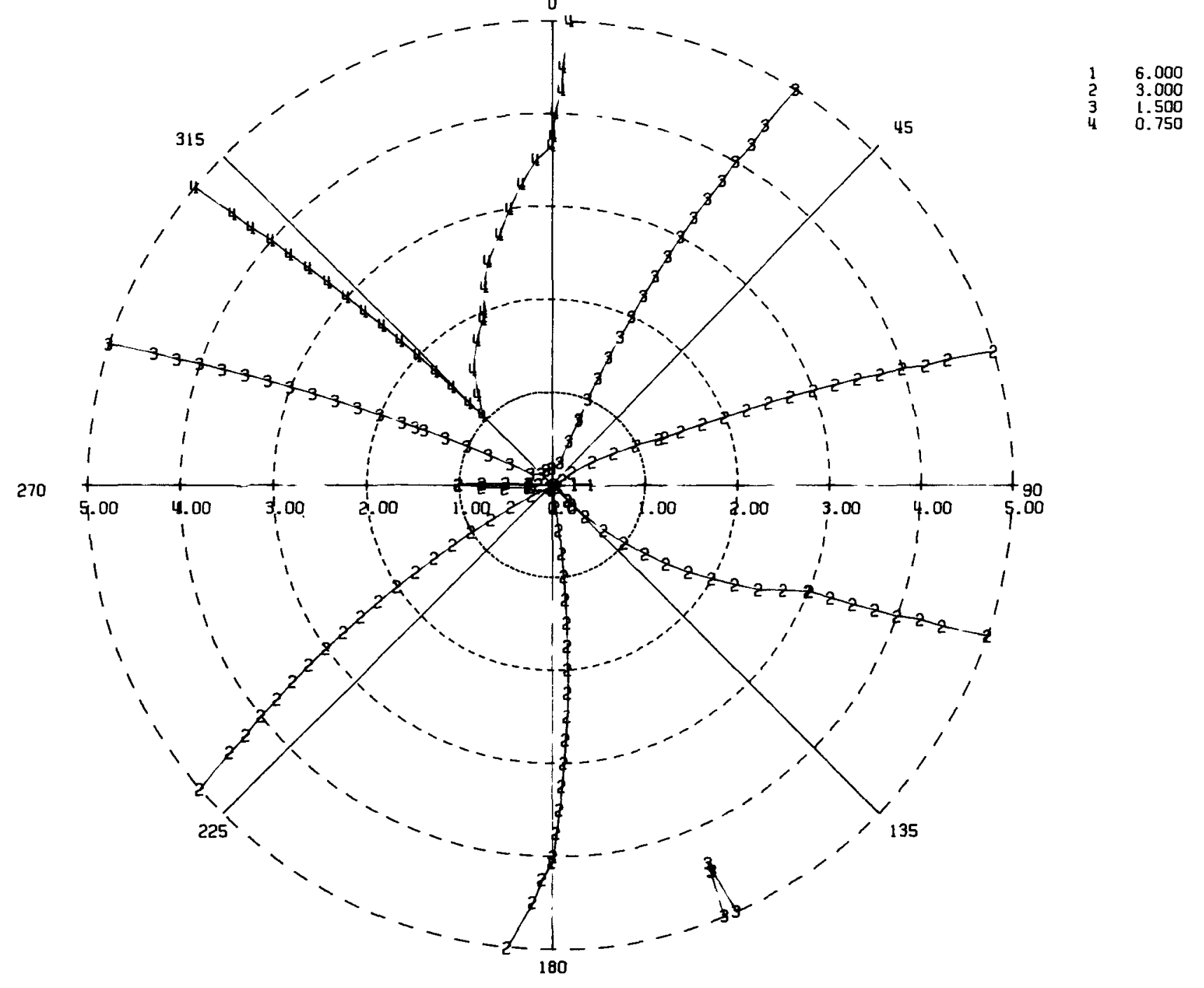

3 HOURS OF ICE

04-03-76 
EXAMPLE COOLING TOWER CALCULATION - NATURAL DRAFT - CASE 1

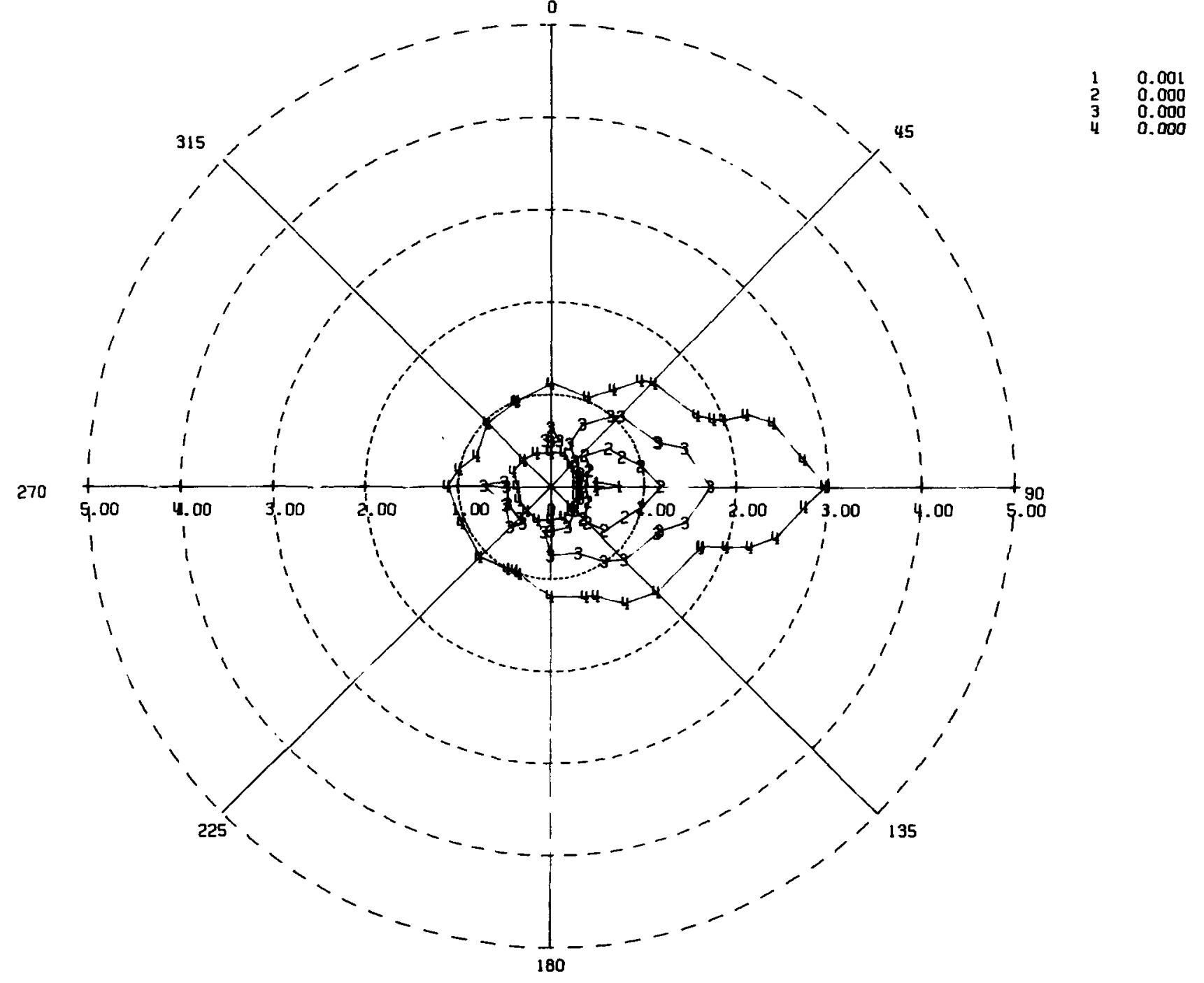

4 SALT IN AIR

$04-03-76$ 
Appendix $G$

TRANSLATION OF CODED WIND DIRECTIONS TO DIRECTION INDEXES

A somewhat cryptical FORTRAN formula,

$$
\operatorname{IWD}=\operatorname{IWD}-9 *(\operatorname{IWD} / 10)--1
$$

appears in the ORFAD main program in the section devoted to weather data processing. Since the question "What does 1t do?" has arisen several times, the following is offered in explanation.

Wind directions on an 8-point compass are coded by NOAA, as shown on the left-hand side of Table G-1. Wind directions on the 16-point compass are then coded by combining approprlate terms from two of the 8-point directions; for example, east-northeast (ENE) is coded as 32 , since $E$ is 3 and $N E$ is 2 . This process yields the coded directions on the right-hand side of the table.

Let us now apply Eq. (G-I) piecemeal to the ENE coded direction, that is, take IWD as 32 inftially. First, we get

$$
\operatorname{IWD} / 10=3 \text {, }
$$

because we are using 1nteger artthmetic. As a result, we have

$$
9 *(I W D / 10)=27,
$$

and, finally,

$$
\text { IWD }=32-27-1=4 \text {, }
$$

that is, the direction index for ENE is 4. Simllarly, for south-southwest (SSW), we get

$$
I W D=56-45-1=10
$$

as the direction index for SSW.

For the compass directions $\mathrm{N}$ through NW, Eq. (G-1) thus yields the numbers 1 through 15 as the corresponding direction indices. The equation fails, however, for $\mathrm{NNW}$ and CALM. These latter two are treated as special cases and assigned indices 16 and 17 , respectively. 
Table G-1. Relation of compass directions, coded directions, and direction Indices for the 8- and 16-point compasses

\begin{tabular}{|c|c|c|c|c|}
\hline \multicolumn{2}{|c|}{ For 8-polnt compass } & \multicolumn{2}{|c|}{ For 16-point compass } & \multirow{2}{*}{$\begin{array}{c}\text { Direction } \\
\text { Index }\end{array}$} \\
\hline $\begin{array}{l}\text { Compass } \\
\text { direction }\end{array}$ & $\begin{array}{c}\text { Coded } \\
\text { drection }\end{array}$ & $\begin{array}{l}\text { Compass } \\
\text { direction }\end{array}$ & $\frac{\text { Coded }}{\text { direction }}$ & \\
\hline $\mathrm{N}$ & 1 & N & 11 & 1 \\
\hline $\mathrm{NE}$ & 2 & NNE & 12 & 2 \\
\hline E & 3 & $\mathrm{NE}$ & 22 & 3 \\
\hline SE & 4 & ENE & 32 & 4 \\
\hline $\mathbf{s}$ & 5 & $E$ & 33 & 5 \\
\hline SW & 6 & ESE & 34 & 6 \\
\hline W & 7 & SE & 44 & 7 \\
\hline \multirow[t]{10}{*}{ NW } & 8 & SSE & 54 & 8 \\
\hline & & $\mathbf{s}$ & 55 & 9 \\
\hline & & SSW & 56 & 10 \\
\hline & & SW & 66 & 11 \\
\hline & & WSW & 76 & 12 \\
\hline & & W & 77 & 13 \\
\hline & & WNW & 78 & 14 \\
\hline & & $\mathrm{NW}$ & 88 & 15 \\
\hline & & NNW & 18 & 16 \\
\hline & & "Calm" & 00 & 17 \\
\hline
\end{tabular}

Although assigned a direction Index, a calm condition is not actually treated as a wind in a specific direction. Rather, the index merely provides a conventent Identifier for accumulating the occurrences of calm conditions. 
ORNL/TM-5201

\section{Internal Distribution}

1. H. G. Arnold

2. S. I. Auerbach

3. H. F. Bauman

4. S. E. Beal1

5. M. Bender

6. C. R. Boston

7. J. W. Boyle

8. R. W. Brocksen

9. J. B. Cannon

10. N. C. J. Chen

11. W. B. Cottrel1

12. C. C. Coutant

13. R. B. Cralg

14. F. L. Culler

15. D. M. E1ssenberg

16. A. Eraslan

17. G. G. Fee

18. W. Fulkerson

19. T. P. Hamrick

20. H. W. Hoffman

21. L. Jung

22. G. W. Kellholtz

23. R. L. Kroodsma

24-33. M. E. LaVerne

34. J. M. Loar

\section{Externa1 Distribution}

120. H. R. Denton, U.S. NRC, Washington, D.C. 20545

121. D. R. Muller, U.S. NRC, Washington, D.C. 20545

122. V. A. Moore, U.S. NRC, Washington, D.C. 20545

123. G. W. Knighton, U.S. NRC, Washington, D.C. 20545

124. B. J. Youngblood, U.S. NRC, Washington, D.C. 20545

125. W. H. Regan, U.S. NRC, Washington, D.C. 20545

126. M. L. Ernst, U.S. NRC, Washington, D.C. 20545

127. W. R. Ott, U.S. NRC, Washington, D.C. 20545

128. J. E. Fairobent, U.S. NRC, Washington, D.C. 20545

129. R. A. Kornasiewicz, U.S. NRC, Washington, D.C. 20545

130. J. E. Carson, Argonne National Laboratory, 9700 South Cass Avenue, Argonne, I1l. 60439

131. A. J. Policastro, Argonne National Laboratory, 9700 South Cass Avenue, Argonne, I11. 60439

132. W. F. Sandusky, Battelle Paciflc Northwest Laboratories, Richland, Wash. 99352

133. Director, Research and Technical Support Division, ERDA-ORO

134-160. Technical Information Center, ERDA, Oak Ridge, TN 37830 